\title{
ADVANCED THERMALLY STABLE JET FUELS
}

\author{
Technical Progress Report \\ July 1994 - September 1994
}

H.H. Schobert, S. Eser, C. Song, P.G. Hatcher, A. Boehman, M.M. Coleman

\section{Contributions from:}

R. Arumugan, G. Bowers, K. Gergova, W.-C. Lai, Y. Peng A. Schmitz, P. Sanghani, J. Stallman, E. Yoon, and J. Yu

July 1994

Prepared for U.S. Department of Energy under

Contract No. DE-FG22-92PC92104

\section{PENNSTATE

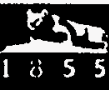 \\ College of Earth and Mineral Sciences}

DISTRIBUTION OF THIS DOCUMENT IS UNLIMITED 


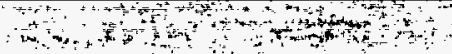




\section{DISCLAIMER}

Portions of this document may be illegible in electronic image products. Images are produced from the best available original document. 
This report was prepared as an account of work sponsored by an agency of the United States Government. Neither the United States Government nor any agency thereof, nor any of their employees, makes any warranty, express or implied, or assumes any legal liability or responsibility for the accuracy, completeness, or usefulness of any information, apparatus, product, or process disclosed, or represents that its use would not infringe privately owned rights. Reference herein to any specific commercial product, process, or service by trade name, trademark, manufacturer, or otherwise does not necessarily constitute or imply its endorsement, recommendation, or favoring by the United States Government or any agency thereof. The views and opinions of authors expressed herein do not necessarily state or reflect those of the United States Government or any agency thereof.

OBJECTIVES.

SUMMARY

TECHNICAL PROGRESS

Task 1. Investigation of the Quantitative Degradation Chemistry of Fuels

1. Pyrolysis of $n$-Alkylbenzene s. (Contributed by Ying Peng)

2. Thermal Decomposition of n-Tetradecane in Near-Critical Region (Contributed by Jian $\mathrm{Yu}$ and Semih Eser.

3. Re-examining the Effects of Reactant and Inert Gas Pressure on Tetradecane Pyrolysis. Effect of "Cold Volume" in Batch Reactor (Contributed by Wei-Chuan Lai and Chunshan Song

Task 2. Investigation of Incipient deposition

1. Uncertainty Analysis on Growth and Deposition of Particles During Heating of Coal-Derived Aviation Gas Turbine Fuels (Contributed by Prashant Sanghani and Andre Boehman

Task 3. Investigation of the Quantitative Degradation Chemistry of Fuels

1. Effects of High Surface Area Activated Carbon and Decalin on Thermal Degradation of Jet A-1 Fuel and n-Dodecane (Contributed by Katia Gergova, Rathnamala Arumugam, and Semih Eser.

Task 4. Coal-Based Fuel Stabilization Studies.

1. Screening Potential Jet Fuel Stabilizers Using the Model Compound Dodecane (Contributed by Emily M. Yoon, Michael M. Coleman, and John B. Stallman)

Task 5. Exploratory Studies on the Direct Conversion of Coal to High Quality Jet Fuels.

1. Shape-Selective Naphthalene Hydrogenation for Production of Thermally Stable Jet Fuels.(Contributed by Andrew D. Schmitz, Grainne Bowers, and Chunshan Song)

Appendix I. Tables.

Appendix II. Figures 


\section{OBJECTIVES}

The Penn State Program in advanced thermally stable coal-based jet fuels has five objectives: 1) development of mechanisms of degradation and solids formation; 2) quantitative measurement of growth of sub-micrometer and micrometer-sized particles suspended in fuels during thermal stressing; 3 ) characterization of carbonaceous deposits by various instrumental and microscopic methods; 4) elucidation of the role of additives in retarding the formation of carbonaceous solids; and 5) assessment of the potential of production of high yields of cycloalkanes and hydroaromatics by direct liquefaction of coal.

\section{SUMMARY}

The effect of chain length on the pyrolytic behavior of various $n$-alkylbenzenes has been evaluated. The formation of various products depends on the initiation of the reaction, which can begin with abstraction of hydrogen from $\alpha$ - or $\gamma$-positions on the alkyl chain. $\alpha$ Hydrogen abstraction is preferred by increasing reaction temperature (i.e., $\alpha$-hydrogen abstraction has a higher activation energy that $\gamma$-hydrogen abstraction. $\gamma$-Hydrogen abstraction is relatively easier as the length of the alkyl chain increases.

Temperature measurements in the reactor system show that the connecting line or "stem" (that attaches the body of the microautoclave to the pressure gauge and value) may be at $200^{\circ} \mathrm{C}$ even when the temperature of the sand bath is $450^{\circ} \mathrm{C}$. This temperature differential may induce circulation of reactants inside the reactor, which in turn might lead to fluctuations in the reaction rates and mechanisms, especially for experiments in the nearcritical region. Further, the average temperature of the sample will be lower than the sandbath temperature and rate constants will be underestimated.

A modification of the standard microautoclave reactor design has led to the discovery that the relatively cool connecting line may have significant effects on the decomposition of $n$-tetradecane. The work leads to an interesting speculation that it might be feasible to reduce reactant (i.e., fuel) decomposition by adding a cooler portion to the fuel system to serve as a "venting place" for some reactive radicals. 
A literature review on the role of oxygen as a promoter or inhibitor of free radical reactions was completed.

The measured particle size distribution of suspended carbon particles formed in thermal stressing has been found to be extremely sensitive to the refractive index of the particles. This work is part of a broader effort to conduct an uncertainty analysis on the growth and deposition of particles during stressing.

The effect of decalin, together with PX-21 activated carbon, was studied during the thermal stressing of $n$-dodecane and Jet A-1. Adding decalin as a hydrogen donor reduced the extent of decomposition of both dodecane and the jet fuel. The activated carbon addition appears to promote $\mathrm{H}$-transfer reactions during the thermal stressing. In addition, primary radicals are stabilized on the carbon surfaces. The degree of thermal degradation of both the fuel and the dodecane depend on both the amounts of activated carbon and decalin added.

Parameters have been developed to predict the effectiveness of organic additives that can be used to stabilize fuels toward thermal degradation and prevent the formation of carbonaceous solids. The additives must be thermally stable above $400^{\circ} \mathrm{C}$. The additive must have hydrogen atoms that can be transferred or abstracted by hydrocarbon radicals. The greater the number of these available hydrogen atoms, the better. The radicals generated from hydrogen atom abstraction should be stabilized by resonance.

The ability to convert naphthalene selectively to trans-decalin could result in a fuel of exceptional stability. Decalin is a useful additive, as in the work mentioned above, to suppress degradation. The propensity of a fuel to form carbons can be reduced by limiting its aromatic content, as for example by converting naphthalene to decalin. Trans-decalin is more stable than cis-decalin. Eight catalysts have been prepared and tested in an effort to selectively convert naphthalene to trans-decalin. 


\section{TECHNICAL PROGRESS}

\section{Task 1. Investigation of the Quantitative Degradation Chemistry of Fuels}

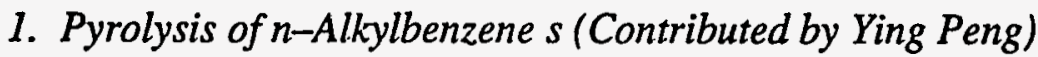

\section{Introduction:}

This section of the report describes the effect of the length of the side chain of an alkylbenzene on pathways and kinetics of pyrolysis reactions. Five $n$-alkylbenzenes, typically present in the aromatic fraction of jet fuels, including ethylbenzene, $n$-butylbenzene, $n$ amylbenzene, $n$-hexylbenzene and $n$-octylbenzene, were thermally stressed under a temperature range from $400^{\circ} \mathrm{C}$ to $475^{\circ} \mathrm{C}$ and batch holding time from 5 minutes to 16 hours. Three alkylbenzenes, $n$-amyl, $n$-hexyl and $n$-octyl-benzene were studied extensively and are discussed in detail below. Results of $n$-butylbenzene (which have been discussed in earlier chapters) at $450^{\circ} \mathrm{C}$ are used for comparison. The reactions were typically monitored by measuring yields of gaseous, liquid and solid products, and by the following analyses of the product composition. Their thermal stabilities have been compared in terms of rate of disappearance of starting materials, global reaction kinetics and the major reaction pathways.

\section{Pyrolysis of $n$-Alkylhenzenes - General Features}

Ethylhenzene: The simplest compound in the family of $n$-alkylbenzenes is toluene. Toluene was not selected here as a major candidate model compound simply because of its known relatively high stability under a temperature regime of 400 to $500^{\circ} \mathrm{C}$, possibly reached by the fuel used for thermal management on board the jet aircraft. Therefore, ethylbenzene becomes the first member of the family of the compounds used in this study. Ethylbenzene was found to be extremely resistant to reaction compared to other members in the family (see discussion later in this section). Almost no conversion was achieved after four hours of reaction at $450^{\circ} \mathrm{C}$. There were hardly any gases produced. The analysis of the gaseous products showed the presence of a small amount of methane and $C_{2}$ species (ethane and ethylene). Over $99 \%$ of the condensed light yellowish liquid after reaction was still constituted of ethylbenzene. Some GC- detectable products in the liquid included very limited amount of toluene and styrene as major products, as shown in Figure 1.

This result is quite surprising, compared to the published literature. According to literature results [Szwarc,1948; Leigh,1952a;Leigh,1952b;Leigh,1952c; Estaban,1963], it is expected that ethylbenzene decomposes at a rate somewhat slower than, for example, $n$-propylbenzene. Because of their obvious structural similarities, that both contain aliphatic $\mathrm{C}-\mathrm{C}$ bonds in the side chain that break at similar activation energies, the reaction rates should be comparable. The 
experimental results, however, were rather different from expectations. The pyrolysis of ethylbenzene proceeded much slower than expected at $450^{\circ} \mathrm{C}$. This leads to the logical deduction that the breaking of the aliphatic $\mathrm{C}-\mathrm{C}$ bonds, as an initiation reaction and rate-controlling step, may not be the only step that causes the tremendous reactivity difference. Some kind of radical transfer reactions might exist as a very slow step. The following discussion focuses on the analysis of some of the possible reasons.

There is little doubt [Robaugh,1981] that the first step of ethylbenzene decomposition is the homolytic breakdown of the $C_{\alpha}-C_{\beta}$ bonds on the side chain. This is probably followed by a series of hydrogen abstraction and $\beta$-scission reactions, as shown in the following reactions:

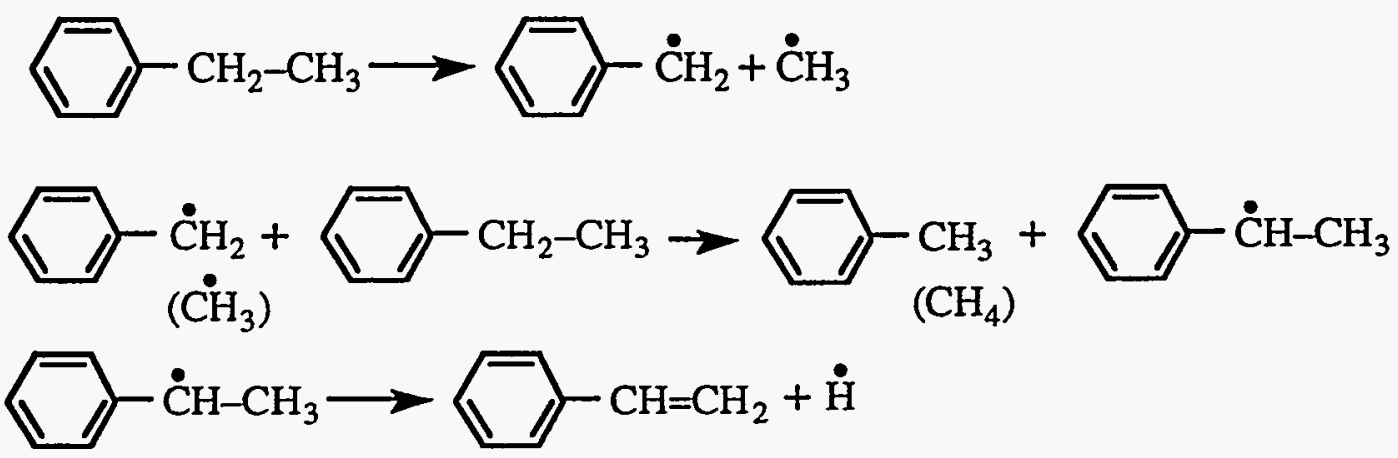

From analyzing the reactions listed above, the stability difference of ethylbenzene compared with other $n$-alkylbenzenes might come from the following aspects. The first reason stems from the initiation reaction (reaction 1$)$. It has a slightly higher activation energy $\left(E_{a}\right)$ than, for example, initiation reaction of $n$-propylbenzene (reaction 4) due to the stabilizing effect of the extra methylene group in the $n$-propylbenzene molecule. Reaction (1) usually has an activation energy of around $304.39 \mathrm{~kJ} / \mathrm{mol}$ [Mizerka, 1986], whereas reaction (4) about $288.48 \mathrm{~kJ} / \mathrm{mol}$ [Chen, 1991a; Chen, 1991b]. It is reasonable[Chen, 1991a] to assume that the preexponential factors for the two reactions are the same (Table 1 ).

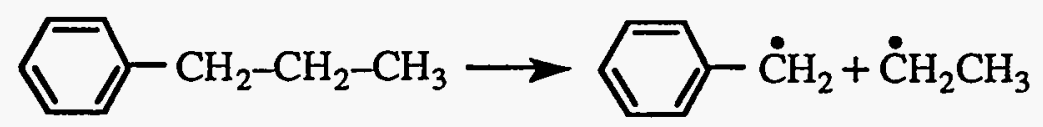

From the analysis of Table 1, it is obvious that this reason alone would not cause a significantly lower reactivity of ethylbenzene. Rates for initiation reactions are almost equally slow for the two initiation reactions at $450^{\circ} \mathrm{C}$ in ethyl- and $n$-propylbenzene pyrolysis. It is noted from Table 1 that initiation of $n$-propylbenzene (reaction 4) proceeds about 6 times faster than ethylbenzene at $800^{\circ} \mathrm{C}$. A more important and unique property of ethylbenzene may exist. Reaction (3) is a $\beta-$ scission reaction that produces a styrene and a hydrogen atom by breaking the $\beta \mathrm{C}-\mathrm{H}$ bonds. Compared with reaction (3), the pyrolysis of other compounds in the series of $n$-alkylbenzene, 
(again, take $n$-propylbenzene as an example), involves a $\beta$-scission of both $\mathrm{C}-\mathrm{H}$ and $\mathrm{C}-\mathrm{C}$ bonds, as are shown in reactions (5) and (6).

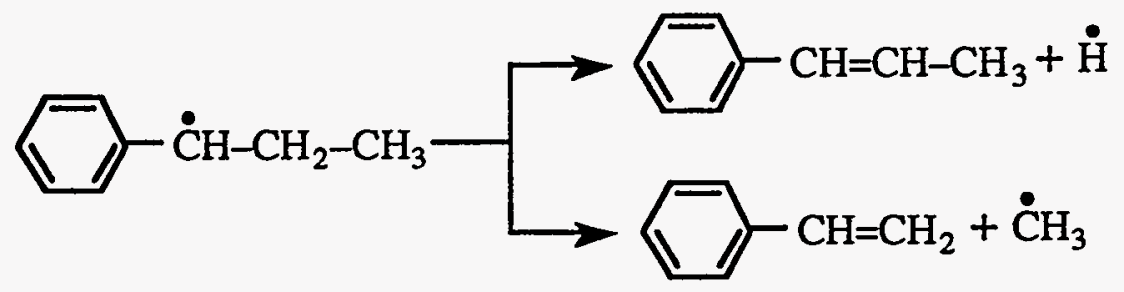

The estimated Arrhenius parameters [Allara, 1980] for reactions (3), (5) and (6) are also shown in Table 1. At a temperature of $450^{\circ} \mathrm{C}$, only reaction (6) proceeds at a measurable rate. The rate of $\beta-$ scission through ejecting hydrogen atoms (reactions (3) and (5)) is very slow. Because of this reason, ethylbenzene hardly decomposes at a temperature of $450^{\circ} \mathrm{C}$. At higher temperature, however, the rate difference between reaction (3) and (6) is much less. Reaction (6) is about $9 \times 10^{2}$ times faster than reaction (3) at $800^{\circ} \mathrm{C}$, instead of $1.4 \times 10^{5}$ times at $450^{\circ} \mathrm{C}$. Therefore, it seems that $\beta C-C$ bond cleavage (reaction 6 ) is a much easier reaction at $450^{\circ} \mathrm{C}$ than $\beta \mathrm{C}-\mathrm{H}$ bond cleavage. This probably constitutes the major reactivity difference in ethyl- and $n$-propyl-benzene pyrolysis.

There is probably another reason concerning the low reactivity of ethylbenzene. As discussed above in Figure.1, one of the major condensed reaction products from the pyrolysis of ethylbenzene is styrene. According to the discussion in literature [Savage, 1989b], styrene can be rapidly consumed to form ethylbenzene itself. The transformation from styrene to ethylbenzene (reaction 7) has been generally accepted to explain the rapid disappearance of the former as a primary product in the neat, batch pyrolysis of $n$-alkylbenzenes, and at the same time, the steady increase of the latter as a secondary reaction product [Savage, 1989b; Savage, 1987b]. Because of this transformation, even though there might be some styrene generated from reaction (3), the styrene reacts "back" to form ethylbenzene.

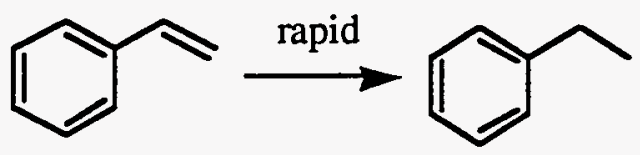

Other $n$-Alkylbenzenes: Different from the pyrolysis of ethylbenzene, other $n$-alkylbenzenes studied showed a considerablely higher degree of reaction in the temperature range of $400^{\circ} \mathrm{C}$ to $475^{\circ} \mathrm{C}$. The extents of reaction depend on the actual temperature and the duration of the reactions. Yields of gaseous, condensed liquid and solid products obtained from the pyrolysis of $n-$ amylbenzene at temperature range from $425^{\circ} \mathrm{C}$ to $475^{\circ} \mathrm{C}$ are listed in Table 2. Similar data for the pyrolysis of $n$-hexyl- and $n$-octylbenzenes are in preparation for publication. As expected, the 
yields of gaseous and solid products increase with reaction time and temperature. The yields for liquid products decrease with reaction time and temperature. $n$-Octylbenzene forms the highest amounts of gaseous products under similar stressing severities. Gases formation can reach about $34 \mathrm{wt} \%$ yield after 8 hours of reaction at $450^{\circ} \mathrm{C}$. There are generally higher amounts of gases produced for $n$-amylbenzene pyrolysis than that of $n$-hexylbenzene. The reason for this is not known. Solid formation for the selected $n$-alkylbenzenes is not very extensive although alkylbenzenes are generally accused of being "precursors of solid formation" [Song, 1991]. Generally, less than $10 \mathrm{wt} \%$ of solid deposits is formed after a batch holding time of 8 hours. It is realized [Song, 1992b] that radicals generated from $n$-alkylbenzenes themselves may not be sufficient in forming a large amount of PAHs and solids. The amounts of solid products produced by petroleum-derived jet fuels at similar treatment severity are sometimes significantly higher than that from $n$-alkylbenzenes. This suggests that it is the complex interaction between radical fragments thermally produced from various types of compounds in jet fuels that determines the solid-forming tendency. Intermediate radicals formed from $n$-alkylbenzene pyrolysis can facilitate this process either by actively attacking other radicals in the system of jet fuel pyrolysis or inactively being attacked by other more reactive radicals to produce solid products.

\section{Distribution of Major Products}

The results are discussed in terms of the product identities and yields, product interrelationships and reaction pathways, kinetics, mechanisms and implications to the thermal stability of jet fuels.

A complete listing of the yields of major products for the pyrolysis of $n$-amylbenzene is presented in Tables 3-5. Similar tables for those of $n$-hexylbenzene and $n$-octylbenzene are not given here, because they have identical trends with $n$-amylbenzene. An illustrative but detailed discussion of experimental results is presented only for the pyrolysis of $n$-amylbenzene in this section. Results obtained for other compounds are mainly viewed comparatively with that of $n$ amylbenzene. Figure 2 gives representative gas chromatogram traces of gaseous and liquid products for the pyrolysis of $n$-amylbenzene at $425^{\circ} \mathrm{C}$ for 2 hours.

It should be mentioned that the liquid and gaseous products were analyzed immediately after the reactor was opened. This is necessary because the liquid products are extremely volatile and the gaseous products are easily escape from the gas sampling bags. This is especially true for some of the light compounds in liquid products. Butane and 1-butene are frequently detected in quite high amounts in liquids and, the longer the side chain of the $n$-alkylbenzenes, the higher the amounts of this type of light compounds present in liquid products. Therefore, the results are severely affected if the samples are allowed to stand in the laboratory for even a short period of 
time. For the compounds that are detected in both liquid and gaseous products, the yields were determined from the summation of the two sources.

Major condensed products observed at $425^{\circ} \mathrm{C}$ for $n$-amylbenzene pyrolysis were toluene and ethylbenzene. Other compounds, including styrene, methylethylbenzene, $n$-propylbenzene, $n$ butylbenzene, naphthalene and methylated naphthalenes, were found only in significantly lower yields. Also appearing in yet lower yields were phenylalkenes, benzene, indan and substituted indans. Gaseous products from $n$-amylbenzene pyrolysis at $425^{\circ} \mathrm{C}$ for 2 hours included propane, ethane, methane, $n$-butane, 1-butene, propylene, hydrogen, ethylene and isobutane, with the amounts listed in decreasing order. The obvious predominance of saturated over unsaturated gaseous and liquid products was generally observed at all reaction conditions. There is usually about less than 2 mol\% of hydrogen gas in the product mixtures.

Figures 3-5 show the general profiles of product distribution of pyrolysis of $n-$ amylbenzene at 425,450 and $475^{\circ} \mathrm{C}$. Propane, toluene and ethylbenzene are formed in high yields in all three temperatures. Methane, ethane, 1-butene, methylethylbenzene and $n$-propylbenzene are also produced as major products. Numerous other compounds are also formed, but only in very low yields. A significant increase in the gaseous product branch of the product spectrum with reaction temperature can be discerned. The gaseous product propane starts to dominate over liquid products toluene and ethylbenzene with increasing temperature. Also in the gaseous products, the concentration of methane rapidly increases with increasing temperature. Another trend that needs mentioning is that the yield of ethylbenzene relative to toluene increases significantly with temperature. In other words, the concentration of ethylbenzene increases at a faster pace than toluene. This will be explained later in this section.

Figures 6-8 show the temporal variations of the yields of some major products for $n-$ amylbenzene pyrolysis at $450^{\circ} \mathrm{C}$. Toluene, the most abundant product throughout the course of the reaction, attains a yield of about $32 \mathrm{~mol} \%$ at 2 hours of reaction. The yield of ethylbenzene, the second most abundant product, increases almost linearly with that of toluene Also showing a very rapid increase in yield is propane, as is seen in Figure 6. Most olefinic compounds exhibit a maximum in concentration with increasing of reaction time. This type of compound includes: 1butene, propylene, ethylene 1-ethenyl-2-methylbenzene, 1-methylethenylbenzene and styrene. For example, during the initial $20 \mathrm{~min}$ of reaction, the yield of styrene exceeded that of ethylbenzene, but decreased after that time from a maximum of $4 \mathrm{~mol} \%$. There is also the formation of methylethylbenzene and $n$-propylbenzene, the concentrations of which increase steadily with reaction time. Compounds such as indan and $n$-butylbenzene are formed at short reaction times and disappear rapidly at high treatment severity. Figure 8 shows that naphthalene formation, although very low at short times of the reaction, consistently increases. It is the only multi-ring compound that can be detected frequently in the neat liquid products of pyrolysis of 
alkylbenzenes by gas chromatograpghy. Other PAHs, although present and contributing to the dark color of the liquid products, are difficult to detect and quantify by GC either because of their limited amounts or their relatively high molecular weights.

As is mentioned above, an overwhelming predominance of saturated compounds over unsaturated ones has been discerned in the batch tubing bomb reactions. This is distinctly different from pyrolysis reactions undertaken at low pressures and high temperatures. In high-temperature and low-pressure pyrolysis, the so-called Rice Kossiakoff mechanism [Rice, 1934; Rice, 1935; Kossiakoff, 1943] dominate in the free-radical reactions. $\beta-$ Bond scission is the major mode of the chain propagation reaction, and because of this, olefinic products naturally become dominant compounds in the product mixture. In the present reaction conditions, however, the pyrolyses of the neat liquid compounds were conducted under $0.69 \mathrm{MPa}$ of UHP $\mathrm{N}_{2}$ in a closed vessel. The high pressure and comparatively low temperature used may well facilitate the hydrogen-transfer reactions that have low activation energies. The net outcome of this pressure increase is, therefore, the formation of saturated compounds as a direct result of hydrogen abstraction reactions of various primary and secondary radicals. This is a process that follows the Fabuss-SmithSatterfield mechanism [Fabuss, 1964a].

These experimental results are in substantial agreement with those of Mushrush and Hazlett[ Mushrush, 1984] and Savage and Klein [Savage, 1987b] for the pyrolysis of much longer chain alkylbenzenes. One major difference is that the relative concentration of ethylbenzene in the present study is much higher compared to that of Savage and Klein [Savage, 1987b]. This is probably due to the $\mathrm{N}_{2}$ pressure exerted on the reactants in the present study, whereas Savage et al. [Savage, 1987b] studied only neat pyrolysis of long-chain alkylbenzenes with no inert gas pressure.

Figure 9 shows the plots of selectivities for the formation of five major products versus conversion, where the selectivity is defined as a product's molar yield divided by the reactant conversion. The selectivities for toluene and 1-butene (Figure 9 (a) and (b)) appear to decrease with increasing temperature. Their changes with conversion, however, show different patterns. The selectivity for 1-butene rapidly decreases with conversion or passes through a maximum, but that of toluene shows a more or less increasing trend. A strong dependence of the selectivitites on temperature for propane and styrene was not observed (Figure 9 (c), and (d)). The characteristic of the styrene selectivity diagram is that the selectivity decreases rapidly with conversion. With the decrease of the selectivity of styrene, a solid increase in generation of ethylbenzene is observed (Figure 9(e)), indicating the transition between them, as is also noted by the other researchers [Klein, 1983; Poutsma, 1982; Savage, 1987b]. In order to understand the major reaction pathways, it is important to know whether a product is a primary or a secondary product. Discrimination between them [Savage, 1991c] can be achieved through examining the $y$-intercept 
of the selectivity diagrams by applying the Delplot technique [Bhore, 1990]. Products that possess non-zero intercepts are of first rank, and those that possess zero-intercepts are of higher order. The rank is the order of appearance of a product within the reaction network. The products of first rank are primary products. Examining Figure 9 reveals that toluene, 1-butene, styrene and propane are primary reaction products and ethylbenzene is a secondary product.

According to the above analysis of product distribution and formation profiles of the major products, a general pyrolysis network for $n$-amylbenzene is deduced and shown schematically in Figure 10. The slow initiation reaction would prefer to break the bonds between $C_{\alpha}-C_{\beta}$ along the side chain. Since this is the slow rate-controlling step that has an activation energy of as high as $287 \mathrm{~kJ} / \mathrm{mol}$ and preexponential factor of $10^{16} \mathrm{~s}^{-1}$ [Benson, 1976; Kochi, 1973], the reaction products derived from this process, toluene, ethylene, ethane and butane, would be extremely low if this were the only reaction pathway for them. The first few radicals generated by initiation reaction tend to abstract hydrogen atoms preferably from the side chain. Abstraction of aliphatic hydrogen by hydrocarbon radicals generally proceeds with preexponential factor of $10^{8.5 \pm 0.5}$ 1/mol-s and activation energies between 29.3 and $100 \mathrm{~kJ} / \mathrm{mol}$ [Poutsma, 1982; Kochi, 1973]. The activation energy for abstraction of hydrogen at benzylic $\alpha$-position is about $15 \mathrm{~kJ} / \mathrm{mol}$ lower than for abstraction a more strongly bonded hydrogen at all non-benzylic secondary positions. Table 6 lists estimated kinetic parameters and rate constants for some typical hydrogen abstraction reactions in $n$-amylbenzene pyrolysis [Froment, 1991b]. Benzyl and methyl radicals are probably the most abundant and also active radical chain carriers in alkylbenzene pyrolysis. Methyl radicals are significantly more reactive than benzyl radicals. It is imaginable that radicals formed from the above hydrogen abstraction process will rapidly decompose by $\beta$-scission to form smaller radicals. Few experimental data exist for rates of $\beta$-scission reactions of alkylbenzenes. Poutsma and Dyer [Poutsma, 1982] estimated that $\beta$-scission of an $\alpha$-alkylbenzene radical in diphenylbutane proceeded with preexponential factor $A=10^{15.2} \mathrm{~s}^{-1}$ and activation energy $E_{a}=160$ $\mathrm{kJ} / \mathrm{mol}$. Froment's modeling [Froment, 1991b] of $n$-propylbenzene pyrolysis gives consistent values with Poutsma and Dyer [Poutsma, 1982]. Additionally, both Poutsma and Dyer [Poutsma, 1982] and Gilbert [Gilbert, 1982] estimated Arrhenius parameters of $\beta$-scission of a $\gamma-$ alkylbenzene radical to be $A=10^{15} \mathrm{~s}^{-1}$ and $E_{a}=117 \mathrm{~kJ} / \mathrm{mol}$, a value significantly lower than that from other positions. Froment and coworkers [Froment, 1991b] also estimated the $\beta$-scission of a $\beta$-alkylbenzene radical to generat a very reactive phenyl radical and the corresponding 1-alkene in the pyrolysis of $n$-propylbenzene in a flow reactor. A higher value of $E_{\mathrm{a}}=168 \mathrm{~kJ} / \mathrm{mol}$ and $A=10^{14.63}$ compared with the series of values used in their modeling was used. This reaction (cleaving at the ring site) is about one order of magnitude slower than $\beta$-scission of an $\alpha-$ alkylbenzene radical and four orders of magnitude slower than that of a $\gamma$-alkylbenzene radical at $450^{\circ} \mathrm{C}$. Therefore, it appears that formation of a phenyl radical by $\beta$-scission of a $\beta$-alkylbenzene 
radical is difficult and this may be one for the reasons of the low yield of benzene. Table 6 lists the relevant kinetic data for $\beta$-scission reactions according to the discussions above.

From the data in Table 6 , the rate of hydrogen abstraction at $450^{\circ} \mathrm{C}$ at the $\alpha$-position is about two orders of magnitude higher than at other positions. The rates of hydrogen abstraction at positions other than $\alpha$ can be considered roughly identical [Froment, 1991b]. Rates of $\beta$-scission of the secondary alkylbenzene radicals are different. $\beta$-Scission of a $\gamma$-alkylbenzene radical is significantly faster than other secondary alkylbenzene radicals. As a result, it appears that $\gamma$ hydrogen abstraction at $450^{\circ} \mathrm{C}$ can be facilitated by the subsequent fast $\beta$-scission step. The also exemplifies the principle that the operation of hydrogen abstraction and $\beta$-scission determines product distribution. Therefore, hydrogen abstractions at $\alpha$ - and $\gamma$-positions, probably by benzyl radicals, at the relatively low conversion of pyrolysis are two major ways to consume the parent $n$ amylbenzene molecules, as is illustrated in Figure 10. The products formed by the two major steps are expected to dominate in the product mixture, and indeed, styrene (ethylbenzene), propane, toluene and 1-butene are the five most important products (Figure 9). Hydrogen abstraction at other places $(\beta, \delta$ and $\varepsilon$ ) happens at a considerably lower rate. The products thus formed would not have high abundance.

\section{Possible Maior Pathways of Pyrolysis of $n$-Alkylbenzenes:}

The general features of the pyrolyses for $n$-hexylbenzene and $n$-octylbenzene remain the same as that of $n$-amylbenzene. The thermal reactions of $n$-hexylbenzene and $n$-octylbenzene form toluene and ethylbenzene as major reaction products. The most abundant gaseous products are $n-$ butane and $n$-hexane, respectively, at low reaction temperature for the two compounds. It should be noted that the type and amounts of gases formed for $n$-octylbenzene are increased for the longer chain compounds. Taking one hour reaction at $450^{\circ} \mathrm{C}$, for example, methane formation increased from $6 \mathrm{~mol} \%$ for $n$-amylbenzene to $11 \mathrm{~mol} \%$ for $n$-hexylbenzene to $14 \mathrm{~mol} \%$ for $n$-octylbenzene. 1-Pentene is also present in the gaseous product mixture for $n$-hexylbenzene pyrolysis, and so is 1-heptene for $n$-octylbenzene. $C_{1}$ to $C_{3}$ gases formation for $n$-hexyl- and $n$-octylbenzenes are quite extensive. Their yields increase rapidly with reaction time and temperature. It is obvious that these gases are produced as a result of complex secondary decomposition reactions. The pathways for their formation are very difficult to deduce.

The formation of the major reaction products from $n$-hexyl- and $n$-octylbenzenes can also be explained using the steps described for $n$-amylbenzene. In summary, the general possible major pathways for the pyrolysis of $n$-alkylbenzenes are shown in Figure 11. It can be seen that the major characteristics of $n$-alkylbenzenes pyrolysis are the same. They have similar initiation reactions and propagation modes. For an $n$-alkylbenzene, $\alpha$-hydrogen abstraction produces styrene (ethylbenzene) and n-2 alkane, and $\gamma$-hydrogen abstraction produces toluene and n-1 1- 
alkene. The reactions at the other sites on the side chain produce only minor reaction products. There exist probably only minor differences that might cause the difference in the reactivites of the $n$-alkylbenzenes, for example, the difference in quantity of each major product and number of abstractable hydrogens other than $\alpha$ and $\gamma$ positions in the side chain. Yet the general mechanism shown in Figure 11 well explains the major behavior of their pyrolysis characteristics.

\section{Global Reaction Kinetics}

Kinetic regression has been performed for $n$-amylbenzene, $n$-hexylbenzene and $n$ octylbenzene based on conversion data obtained from batch thermal treatments. Figure 12 shows the plot of conversion of $n$-amylbenzene versus reaction time. The conversion increases with reaction time and temperature, as expected. Figure 13 is a graph that compares the conversion of four $n$-alkylbenzenes at $450^{\circ} \mathrm{C}$. Qualitatively, at same stressing time, $n$-octylbenzene has the highest conversion and $n$-butylbenzene has the lowest. Since most studies [Savage, 1987b; Freund, 1989] have established that the pyrolysis of long-chain $n$-alkylbenzene and $n$-alkyl polycyclic aromatics are generally first order with respect to the reactant, first-order kinetics is assumed in the study. Equation (8) is the first-order reaction rate expression in terms of concentration, where $C$ is the reactant concentration (mol/L), $t$ is reaction time (s), and $k$ is the first-order rate constant $\left(\mathrm{s}^{-1}\right)$ :

$$
-\frac{\mathrm{dC}}{\mathrm{d} t}=k \mathrm{C}
$$

Equation (8) can be transformed into equation (9) by integration, where $\mathrm{x}$ is conversion of the reactant:

$$
\ln (1-\mathrm{x})=-\mathrm{k} t
$$

Plotting $\ln (1-x)$ against reaction time $t$ should yield a straight line with slope of first-order reaction rate constant $k$. It should be mentioned that the reactor heatup to the desired reaction temperature needs about $4.5 \mathrm{~min}$ on average [Song, 1994b]. For the calculation of global reaction kinetics, the time of a reaction is the reactor residence time minus $4.5 \mathrm{~min}$. Some very short and long residence time runs were deleted from the calculations. Relatively large experimental errors might be associated with the short-time runs because of the smaller amounts of gases produced. Some of very high conversion runs were not included in the calculation because of the obvious deviation from first-order reaction caused by either the very complex nature of the reactions or the possibility 
of near thermodynamic equilibrium at long reaction duration. Excellent fittings of the experimental data to the first-order kinetics have been obtained, suggesting that the reactions were indeed proceeding according to first order.

The rate constants obtained are shown in Table 7. The rate constants increase smoothly as reaction temperature increases. As the side chain lengths increase from five to eight, the first-order rate constants increase. The rate constants are correlated with reaction temperature by Arrhenius equation, as shown in equation (10):

$$
\mathrm{k}=\operatorname{Aexp}(-\mathrm{Ea} / \mathrm{RT})
$$

where $A$ is the preexponential factor $\left(\mathrm{s}^{-1}\right), E_{\mathrm{a}}$ is the apparent activation energy $(\mathrm{kJ} / \mathrm{mol})$, and $\mathrm{R}$ is the universal gas constant $\left(\mathrm{J} \mathrm{mol}^{-1} \mathrm{~K}^{-1}\right) . \mathrm{E}_{\mathrm{a}}$ and $\mathrm{A}$ thus obtained are also listed in Table 7 .

It is noted that the $\mathrm{E}_{\mathrm{a}}$ values obtained from the current study are significantly lower, and the A factor higher, than some of the values reported in the literature [Savage, 1987b; Freund, 1989]. Freund [Freund, 1989] reported $E_{a}$ value of $221.12 \mathrm{~kJ} / \mathrm{mol}$ and $A$ value of $1.1 \times 10^{12} \mathrm{~s}^{-1}$ for the decomposition of $n$-butylbenzene. Savage [Savage, 1987b] obtained even higher values of 232 $\mathrm{kJ} / \mathrm{mol}$ and $10^{14} \mathrm{~s}^{-1}$. The activation energies obtained agree quite well with those of Banerjee [Banerjee, 1982] for the pyrolysis of $n$-butylbenzene in a flow reactor with molar ratio of $n$ butylbenzene and diluent inert gas $\mathrm{N}_{2}$ 1:1. Banerjee [Banerjee, 1982] ascribed the low kinetic parameters to different experimental conditions, calculation methods used, and different degrees of "inhibition".

A further examination of the rate constant data shown in Table 7 revealed that rate constants obtained at $425^{\circ} \mathrm{C}$ agree quite well with those of the literature [Savage, 1987b], whereas rates at $450^{\circ} \mathrm{C}$ and $475^{\circ} \mathrm{C}$ are much lower than the literature values. This might be the reason for the low Arrhenius parameters obtained by the current study. Although it is very difficult to reconcile the apparent disagreement at this stage, a few differences in experimental details should be pointed out. The current work was carried out at a relatively high inert gas pressure $\left(0.69 \mathrm{MPa}\right.$ of UHP $\mathrm{N}_{2}$ was used as starting pressure). This is a distinctly different reaction condition from most of the literature. The effect of inert gas pressure on the kinetics of pyrolysis of hydrocarbons is very rarely reported. For this reason, it may not be appropriate to compare kinetic results obtained from different procedures.

\section{Comparison of Relative Importance of $\alpha-$ and $\psi-\mathrm{H}$ Abstraction Reactions}

Both theoretical and experimental data have substantiated that $\alpha$ - and $\gamma$ - hydrogen abstractions represent two major pathways for the consumption of the substrate alkylbenzene 
molecules. Styrene and n-2 alkane are directly formed as a result of $\alpha$-hydrogen abstraction (Figure 11). Ethylbenzene can be considered as an indirect product of $\alpha$-hydrogen abstraction from the assumption that most of the ethylbenzene might be generated rapidly from styrene. In the case of $n$-amylbenzene pyrolysis, styrene, ethylbenzene and propane are the products of $\alpha-$ hydrogen abstraction. On the other hand, $\gamma$-hydrogen abstraction gives toluene and $n-1$ alkene, or toluene and 1-butene for $n$-amylbenzene pyrolysis. Figures 14 and 15 plot the changing pattern of each pair of major products with conversion for $n$-amylbenzene pyrolysis in a temperature range from $425^{\circ} \mathrm{C}$ to $475^{\circ} \mathrm{C}$. The summation of molar yields of ethylbenzene and styrene in Figure 14 increases with conversion in a very similar pace as that of propane. This further verifies the assumption that they (styrene and propane) are formed as a pair and at the same time. Monotonic increase in their concentration with the increase of conversion demonstrates propane and ethylbenzene are relatively stable in the testing temperature range. Similar plots in Figure 15 illustrate that the changing of molar yields with conversion of another major product pair resulted from $\gamma$-hydrogen abstraction. Although their concentration may be quite similar at the beginning of the thermolysis, indicating that they were formed at the same time, the concentration of toluene rapidly increases with conversion. The concentration of 1-butene, however, is significantly lower. Its concentration proceeds through a maximum similar to other olefinic products. This indicates that 1-butene is not stable and undergoes rapid secondary reactions in the reaction temperature range.

Based on the above discussions, the characteristic products ethylbenzene+styrene can be employed as an indication of $\alpha$-hydrogen abstraction. Similarly, toluene can be considered as an indication of $\gamma$-hydrogen abstraction. The molar ratio of ethylbenzene+styrene over toluene can be viewed as an index to compare the relative importance of hydrogen abstraction reactions at $\alpha$ - and $\gamma$-positions. The higher the ratio, the more important $\alpha$-hydrogen abstraction is, and otherwise, the more important $\gamma$-hydrogen abstraction is. Figure 16 shows the molar ratio of ethylbenzene+styrene over toluene for three of the $n$-alkylbenzenes from $425^{\circ} \mathrm{C}$ to $475^{\circ} \mathrm{C}$.

Several trends should be pointed out. First, for all three compounds, the ratio increases as temperature increases. The ratio decreases from about 0.77 at $475^{\circ} \mathrm{C}$ to about 0.39 at $425^{\circ} \mathrm{C}$ at $40 \%$ of conversion for $n$-amylbenzene. The ratio changes from 0.60 to 0.36 for $n$-hexylbenzene in the same temperature range. For $n$-octylbenzene from $400-450^{\circ} \mathrm{C}$, the ratio decreases from 0.41 to 0.20 . This is most obviously manifested by the plot for $n$-amylbenzene. It probably indicates that $\alpha$-hydrogen abstraction is preferred by increasing temperature, or in other words, $\alpha$-hydrogen abstraction has a higher activation energy than $\gamma$-hydrogen abstraction. This can be explained as follows according to the data in Table 6 . The so-called " $\alpha$-hydrogen abstraction products", ethylbenzene and styrene, are formed by $\alpha$-hydrogen abstraction and the subsequent $\beta$-scission. The activation energies for them are 63.56 and $157 \mathrm{~kJ} / \mathrm{mol}$, respectively, taking hydrogen 
abstraction reaction of benzyl radicals as an example. Similarly, " $\gamma$-hydrogen abstraction product", toluene, is formed by the combination of hydrogen abstraction and $\beta$-scission. The activation energies for this process are 90.70 and $117 \mathrm{~kJ} / \mathrm{mol}$. The highest activation channel is the $\beta$ scission to form styrene and it should also be the most temperature-sensitive reaction. Therefore, when temperature increases, the formation of styrene and ethylbenzene should increase as well.

Another trend is that at similar temperature and conversions, the ratio decreases as the length of the chain increases. This indicates that $\gamma$-hydrogen abstraction is relatively easier for a longer chain alkylbenzene. As conversion increases $(\leq 50 \%)$, the ratio also decreases, indicating the increasing of $\gamma$-hydrogen abstraction. It is difficult to formulate the reasons from mechanistic and kinetic aspects because of the complex reaction processes and many factors affecting them.

\section{Thermal Decomposition of n-Tetradecane in Near-Critical Region (Contributed by Jian $Y u$ and Semih Eser)}

\section{Introduction}

Thermal stressing experiments in tubing bomb reactors showed that pressure has a significant effect on the thermal decomposition of $n$-tetradecane $\left(n-\mathrm{C}_{14}\right)$ in the near-critical region [1,2]. It was found that at $425^{\circ} \mathrm{C}$, a few degrees above the critical temperature $\left(T_{c}\right)$ of $n-C_{14}$ $\left(419.15^{\circ} \mathrm{C}\right)$, both the first-order rate constants and the product distributions exhibited larger pressure dependence in the near-critical region. The larger pressure dependence of the first-order rate constants and product distributions only occurs in the near-critical region and is not seen in the far supercritical region. While unusual pressure dependence of the first-order rate constants and product distributions may result from unusual properties of a fluid near its critical point, such as large partial molar volume, local anisotropy, and high compressibility, the complex pressure dependence of the rate constants and the yield of olefinic components can not be readily explained. For example, the first-order rate constants for $n-\mathrm{C}_{14}$ decomposition neither increase nor decrease monotonously but fluctuate with pressure in the pressure range near the critical pressure $\left(\mathrm{P}_{c}, 1.573\right.$ $\mathrm{MPa}$ for $n-\mathrm{C}_{14}$ ) [1]. When the reactions were carried out at $425^{\circ} \mathrm{C}$ for $30 \mathrm{~min}$ the yield of olefinic components also fluctuates with pressure in the near-critical region [2]. It is felt that the observed complex relationships may result from uncontrolled mixing problem in the tubing bomb reactor which includes a top stem with lower temperature. Measurements showed that the temperature in the stem at just above the surface of the fluidized sand bath was as low as $200^{\circ} \mathrm{C}$ when the temperature of the sand bath was $450^{\circ} \mathrm{C}$ [3]. It can be expected that there exists a circulation of the reactants inside the whole reactor, that is, the reactants with lower density at higher temperature at the reactor body go up to the top stem, condense at certain position due to lower temperature, and then come down because of higher density. This circulation continues throughout an experiment. It is clear that such a circulation of the reactants will lead to fluctuations in the reaction rates and 
mechanisms especially during the experiments which carried out in the near-critical region of the compound studied. Also, it is clear that the average temperature of the sample stressed will be lower than the sand-bath temperature and underestimated rate constants will be obtained from thermal reactions carried out in tubing reactors with long stems. Since it is difficult to correct for the effect of the top stem, the resulting kinetic parameters may be misleading. Therefore, either a modified tubing bomb reactor or a new reactor should be used to obtain more reliable kinetic data.

In this study, we used glass tubes as reactors for the thermal decomposition experiments of $n-C_{14}$. The following section presents the results of the kinetic studies for $n-C_{14}$ in the near-critical region.

\section{Experimental}

The $n$-tetradecane was obtained from Aldrich with $99+\%$ purity and was used as received. A pyrex glass tube was used as the reactor. The sample section of the tube was made of nonprecision quarter-inch outer diameter and $1 \mathrm{~mm}$ bore capillary tubing with a 5.25 inch length. According to the desired loading ratio, a certain amount of sample was loaded into the tube using a glass syringe with a 6 inch long needle and a band was marked around the tube at the sealing position using a permanent marker. The loaded and marked sample tube was evacuated using a vacuum pump and then sealed off under vacuum using an oxygen-acetylene torch using the marked band as a guide.

A fluidized-sand bath was used to carry out thermal stressing experiments. Before a thermal stressing experiment was started, the sand bath was preheated to a desired temperature. The sealed tube was fastened onto a holder and was then plunged into the sand bath. The heat capacity of the whole set was so small that the temperature of the sand bath was not affected after the reactor set was plunged into the bath. It was expected that the glass tube reached to desired temperature in less than two minutes. (Measurements showed that it took about one minute for a thermal couple probe with a sheath, which has equivalent volume to the reactor set, to be heated to the temperature of the bath at $425^{\circ} \mathrm{C}$ ). After the desired reaction time the tube was removed from the sand bath and was cooled down using pressurized air.

A Perkin Elmer $8500 \mathrm{GC}$ with an FID detector was used for the quantitative analysis of the liquid products. The column temperature was programmed from $40^{\circ} \mathrm{C}$ to $280^{\circ} \mathrm{C}$ at the rate of $4^{\circ} \mathrm{C} / \mathrm{min}$ with an initial isothermal period of $5 \mathrm{~min}$ at $40^{\circ} \mathrm{C}$ and a final isothermal period of $10 \mathrm{~min}$ at $280^{\circ} \mathrm{C}$. The compounds in the liquid products were identified using a Hewlett Packard GC interfaced with an HP mass selective detector. The $n$-alkanes can also be identified from the run of the standard mixture.

When GC and GC/MS were ready the sample tube was broken and the liquid products were injected into the columns for quantitative analysis. The gas yield from the reaction was 
determined from the corresponding tubing bomb reactor experiment. The GC analysis of $n$-alkane standard mixture with carbon number from 7-26 showed that there are only slight differences in the weight response factors, defined as the area in the chromatogram divided by the weight of the compound, of $\mathrm{C}_{7}-\mathrm{C}_{14} n$-alkanes. The response factors for $\mathrm{C}_{14}{ }^{+} n$-alkanes gradually decrease as carbon number increases. For example, the relative weight response factor for $n-\mathrm{C}_{26}$ is around 0.8 if the corresponding value for $n-C_{9}$ is taken as $1 . C_{3}-C_{6}$ components are expected to have higher response factors although their values are difficult to be determined because of high volatility of these light components. In this work the response factor for each component is assumed to be equal. Such an assumption will not result in large errors in determining the molar yields of the major products since the yields of $\mathrm{C}_{14}{ }^{+}$components are low and the overestimated yields of the lighter components in liquid products are used to offset the losses of these components after opening the tube. Therefore, the area percents in the chromatogram were used as weight percents which were then converted to molar percents relative to charged reactant. In this way conversion can be calculated and the molar yield of each component corresponding to $100 \mathrm{~mol}$ of reacted $n$ $\mathrm{C}_{14}$ can then be determined.

\section{Results and Discussion}

1. Effects of Pressure on Conversion and Product Distributions. The effects of pressure on the conversion and product distributions were studied in the near- and supercritical regions. The experiments were carried out at $425^{\circ} \mathrm{C}$ for 15 and $30 \mathrm{~min}$. The different loading ratios were used to obtain different initial pressures.

Figure 17 shows the change in conversion with initial reduced pressure from thermal decomposition of $n-C_{14}$ at $425^{\circ} \mathrm{C}$ for 15 and $30 \mathrm{~min}$. The reduced pressure $\left(\mathrm{P}_{\mathrm{r}}=\mathrm{P} / \mathrm{P}_{\mathrm{c}}\right)$ was calculated at given temperature and loading ratio using Soave-Redlich-Kwong equation of state [4]. It can be seen that pressure has a significant effect on conversion in the near-critical region. For example, when $\mathrm{P}_{\mathrm{r}}$ increases from 1 to 1.5 the conversion at 15 min decreases from $\approx 12 \%$ to $\approx 9 \%$ and the conversion at $30 \mathrm{~min}$ decreases from $\approx 19 \%$ to $16 \%$. It seems that the significant changes in the conversions fall in the near-critical region and do not extend to far supercritical region. The experiment at $425^{\circ} \mathrm{C}$ for 30 min showed that the conversion with $P_{r}$ of 7.7 had no significant difference from that with $\mathrm{P}_{\mathrm{r}}$ of 1.5. When the present results were compared with the previous data [1], it was found that the conversions from tubing bomb reactor experiments are lower than those from glass tube experiments. The lower reaction rates in the tubing reactor experiments result from lower average temperature of the sample stressed because of the effects of the top stem of the reactor which has lower temperature, as discussed before, and accounts for almost 1/5 of the total volume of the reactor. It was expected that the uncontrolled low-temperature region in the top stem of the tubing bomb reactor resulted in underestimated reaction rates. 
Figures 18-21 show the changes in product composition with initial reduced pressure from the thermal decomposition of $n-\mathrm{C}_{14}$ at $425^{\circ} \mathrm{C}$ for $15 \mathrm{~min}$. Figure 18 shows the changes in molar yields of $n$-alkanes, 1-alkenes, and internal alkenes (all including $\mathrm{C}_{6}-\mathrm{C}_{13}$ components), as well as $\mathrm{C}_{14}{ }^{+}$alkanes with pressure. Figure 19 shows the changes in molar yields of $\mathrm{C}_{7}$ fractions with pressure. It can be seen that the yields of $n$-alkanes increase with pressure and the yields of 1 alkenes decrease with pressure. The large changes in the yields of $n$-alkanes and 1-alkenes with pressure occur in the near-critical region. It can also be seen from Figure 18 that there exist small amounts of minor reaction products such as internal alkenes and straight-chain and branched-chain alkanes with carbon number from 15 to 26 . While the amounts of $\mathrm{C}_{14}{ }^{+}$alkanes are low at lower pressure, their amounts are significant at higher pressure. Besides the yield of $\mathrm{C}_{14}{ }^{+}$alkanes also exhibits larger increase with pressure in the near-critical region than in the far supercritical region. Figures 20 and 21 show the changes in molar yield of individual paraffinic components and olefinic components with pressure. The relationship between the molar yield of individual component and pressure is consistent with that shown in Figure 18. Figures 18, 20 and 21 also reveal that under the conditions used in this study the major pyrolytic products are $n$-alkanes with carbon number up to 11 and 1-alkenes with carbon number up to 12 . While $n-\mathrm{C}_{12}, n-\mathrm{C}_{13}$, and 1$\mathrm{C}_{13}=$ are also present in pyrolytic products, their yields are considerably lower than those of the major products.

Figures 22 and 23 show the change in molar ratio of overall $\mathrm{C}_{6}$ - $\mathrm{C}_{13} n$-alkanes to 1-alkenes with pressure and the changes in corresponding ratios with pressure for selected $\mathrm{C}_{7}, \mathrm{C}_{8}$, and $\mathrm{C}_{9}$ components from the thermal decomposition of $n-\mathrm{C}_{14}$ at $425^{\circ} \mathrm{C}$ for $15 \mathrm{~min}$. It can be seen that the selectivity for paraffinic component relative to olefinic component with the same carbon number increases with pressure. Large changes in $n$-alkane/1-alkene ratios with pressure occur in the nearcritical region. Under supercritical conditions the product selectivities for $n$-alkanes are very high and even over those for corresponding 1-alkenes. These results are largely different from those obtained under typical $n$-alkane pyrolysis conditions ( $\approx$ atmospheric pressure, $>600^{\circ} \mathrm{C}$ ) which usually give methane and ethane as the only paraffinic products.

The results obtained from this study can be explained by free radical theory and transition state theory, which has been discussed in the last quarterly report [2] and will not be presented here.

2. Kinetics of Supercritical-Phase Thermal Decomposition. As stated above, the rate constants from the tubing bomb reactor experiments were underestimated because of the effect of the top stem of the reactor which had a lower temperature. Therefore, the kinetic parameters from previous experiments may not be reliable and need to be reexamined.

Kinetic data were obtained from the thermal decomposition of $n-C_{14}$ at 400,425 , and $450^{\circ} \mathrm{C}$ for different time. Previous studies show that simple first-order kinetics holds reasonably 
well for the thermal decomposition of straight-chain alkanes $[5,6]$. Therefore, in this work the rate constants were determined by the following first-order expression

$$
\ln [1 /(1-x)]=k t
$$

where $\mathrm{x}$ is the fraction of the reactant converted, $\mathrm{k}$ is the rate constant $\left(\mathrm{h}^{-1}\right)$, and $\mathrm{t}$ is the reaction time (h). Since pressure affects conversion considerably in the near-critical region, a suitable loading ratio must be selected to avoid larger pressure effect in kinetic analysis. Also, loading ratio must be maintained fixed to obtain reproducible results. It was found that when the loading ratio was larger than 0.35 , which corresponds to a $\mathrm{P}_{\mathrm{r}}$ of about 1.5 , the conversion did not change significantly with pressure. In this work a loading ratio of 0.36 was used.

For three different temperatures $\left(400^{\circ} \mathrm{C}, 425^{\circ} \mathrm{C}\right.$, and $\left.450^{\circ} \mathrm{C}\right)$, the first-order rate constants $\mathrm{k}$ 's were obtained from the method of least-squares by plotting $\ln [1 /(1-\mathrm{x})]$ as the function of $\mathrm{t}$. Figure 24 shows the relationship between $\ln [1 /(1-\mathrm{x})]$ and $t$. The straight lines at three different temperatures indicate that $n-\mathrm{C}_{14}$ thermal decomposition under supercritical condition can be represented quite well by the first-order kinetics. From the slopes of the three lines in Figure 24 the following first-order rate constants were obtained: $0.0620,0.3477$, and $1.7081 \mathrm{~h}^{-1}$ for 400,425 , and $450^{\circ} \mathrm{C}$, respectively. According to these data the apparent kinetic parameters for the thermal decomposition of $n-C_{14}$ were calculated using the Arrhenius law. Figure 25 shows the relationship between rate constant and temperature. The estimated activation energy is $64.2 \mathrm{kcal} / \mathrm{mol}$, in good agreement with the value of $60-65 \mathrm{kcal} / \mathrm{mol}$ usually observed for the first-order reactions of longchain alkane pyrolysis [5].

\section{References}

1. Schobert, H. H.; Eser, S.; Song, C.; Hatcher, P. G.; Walsh, P. M.; Coleman, M. M. Advanced Thermally Stable Jet Fuels. Technical Progress Report (January 1994 - March 1994), May, 1994, The Pennsylvania State University.

2. Schobert, H. H.; Eser, S.; Song, C.; Hatcher, P. G.; Walsh, P. M.; Coleman, M. M. Advanced Thermally Stable Jet Fuels. Technical Progress Report (April 1994 - June 1994), July, 1994, The Pennsylvania State University.

3. Lai, W.-C. Private Communications. 1994.

4. Soave, G. Chem. Eng. Sci. 1972, 27, 1197.

5. Fabuss, B. M.; Smith, J. O.; Satterfield, C. N. Adv. Pet. Chem. Refin. 1964, 9, 157.

6. Voge, H. H.; Good, G. M. J. Am. Chem. Soc. 1949, 71, 593. 


\section{Re-examining the Effects of Reactant and Inert Gas Pressure on Tetradecane Pyrolysis. Effect of "Cold Volume" in Batch Reactor (Contributed by Wei-Chuan Lai and Chunshan S Song)}

\section{Introduction}

While batch reactors have been used in many laboratories in the world, including this laboratory, little is known about the effect of the volume of tube connecting the reactor and the pressure gauge, which is a common part of most batch reactors but is much cooler than the reactor tube, whose volume may be called "cold volume". We will discuss the effect of the "cold volume" based on our recent results.

In a previous quarterly report, we have reported the unusual pressure effects observed in pyrolysis of $n$-tetradecane $\left(n-\mathrm{C}_{14}\right)$ at $450^{\circ} \mathrm{C}$ for $30 \mathrm{~min}$ under initial (cold) $\mathrm{N}_{2}$ pressure of 0.17 2.03 MPa using 1-11 mL of samples in 28-mL microreactors (Schobert et al., 1994). It was observed that there exist unusual and large effects of both reactant pressure (reflected by initial sample volume) and inert gas pressure in pyrolysis near the critical temperature and pressure of the $n-\mathrm{C}_{14}-\mathrm{N}_{2}$ mixture. Increasing the initial sample volume of $n-\mathrm{C}_{14}$ can either decrease or increase its conversion, depending on the inert gas and reactant pressure range.

The microreactors used in previous pyrolysis experiments are tubing bombs consisting of a single Swagelok port connector with two end caps made of 316 stainless steel. The capacity of the tubing bomb body is about $22.5 \mathrm{~mL}$. There are connecting tubes ( $6.35 \mathrm{~mm}$ o.d.; $4.4 \mathrm{~mm}$ i.d.) from the reactor to a pressure gauge and to a valve and quick-connect stem; the total length is about $40 \mathrm{~cm}$. The total volume of the reactor system is about $28 \mathrm{~mL}$. This design has several merits, but there is one drawback of this autoclave. The volume of the connecting line, which is much cooler than the bomb body during reaction, is about $20 \%$ of the total reactor volume. It has been recently found that the cool connecting line ("cold volume") has significant effects on the $n-\mathrm{C}_{14}$ decomposition behavior.

In order to obtain a better defined reaction system, we have recently modified the microreactors by minimizing the volume of the connecting lines. This was done by replacing the $1 / 4^{\prime \prime}\left(6.35 \mathrm{~mm}\right.$ o.d.) connecting tubings with $1 / 8^{\prime \prime}$ ones and stuffing the interior with inert glass beads or rods wherever is needed. For the modified microreactors, the volume of the connecting line is now only about $3 \%$ of the total reactor volume $(23.2 \mathrm{~mL})$.

In this report we present the experimental results of $n$-tetradecane pyrolysis at $450{ }^{\circ} \mathrm{C}$ for 30 min under initial (cold) $\mathrm{N}_{2}$ pressure of $0.17-1.41 \mathrm{MPa}$ using 1-11 mL of samples in the modified 23.2-mL microreactors. The results are also compared with what was previously obtained using 28-mL microreactors with larger cool connecting tubing (larger "cold volume"). 
Results and'Discussion

1. Pressure effects observed in the modified 23.2-mL microreactors. The uniformity of concentration and temperature inside the tubing reactor was obtained by agitating the reactor vertically at the speed of about 240 cycles/min. The temperature uniformity inside the reactor, which is about $10 \mathrm{~cm}$ in length, was confirmed by the temperature measurements near the centerline at several different positions. Figure 26 gives the temperature profiles inside the reactor at two positions ( $2.5 \mathrm{~cm}$ and $7.5 \mathrm{~cm}$ from the bottom of the reactor) for three $n-\mathrm{C}_{14}$ loadings $(0,5$, and $11 \mathrm{~mL}$ of $n-\mathrm{C}_{14}$ ) under an initial $\mathrm{N}_{2}$ pressure of $0.79 \mathrm{MPa}$. Regardless of the difference of the sample loadings, the sample reaches the final temperature of $450^{\circ} \mathrm{C}$ after a 6 -minute heating up time. The major temperature history difference occurs in the first 4 minutes of the heating-up period. The conversion in this period (below $425^{\circ} \mathrm{C}$ ) is less than $1 \mathrm{~mol} \%$ and can be considered to have small effects on the overall conversion results.

Figure 27 shows the $n-\mathrm{C}_{14}$ conversion as a function of the initially charged $n$ - $\mathrm{C}_{14}$ volume at three different initial $\mathrm{N}_{2}$ pressures in the $23.2-\mathrm{mL}$ microreactors. Note that $1 \mathrm{~mL}$ of $n-\mathrm{C}_{14}$ corresponds to a $n-\mathrm{C}_{14}$ concentration of $0.166 \mathrm{~mol} / \mathrm{L}$. The current results show that there are considerable changes in $n-\mathrm{C}_{14}$ conversions with changes in sample volume (concentration), especially when the $n-\mathrm{C}_{14}$ loading increases from $1 \mathrm{~mL}$ to 2 and $3 \mathrm{~mL}$. For example, at a low initial $\mathrm{N}_{2}$ pressure $(0.17 \mathrm{MPa})$, increásing sample volume from 1 to $2 \mathrm{~mL}$ significantly increased $n-\mathrm{C}_{14}$ conversion from 39 to $48 \mathrm{~mol} \%$. Further increase in sample volume from 2 to $3 \mathrm{~mL}$ could increase the conversion by 2 more \%. Changes in sample volume between 3 and $7 \mathrm{~mL}$ had little impact on $n-\mathrm{C}_{14}$ conversion, but one can find a decrease in conversion with further increase of sample volume up to $11 \mathrm{~mL}$. In contrast to the effect of reactant pressure (concentration or sample volume), the pressure of the inert gas $\left(\mathrm{N}_{2}\right)$ has less impact on the decomposition rate of $n$ - $\mathrm{C}_{14}$ under the studied $\mathrm{N}_{2}$ pressure ranges.

The $n-\mathrm{C}_{14}$ conversion displays a concave downward behavior with the reactant volume (concentration); a maximum conversion occurs near $0.66 \mathrm{~mole} / \mathrm{L}$ (or $4 \mathrm{~mL}$ of $n$ - $\mathrm{C}_{14}$ ). The $3 \mathrm{~mL}$ conversion data in Figure 27 were fitted to a three-parameter model as shown in equation 1.

$$
X=\frac{a_{1} C\left(1+a_{3} C\right)}{\left(1+a_{1} C\right)\left(1+a_{2} C+a_{3} C\right)}
$$

where $\mathrm{X}$ is the $n-\mathrm{C}_{14}$ conversion (the fraction of $n-\mathrm{C}_{14}$ reacted), $\mathrm{C}$ is the $n-\mathrm{C}_{14}$ concentration $(\mathrm{mol} / \mathrm{L})$, and $\mathrm{a}_{1}, \mathrm{a}_{2}$, and $\mathrm{a}_{3}$ are the three parameters with the values of 5.61, 1.33, and 0.90 , respectively. Equation 1 was presented as the solid curve in Figure 27.

The results in Figure 27 show that the influence of the reactant volume (concentration) appears to also depend on the system phases. We have discussed the phase of the reactant under 
different conditions to facilitate the discernment of the pressure effects and reported the procedures of estimating the reduced pressure and temperature in an earlier report (Schobert et al., 1994). In short, the mixture critical temperature was usually bounded by the maximum and minimum critical temperatures among the components; this implies that in our reaction system $n$ - $\mathrm{C}_{14}$ could exist in either gas or supercritical state since the reaction temperature of $450^{\circ} \mathrm{C}$ is well above the critical temperature $\left(\mathrm{T}_{\mathrm{c}}\right)$. Figure 28 presents the estimated reduced pressure (ratio of the system pressure to the critical pressure) as a function of the charged volumes of $n-\mathrm{C}_{14}$ under vacuum condition, i.e., without the addition of $\mathrm{N}_{2}$ for two tubing bombs with different capacities. Though no reaction was run without $\mathrm{N}_{2}$, Figure 28 is still useful in helping estimate the mixture phase at low $\mathrm{N}_{2}$ mole fraction. Figure 28 shows that for a pure $n-\mathrm{C}_{14}$ system, it is likely that at $450^{\circ} \mathrm{C}$ the reactant exists in supercritical phase when the initial sample volume is greater than $3 \mathrm{~mL}$, and in gas phase otherwise. If the reaction mixture displays similar phase behavior as shown in Figure 28, we can find by comparing Figures 27 and 28 that near the critical condition the $n-\mathrm{C}_{14}$ decomposition rate was enhanced when the system phase was changed from gas to supercritical phase. However, at conditions far above the critical point such as $\mathrm{P}_{\mathrm{r}}>2$, the $n-\mathrm{C}_{14}$ conversion decreased with further increase of pressure (density). The decrease might be attributed to cage effects or diffusion limitations, which may be expected at extremely high density due to the more restricted mobility of molecules.

The ratios of lumped 1-alkenes $\left(C_{2}-C_{13}\right)$ to $n$-alkanes $\left(C_{1}-C_{13}\right)$ pyrolysis products from $n$ $\mathrm{C}_{14}$ are shown in Figure 29 as a function of the initially charged $n-\mathrm{C}_{14}$ volume and $\mathrm{N}_{2}$ pressure. It can be seen that 1-alkene/n-alkane ratio decreases with both increasing initial pressure of $\mathrm{N}_{2}$ and increasing sample volume. Note that the ratios of 1-alkene to the corresponding $n$-alkane for $\mathrm{C}_{2}$ through $\mathrm{C}_{13}$ also display similar trends as the lumped yields. These observations imply that lower pressure facilitates unimolecular reaction ( $\beta$-scission) to form alkenes while higher pressure favors bimolecular reaction (H-abstraction) to form alkanes. It is possible to control the product distributions as well as reaction extent by isothermally adjusting the system pressure in terms of sample volume or inert gas pressure.

Another interesting result is that there are significant radical addition reactions at high pressure. Figure 30 presents the molar selectivity of branched higher alkanes $\left(C_{15}-C_{26}\right)$ as a function of the initially charged $n-\mathrm{C}_{14}$ volume and $\mathrm{N}_{2}$ pressure. In addition, the molar selectivity of $n$-alkanes $\left(\mathrm{C}_{15}-\mathrm{C}_{26}\right)$ also displays a similar trend as shown in Figure 30 . The higher $n$-alkanes mainly result from the addition reactions of primary $n$-alkyl (mainly $n$-tetradecyl) radicals to 1 alkenes followed by $\mathrm{H}$-abstraction. The major higher $n$-alkanes products are $n-\mathrm{C}_{15}-n-\mathrm{C}_{19}$ in decreasing abundance order. As for the branched higher alkanes, they are mainly produced from the addition reactions of secondary $n$-alkyl (mainly $n$-tetradecyl) radicals to 1 -alkenes followed by $\mathrm{H}$-abstraction. The yields of higher $n$-alkanes are usually about $1 / 4$ of that of branched higher 
alkanes; this is probably owing to the fact that there are more secondary $n$-tetradecyl radicals than primary $n$-tetradecyl radicals. One might suggest that the formation of higher alkanes be the results of the radical combination involving $n$-tetradecyl and lower alkyl radicals instead of radical addition to 1-alkenes. We think that the radical combination reactions are possible but they can only be the minor sources for the formation of higher alkanes under the conditions employed. If radical combination rather than radical addition to 1-alkenes dominates, the ratios of 1-alkenes to n-alkanes would have been great than 1, which is opposite to the trend shown in Figure 29.

2. Results comparison hetween modified 23.2-mL and unmodified 28 -mL microreactors. Figure 31 presents the $n-\mathrm{C}_{14}$ conversion as a function of the initial sample volume of $n-\mathrm{C}_{14}$ in these two tubing bombs with different capacities $(23.2-\mathrm{mL}$ and $28-\mathrm{mL})$. Notice that the significant effect of initial $\mathrm{N}_{2}$ pressure on the conversion was observed in unmodified reactors but was not in the modified reactors. Figure 31 shows also that in general the pyrolysis experiments carried out in the modified reactors exhibit higher conversions. We speculate that the differences may be explained as follows. First, the cooler upper portion of the reactor system, i.e., the connecting line, introduced nonuniform distributions of radical concentration and temperature inside the system. The lower (shorter) alkyl radicals tend to escape to the cooler upper portion and stay there longer than the higher radicals; the phenomena are similar to removing a great deal of reactive radicals from the reaction system and thus retarding the decomposition process. The lack of lower alkyl radicals also results in the much lower yields of higher alkanes $\left(\mathrm{C}_{15}-\mathrm{C}_{26}\right)$, which is obviously observed in the reaction products from unmodified reactor. Second, with the additional cool parts and thus larger total reactor volume, the reactant concentration or the system pressure in the unmodified reactor is lower than its counterpart when same amount (volume) of $n$ - $C_{14}$ was added initially. The lower concentration may also result in lower decomposition rates under the studied conditions. Third, $\mathrm{N}_{2}$ competes with the lower radicals for the cooler space in the upper part of the unmodified reactor system, and thus reduces the chance of the lower radicals to escape to there from the tubing bomb body where the reactions occur. This is consistent with the observation from unmodified reactor that the decomposition rate increases with increasing initial $\mathrm{N}_{2}$ pressure in or near supercritical phase.

We showed that application of $\mathrm{H}$-donors to improve jet fuel thermal stability is promising (Song et al., 1994). In similar reasoning, is it feasible to reduce reactant decomposition by adding a cooler portion in a reactor system to serve a venting place for some reactive radicals?

\section{References}

1. Schobert, H. H.; Eser, C.; Song, C.; Hatcher, P. G.; Walsh, P. M.; Coleman, M. M. Advanced Thermally Stable Jet Fuels. Technical Progress Report (January 1994 - March 1994), May 1995, The Pennsylvania State University. 
2. Song, C.; Lai, W.-C.; Schobert, H. H. Hydrogen-Transferring Pyrolysis of Long-Chain Alkanes and Thermal Stability Improvement of Jet Fuels by Hydrogen Donors. Ind. Eng. Chem. Res. 1994, 33, 548-557. 


\section{Task 2. Investigation of Incipient Deposition}

1. Uncertainty Analysis on Growth and Deposition of Particles During Heating of Coal-Derived Aviation Gas Turbine Fuels (Contributed by Prashant C. Sanghani and Andre Boehman)

The ultimate objective of this work is to describe particle and deposit growth in sufficient detail and with sufficient accuracy to simulate the fuel composition, pressure, temperature, heating rate, oxygen, impurity and time dependences of suspended particle concentration. The deposit formation exhibits an induction period, during which deposit formation is slow, followed by a period of rapid growth, then a decline in deposition rate as deposit forming species are depleted. The ability to simulate this behaviour is considered a critical test of any model. The accuracy of any model depends on the uncertainties associated with the measurement of relevant variables such weight change, species concentration, particle size, temperature, pressure and the overall reproducibility of the tubing bomb. Reported uncertainties in experimental measurements demonstrate whether the observed scatter in measured quantities is due to the physical or chemical phenomena occuring in the system or due to flaws in the measurement system or experimental protocol.

\section{Basic Mathematics of Error Analysis}

Moffat $[1,2]$ has described the method to evaluate the uncertainties in experimental results. Moffat's method has been used in our uncertainty analysis. Suppose $\mathrm{X}_{\mathrm{i}}$ is a variable with known uncertainty $\delta \mathrm{X}_{\mathrm{i}}$, then $\mathrm{X}_{\mathrm{i}}$ and its uncertainty is represented by:

$$
\mathrm{X}_{\mathrm{i}}=\mathrm{X}_{\mathrm{i}} \text { (measured) } \pm \delta \mathrm{X}_{\mathrm{i}} \quad \text { (20:1 odds) }
$$

The above statement means: 1). The best estimate of $X_{i}$ is $X_{i}$ (measured). 2). There is an uncertainty in $\mathrm{X}_{\mathrm{i}}$ that may be as large as $\pm \delta \mathrm{X}_{\mathrm{i}}$. 3). The odds are 20 to 1 against the possibility of $X_{i}$ being outside of the range $X_{i}$ (measured) $\pm \delta X_{i}$.

The value $X_{i}$ (measured) represents the mean of a set of $N$ observations in a multiple sample experiment or it is the value of a particular single observation in a single sample experiment. The value of $\delta \mathrm{X}_{\mathrm{i}}$ represents $2 \sigma$ for single sample analysis where $\sigma$ is the standard deviation of the population of possible measurements from which the single sample $\mathrm{X}_{\mathrm{i}}$ was taken. For multiple sample analysis $\delta \mathrm{X}_{\mathrm{i}}$ may represent any one of the following:

- It may represent $t * S_{N} / N^{1 / 2}$ for random error components, where $S_{(N)}$ is the standard deviation of the set of $\mathrm{N}$ observations used to calculate the mean value $\mathrm{X}_{\mathrm{i}}$ and $\mathrm{t}$ is the 
student's $t$ statistic appropriate for the number of samples $\mathrm{N}$ and the confidence level desired.

- It may represent $\mathrm{U} .95$, the overall uncertainty in $\mathrm{X}_{\mathbf{i}}$.

The result $R$ of the experiment (in our analysis it can be rate constant, weight, species concentration or particle size) is calculated from a set of measurements $\mathrm{X}_{1}, \mathrm{X}_{2}, \mathrm{X}_{3}, \ldots . \mathrm{XN}_{\mathrm{N}}$, and is represented by following function:

$$
\mathrm{R}=\mathrm{R}\left(\mathrm{X}_{1}, \mathrm{X}_{2}, \mathrm{X}_{3}, \ldots . \mathrm{X}_{\mathrm{N}}\right)
$$

Since $R$ is a function of $X_{1}, X_{2}, X_{3}, \ldots X_{N}$ the uncertainty in each individual measurement will affect the value of $R$. The effect of the uncertainty in a single measurement on the calculated result, if only that one measurement were in error, can be calculated from equation 3. The partial derivative of $R$ with respect to $\mathrm{X}_{\mathrm{i}}$ is the sensitivity coefficient of result $\mathrm{R}$ with respect to measurement $\mathrm{X}_{\mathrm{i}}$.

$$
\partial \mathrm{R}_{\mathrm{x}_{\mathrm{i}}}=\frac{\partial \mathrm{R}}{\partial \mathrm{X}_{\mathrm{i}}} \partial \mathrm{X}_{\mathrm{i}}
$$

If $\delta \mathrm{X}_{\mathrm{i}}$ is the uncertainty in $\mathrm{X}_{\mathrm{i}}$, then the total uncertainty in $\mathrm{R}, \delta \mathrm{R}$, is given by the root sum square (RSS) of each error component as follows:

$$
\partial \mathrm{R}=\left[\sum_{\mathrm{i}=1}^{\mathrm{N}}\left(\frac{\partial \mathrm{R}}{\partial \mathrm{X}_{\mathrm{i}}} \partial X_{\mathrm{i}}\right)^{2}\right]^{1 / 2}
$$

Each term in equation 4 represents the contribution made by the uncertainty in one variable $\delta \mathrm{X}_{\mathrm{i}}$ to the overall uncertainty in the result, $\delta \mathrm{R}$. The equation 4 is valid as long as 1 ). Each of the measurements are independent. 2). Repeated observations of each measurement, if made would display gaussian distributions.

Single Sample and Multiple Sample Analysis

Single sample experiments are those in which each test point is run only once or a few times. Most of the exploratory research experiments are single-sample experiments. Single sample analysis is applied to the measurement of species concentrations, weight change of the reactor and particle size. Multiple sample analysis is applied to the measurement of voltage levels 
associated with temperature and heater power outputs for the sand bath. Both the thermocouple and heater power outputs of the sand bath are quite steady.

In single sample uncertainty analysis, each measurement is assigned three uncertainty values: zeroth-, first-, and Nth order uncertainties.

- Zeroth order uncertainty : associated with errors introduced by the measurement system, such as minimum read-out range on a digital voltmeter, minimum readout on the weight balance or minimum demarcation on the particle size analyzer reading. Typically, this uncertainty value is well below the overall uncertainty of the measurement and represents a lower limit on the uncertainty obtainable with a given measurement system.

- First order uncertainty : associated with scatter in repeated trials using the same measurement system and experimental procedures, while the experiment is running and held in a stationary state. This uncertainty value includes the effects of process unsteadiness and system noise.

- $\quad \mathrm{N}^{\text {th }}$ order uncertainty : characterizes the overall uncertainty in the result, acknowledging all identified sources of error in the measurement system and including variable errors that arise when the process is running. For reduced quantities such as the reaction rate the $\mathrm{N}^{\text {th }}$ order uncertainty is the root-sum-square of the $\mathrm{N}^{\text {th }}$ order uncertainties of each measured quantity that is used to calculate the reduced quantity.

The multiple and single sample uncertainty analyses developed by Moffat were originally developed for a dynamic system to study fluid mechanics and heat trasfer in a flowing system such as a gas turbine. They may not be applied to our batch system directly but the basic principles are directly applicable.

We found that particle size measured by the analyzer is extremely sensitive to the refractive index of the black carbonaceous suspended particles. Even the opaque materials such as metals or black particles have certain refractive index [3]. Refractive index measurements of soot particles have been made extensively by several research workers [4]. So far we have used the refractive index of polystyrene polymer in the calculation of size distributions of particles formed during pyrolysis. When a particle absorb light, its refractive index has real part as well as an imaginary part. When a sample consists of particles in the size range of 1 micon to more than 5 microns a small change in the real or imaginary part of the refractive index can change the size distribution significantly.

Figure 32 shows particle size distributions calculated for carbon black particles at four different refractive indices of $1.18,1.23-4.13 i, 1.12$, and 1.3. It is clear from the figure that size distribution is very sensitive to refractive index. Currently we do not have sufficient values of refractive indices in our data base to determine the sensitivity coefficient of particle size with 
respect to refractive index. Our database on refractive indices will be updated and the uncertainty with respect to refractive index will be reported in future results.

Another problem that we need to address is authenticity of the weight change measurement of the reactor after fuel stressing. We have observed weight changes from as low as $15 \mathrm{mg}$ up to $500 \mathrm{mg}$. The weight of the reactor is about 170 grams. Therefore determining deposit formation by recording the weight change can be a problem. Accuracy of the balance was found to be \pm 0.3 $\mathrm{mg}$ and it does not change with an increase in weight i.e. accuracy remains the same whether we measure 10 gram or 170 gram. During the early stages of deposit growth deposited material may weigh as little as $15 \mathrm{mg}$ or less. Compared to the uncertainty interval of $\pm 0.3 \mathrm{mg}$, a deposit weight of $15 \mathrm{mg}$ is substantial with a relative uncertainty of just $2 \%$. Another point that we need to address is the effects of sand particles and antiseize thread protecting lubricant on weight change, especially when the weight change is very small. This problem will be solved by carrying out several dummy tubing bomb reactions with lubricant on the thread and no sample in the reactor. These results will give the value of standard deviation $(\sigma)$ and $2 \sigma$ will give us the $95 \%$ confidence interval for weight change measurements. The $95 \%$ confidence interval should remain the same for all tubing bombs used in these measurements. This analysis will ensure that the trends observed in the data are due to physical and chemical changes occuring in the reactor.

\section{References}

1. Moffat R. J., Experimental Thermal and Fluid Science, 1, pp 3-17, 1988

2. Moffat R. J., Trans. ASME, J. Fluid Eng., 104, pp 250-260, 1982.

3. Bohren, C. F., and Huffman, D. R., Absorption and Scattering of Light by Small Particles, Wiley, New York, 1983.

4. Stagg, B. J., and Charalampopoulos, T. T., Combustion and Flame 94, 381-396 (1993). 


\section{Task 3. Investigation of the Quantitative Degradation Chemistry of Fuels}

Effects of High Surface Area Activated Carbon and Decalin on Thermal Degradation of Jet A-1 Fuel and $n$-Dodecane (Contributed by Katia Gergova, Rathnamala Arumugam, and Semih Eser)

\section{Introduction}

Jet fuel degradation occurs under long-term low-temperature (oxidative) storage conditions as well as short-term high-temperature (pyrolytic) stress. During both storage and exposure to high temperatures jet fuel decomposes, forming insoluble materials which could deposit in fuel lines or on other surfaces. The higher temperature that jet fuels may be exposed in the future, possibly in the range of $400-500^{\circ} \mathrm{C}$, as a result of increased demands for "thermal management" on aircraft complicates the problem even further. Many chemicals have been used as additives, antioxidants, metal deactivators, dispersants and passivators for fuel applications in the oxidative regime. They should be used with caution in fuels taken into the pyrolytic region, since at high temperatures the oxygen plays very complex role and participates in many side reactions ${ }^{1}$. Recently, Coleman et al. ${ }^{2}$ reported that benzyl alcohol and 1,4-benzenedimethanol could retard the formation of carbonaceous solids in Jet A-1 fuel at $425^{\circ} \mathrm{C}$ in nitrogen and air atmosphere. The performance of an additive depends on various factors, such as type of fuel, fuel composition, additive concentration, and temperature of stressing. It is well known that a fuel that shows the highest degree of instability also has the highest free radical concentration ${ }^{3}$. Alfelli et al. ${ }^{4}$ reported that solid adsorbents, which they called "fuel stability foam," produced from polyurethane were found to be effective in greatly improving diesel fuel stability.

We have studied the changes in degradation reactions when different carbons were added to JP- 8 jet fuel during thermal stressing at $450^{\circ} \mathrm{C}$ (ref. 5). The solid carbons with the most disordered structure and the highest surface reactivity (i.e., activated carbons) produced the most significant effect on in preventing solid deposition on reactor surfaces. We assumed that the activated carbons added during thermal stressing of jet fuels promoted a variety of surface reactions because of their active surfaces. The reactivity of an activated carbon depends on the nature of the carbon surface, the presence of carbon-oxygen surface structures, the availability of the active sites and the surface area. Spiro ${ }^{6}$ studied the catalytic effect of carbons on reactions in solution and reported that the surface area played an important role on carbon catalytic activity. In our previous studies, we showed that the activated carbon surface area is a parameter which determines to a high degree the effectiveness in suppressing solid deposition during thermal stressing at high temperatures ${ }^{7}$. It should be noted, however, that BET $\mathrm{N}_{2}$ surface areas of carbons may not necessarily relate to the active surface areas of the solid carbons which are accessible to reactants or products of the thermal reactions. For better understanding the role of activated carbon during thermal stressing, we used 
model compounds $n$-dodecane and $n$-octane. Using model compounds simplifies the study of the chemical changes upon activated carbon addition 8 .

The main objective of present work is to study the thermal degradation of commercial petroleum-derived Jet A-1 jet fuel (as well as model compounds $n$-dodecane) in the presence of decalin and high surface area activated carbon PX-21.

\section{Experimental}

Thermal stressing experiments were carried out on $10 \mathrm{~mL}$ samples of a commercial petroleum-derived Jet A-1 fuel and dodecane at $450^{\circ} \mathrm{C}$ for $1 \mathrm{~h}$. In some experiments, 5 or $50 \%$ decalin was added to the alkane model compound. The experiments were carried out in microautoclave reactors purged with ultra-high purity (UHP) grade nitrogen five times to minimize the presence of dissolved oxygen and finally pressurized to $0.7 \mathrm{MPa}$ with nitrogen or air. The $n$ dodecane and cis/trans-decalin used as model compounds were purchased from Aldrich chemical company and used without further purification. The experimental method for stressing and analyzing the dodecane was the same as used for the authentic fuel. The high surface area activated carbon PX-21 was obtained from Amoco Oil Company. The influence of the amount of PX-21 carbon was studied by adding different quantities $(50,150$, and $250 \mathrm{mg})$ during thermal stressing of dodecane or the fuel.

Gas chromatography (GC) of liquid samples was conducted using a Perkin-Elmer 8500 GC with a fused silica capillary column. Quantitative analysis of the liquid products was performed based on the calibration curves obtained from external standards. Compounds in the liquid products were identified by capillary gas chromatography-mass spectrometry (GC-MS) using a Hewlett-Packard 5890 II GC coupled with HP 5971A mass selective detector.

The thermogravimetric measurements of activated carbon PX-21 before and after stressing experiments were performed on Mettler TA4000 System.

\section{Results and Discussion}

Thermal stressing of $n$-dodecane mixed with $5 \%$ decalin and PX-21 activated carbon at $450^{\circ} \mathrm{C}$ for $1 \mathrm{~h}$ in $\mathrm{N}_{2}$ atmosphere. Figure 50 shows the variations of naphthalene, cis -decalin and transdecalin concentrations of the liquids obtained after stressing of $n$-dodecane alone and with 50,150 and $250 \mathrm{mg}$ PX-21. The naphthalene concentration sharply increases when activated carbon is added. The concentration of naphthalene in the stressed liquids shows a linear dependence on the amount of activated carbon mixed with dodecane, and increases with the increasing carbon concentration from 50 to $250 \mathrm{mg}$. The amount of cis-and trans-decalin in the stressed liquids shows the opposite trend, i.e., decreasing with the added PX-21 concentration. The decrease in decalin concentration is not as sharp as the increase in the concentration of naphthalene, suggesting 
that part of the naphthalene comes from the pyrolytic degradation that takes place during thermal stressing,

Dodecane $\rightarrow$ Alkylcyclohexenes $\rightarrow$ Alkylbenzenes $\rightarrow$ Naphthalene.

Figure 51 shows the changes in the concentrations of shorter chain alkanes and alkenes as a function of the amount of PX-21 added. The alkanes $n$-butane, $n$-pentane and $n$-hexane coelute with the corresponding alkenes and their area percents can not be calculated separately. There is a sharp drop in the percent area of $n$-butane+butene and $n$-pentane+pentene when activated carbon is added, as well as in the concentration of $n$-hexane+hexene and $n$-heptane. The amount of carbon does not seem to affect the concentration of shorter chain alkanes and alkenes, but it does affect the stability of dodecane, as can be seen from Figure 51. The area percent of dodecane stressed without carbon is $10 \%$ lower than with PX-21. There is an additional stabilization of dodecane when the amount of carbon increases from 50 to $250 \mathrm{mg}$. However, dodecane concentration does not differ very much in the stressed liquids, being $62.80 \%$ in the liquid with $50 \mathrm{mg} \mathrm{PX}-21$ and $65.15 \%$ in the liquid with $250 \mathrm{mg} \mathrm{PX}-21$ (Figure 52).

Thermal stressing of n-dodecane mixed with $50 \%$ decalin and PX-21 at $450^{\circ} \mathrm{C}$ for $1 \mathrm{~h}$ in $\mathrm{N}_{2}$ atmosphere. Table 13 compares the experimental results obtained after stressing dodecane with $50 \%$ decalin and with $5 \%$ decalin. It was seen that the color of stressed liquid is darker and there is less liquid left after stressing of dodecane with $5 \%$ decalin than with $50 \%$ decalin. There is no deposit formation on the reactor walls when activated carbon is added in both cases, but there is a larger increase in the activated carbon weight when the decalin concentration is $5 \%$. These results suggest that the degree of thermal degradation of dodecane depends on both the amounts of decalin and the activated carbon added. Most probably, activated carbon added to dodecane mixed with $5 \%$ decalin adsorbed more of the intermediates/or accumulated more deposits from the degradation reactions.

Table 14 shows the main compounds identified in the liquids after thermal stressing of $n$ dodecane+decalin (50\%) mixed with 50, 150 and $250 \mathrm{mg}$ PX-21. The rest of the compounds identified are in negligible concentrations and are not listed in Table 14. From Table 14, the area percents of dodecane, decalin, naphthalene, and tetralin in the liquids obtained from thermal stressing of dodecane $+50 \%$ decalin follow the same trends as those obtained after stressing of dodecane with $5 \%$ decalin. The concentrations of dodecane, naphthalene, and decalin increase with adding activated carbon. The increase depends slightly on the amount of carbon added. In accordance with the increase in naphthalene and tetralin concentration, the cis- and trans-decalin concentration decreases. 
The data in Table 14 for alkane concentration in the stressed liquids with and without PX21 lead to the following speculations. The variation of product distribution with PX-21 is mainly due to distinction between different radicals. The lower concentration of light compounds $\mathrm{C}_{4}-\mathrm{C}_{8}$ and higher concentration of $\mathrm{C}_{9}-\mathrm{C}_{11}$ alkanes obtained from stressing of dodecane+decalin +50 (or 150) $\mathrm{mg}$ PX-21 suggest that the primary radicals were stabilized on the carbon surface. However, with the increasing amount of PX-21, the alkane concentration increases, and, in the liquid stressed with $250 \mathrm{mg} \mathrm{PX}-21$, the concentration of $\mathrm{C}_{6}-\mathrm{C}_{11}$ alkanes is even higher than the alkanes concentration from dodecane+decalin stressed without carbon. These results are in contradiction with the higher percent of dodecane preserved with increasing amount of PX-21 added. Most probably, the active sites of PX-21 carbon promote certain cracking reactions in addition to stabilizing the free radicals.

Thermal stressing of commercial petroleum derived Jet A-1 mixed with 5\% decalin and PX-21 at $450^{\circ} \mathrm{C}$ for $1 \mathrm{~h}$ in $\mathrm{N}_{2}$ atmosphere. The thermal stressing experiments on Jet A-1 fuel in the presence of high surface area activated carbon PX-21 and $5 \%$ decalin were also carried out at $450^{\circ} \mathrm{C}$ for $1 \mathrm{~h}$. Initially, the fuel is a clear, colorless liquid which became light brown after $1 \mathrm{~h}$ at $450^{\circ} \mathrm{C}$ (Figure 53). Figure 53 shows the liquids obtained after thermal stressing of $\mathrm{A} 1+5 \%$ decalin alone and mixed with 50,150, and $250 \mathrm{mg}$ PX-21. One can see the effect of adding different amounts PX21 activated carbon on the appearance of the stressed liquids. The color of the obtained liquids become darker with decreasing amount of carbon added. It is interesting that there is more liquid obtained after stressing with $50 \mathrm{mg}$ PX-21 than after stressing of Jet A-1+ decalin alone. However, with the increasing amount of carbon added, the quantity of liquid obtained decreases. This is due to the larger amount of liquid adsorbed by $250 \mathrm{mg}$ activated carbon than $50 \mathrm{mg}$ carbon. Another reason for the decreasing amount of liquid obtained with the increasing amount of carbon added could be the catalysis some cracking reactions by the added carbon.

Figure 54 shows the gas chromatogram of liquid obtained from $\mathrm{A} 1+5 \%$ decalin stressed alone and $\mathrm{Al}+5 \%$ decalin $+250 \mathrm{mg} P X-21$. The difference between the two chromatograms is only in the concentration of individual compounds. The concentrations of long-chain alkanes ( $n$ decane, $n$-undecane, and $n$-dodecane) are higher in the liquid obtained from stressing of Jet A- $1+$ decalin $+250 \mathrm{mg} \mathrm{PX}-21$, which is due to the ability of the carbon to preserve long-chain alkanes during thermal stressing. The considerably higher amount of naphthalene, the higher concentration of 2-methyl and 1-methyl naphthalene, as well as the lower concentration of cis - and trans -decalin in the liquid obtained from Jet A-1 fuel stressed with carbon shows that the degradation of jet fuel in the presence of decalin and activated carbon follows the same trends as degradation of $n$ dodecane stressed with decalin and PX-21. The presence of activated carbon PX-21 during thermal 
degradation of Jet A-1 fuel, as in the case of thermal stressing of the model compound dodecane, promotes $\mathrm{H}$ transfer reaction and enhances the conversion of decalin into naphthalene.

Thermal properties of PX-21 hefore and after stressing with Jet A-1 fuel and dodecane As discussed in the previous report ${ }^{8}$, there are many exposed defects, dislocations, and discontinuities in and at the edge of layer planes in activated carbons. Carbon atoms in the surface at such defects tend to chemisorb molecules such as oxygen, sulfur, and halogens in order to complete their valency requirements ${ }^{9}$. An important factor that can have an influence on the activated carbon behavior during thermal stressing with jet fuel and model compounds is the chemical nature of the carbon surface i.e., the surface functional groups. We performed the thermogravimetric analysis (TGA) in a nitrogen flow up to $1000^{\circ} \mathrm{C}$ of the stressed PX-21 carbons to get some information about the surface functional groups as well as the amount of liquid adsorbed during thermal stressing of jet fuel and model compounds with activated carbons. Figure 55 shows the percentage of weight loss of PX-21 stressed with dodecane and $50 \%$ decalin at $450^{\circ} \mathrm{C}$ for $1 \mathrm{~h}$. The sample was treated in nitrogen atmosphere at three different heating rates; $10^{\circ} \mathrm{C} / \mathrm{min}(\mathrm{a}), 20^{\circ} / \mathrm{C} \mathrm{(b)}$, and $30^{\circ} \mathrm{C} / \mathrm{min}$ (c). It is clear from Figure 55 that the weight loss is considerably higher when the heating rate is $10^{\circ} \mathrm{C} / \mathrm{min}$ compared to 20 and $30^{\circ} \mathrm{C} / \mathrm{min}$, which have almost equal weight loss. Since we are interested in both surface functional groups and amount of liquid adsorbed during thermal stressing, we performed the TGA experiments with $10^{\circ} \mathrm{C} /$ minute, in order to obtain the most complete desorption of the adsorbed species.

Figure 56 shows the percentage weight loss of PX-21 obtained after stressing with dodecane $+50 \%$ decalin mixed with $250 \mathrm{mg}$ PX-21 (a) and dodecane $+5 \%$ decalin mixed with $250 \mathrm{mg}$ PX-21 (b). It is seen that the sample stressed with $50 \%$ decalin adsorbed significantly larger amount liquid and/or there are more functional groups in the carbon surface of this sample. We mentioned above that the color of stressed liquid is darker and there is less liquid left and a larger increase in the activated carbon weight when the decalin concentration is $5 \%$ compared to $50 \%$ decalin addition. These data are in contradiction with the TGA results which showed $14 \%$ more weight loss in the sample stressed with 50\% decalin compared to that with 5\% decalin. Most probably there is more carbon formed and deposited on the surface of PX-21 stressed with 5\% decalin due, most likely, to a deficiency of donor hydrogen on the carbon surface.

Figure 57 shows the percent weight loss of untreated PX-21 (a), PX-21 stressed with dodecane, 50\% decalin, and $50 \mathrm{mg}$ PX-21(b), $150 \mathrm{mg} \mathrm{PX-21} \mathrm{(c)} \mathrm{and} 250 \mathrm{mg}$ PX-21 (d). The observed mass loss of untreated carbon sample in the temperature range of $50-200^{\circ} \mathrm{C}$ results from the desorption of water. After the sharp weigh loss up to $100^{\circ} \mathrm{C}$, there is a continuous loss of weight up to $1000^{\circ} \mathrm{C}$, which is an indication the presence of various functional groups on the surface. The overall weight loss for the untreated sample is $28 \%$. 
Thermogravimetric analysis of the treated samples show that $250 \mathrm{mg} \mathrm{PX-21}$ adsorb 3\% more liquid than $50 \mathrm{mg} \mathrm{PX-21}$ during thermal stressing. The shape of the three curves of stressed PX-21 is similar and differs from the curve obtained for the unstressed sample. The weak endothermic effects above $250^{\circ} \mathrm{C}$ results from the decomposition of surface oxides. The observed drop of the mass loss around $400-450^{\circ} \mathrm{C}$ is due to decomposition of surface functional groups, such as phenolic and carbonyl groups, which remain stable to these temperature interval. There is 6-9\% difference in the mass loss between stressed and unstressed samples which is due to the amount liquid adsorbed by PX-21 during thermal stressing with dodecane and $50 \%$ decalin.

Figure 58 shows the percentage weight loss of untreated sample PX-21 (a) and PX-21 stressed with Jet A-1, 5\% decalin, and $250 \mathrm{mg}$ PX-21(b). The stressed sample shows approximately $5 \%$ more weight loss than the unstressed carbon. One can see weak endothermic effects disturbing the continuous weight loss of the stressed sample. As we mentioned above, they are due to decomposition of surface oxides and functional groups. However, the 2-3 steps of the mass loss of the samples stressed with jet fuel or model compounds could be attributed also to the fact that the adsorbed compounds were bonded at different types of sites associated with various energies of bonding.

\section{Conclusions}

We studied the presence of hydrogen donor, decalin, together with PX-21 activated carbon during thermal stressing of Jet A-1 jet fuel and $\mathrm{n}$-dodecane. The color of the liquids obtained after stressing of Jet A-1 $+5 \%$ decalin with different amounts PX-21 activated carbon is clearly different and becomes lighter with the increasing amount of carbon added. Adding decalin as $\mathrm{H}$ donor additionally reduced the extent of decomposition of $n$-dodecane and jet fuel. The activated carbon addition appears to promote $\mathrm{H}$-transfer reactions during the thermal treatment. The data also suggest that during thermal degradation of Jet A-1 and n-dodecane the primary radicals are stabilized on carbon surfaces. Most probably, the active sites of PX-21 carbon promotes the Htransfer reactions and some cracking reactions, in addition to stabilizing some free radicals. The degree of thermal degradation of Jet A-1 and $n$-dodecane depend on both, the amounts of activated carbon and decalin added.

Thermogravimetric analysis of stressed PX-21 carbon showed that: (1) The heating rate $10^{\circ} \mathrm{C} / \mathrm{min}$ leads to the highest weight loss compared to the heating rate 20 and $30^{\circ} \mathrm{C} / \mathrm{min}$, i.e. to most complete desorption of the adsorbed species. (2) The samples stressed with $50 \%$ decalin adsorbed higher amount liquid compared to the carbon stressed with 5\% decalin. (3) The stressed samples loose weight during heating in $\mathrm{N}_{2}$ in 2-3 steps, while the unstressed carbon loses weight continuously up to $1000^{\circ} \mathrm{C}$. These data lead to the following conclusions: The adsorbed compounds are most probably inside the pore structure of PX-21 carbon and the longer time is 
needed for their desorption. There seems to be synergistic effect between activated carbon and decalin addition in suppressing the thermal degradation reactions. The stressed samples lose weight in 2-3 steps most probably due to the presence of different types of active sites on the activated carbon surface.

\section{$\underline{\text { References }}$}

1. Hazlett, R.N., Thermal Oxidation Stability of Aviation Turbine Fuels, ASTM Publication, Ann Arbor, MI, December 1991.

2. Coleman, M.M.; Selvaraj, L.; Sobkowiak, M.; Yoon, E. Energy Fuels 1992, 6, 535.

3. Batts, B.D.; Fathoni Zuhdan, A. Energy Fuels 1991, 5, 2.

4. Arfelli, W.; Power, A.J.; Solly, R.K. Proceedings 3rd International Conference of Stability and Handling of Liquid Fuels. 1992

5. Schobert, H.H.; Eser, S.; Song, C.; Hatcher, P.G.; Walsh, P.M.; Coleman, M.M. Advanced Thermally Stable Jet Fuels, Annual Progress Report, WL-TR-93-2007, August 1991-August 1992; pp. 96-111.

6. Spiro, M. Catalysis Today 1990, 7, 167

7. Schobert, H.H.; Eser, S.; Song, C.; Hatcher, P.G.; Walsh, P.M.; Coleman, M.M. Advanced Thermally Stable Jet Fuels, Technical Progress Report, 92PC92104-TPR-2, November 1992- January 1993; pp. 29-36.

8. Schobert, H.H.; Eser, S.; Song, C.; Hatcher, P.G.; Walsh, P.M.; Coleman, M.M. Advanced Thermally Stable Jet Fuels, Technical Progress Report, 92PC92104-TPR-8, April-June 1994; pp.24-28.

9. Coughlin, R.W., Ind.Eng.Chem.Prod.Res.Dev. 1969, 8, 12. 


\section{Task 4. Coal-based Fuel Stabilization Studies}

Screening Potential Jet Fuel Stabilizers Using the Model Compound Dodecane (Contributed by Emily M. Yoon, Michael M. Coleman, John B. Stallman)

\section{Introduction}

We have previously demonstrated that benzyl alcohol enhanced the thermal stability of jet fuels and the model compound dodecane at temperatures above $400^{\circ} \mathrm{C}$ and in turn retards the formation of carbonaceous solids. In an effort to further understand the mechanistic nature of this stabilization, we have now evaluated the effects of a number of new hydrogen donor additives. The new additives that we have tested are shown below.<smiles>OCc1cccnn1</smiles>

1<smiles>OCc1ccccc1Cl</smiles>

5<smiles>OCCOc1ccccc1CO</smiles>

9<smiles>OCc1ccnnc1</smiles>

2<smiles>OCc1ccc(Cl)cc1</smiles>

6<smiles>OCc1ccccc1O</smiles>

3<smiles>O=C1C=CC=CC2C=CC=CC12</smiles>

7<smiles></smiles>

4<smiles>OCc1ccccc1</smiles>

8<smiles>OCc1ccccc1</smiles>

13

We have placed both electron donating $(1,2,3,4)$ and electron withdrawing $(5,6)$ substituents on or in the aromatic ring, as well as, additional aromatic rings in succession $(7,8,9,10,11,12)$ in order to probe their effects on radical stability. This in turn would help to further understand the properties necessary for an efficient additive. It is the ability to stabilize radicals that we believe is responsible for the success of benzyl alcohol, as shown in scheme I. 


\section{Scheme I}

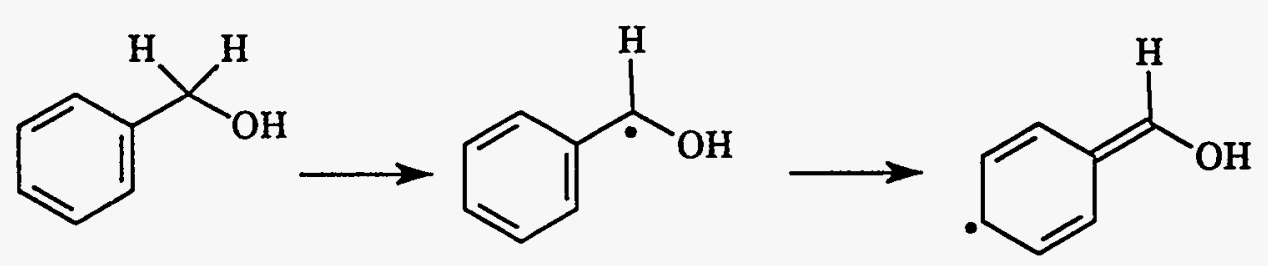

\section{Experimental}

The reactants used in these studies were purchased from Aldrich Chemical Co. Dodecane (Dod), 3-pyridylcarbinol (1), 4-pyridylcarbinol (2), 2-hydroxybenzyl alcohol (3), 1,2,3,4tetrahydroquinoline (4), 2-chlorobenzyl alcohol (5), 4-chlorobenzyl alcohol (6), anthrone (7), 1naphthalenemethanol (8), 9-anthracenemethanol (9), 9-hydroxyfluorene (10), indene 11), 9,10dihydrophenanthrene( 12), and benzyl alcohol (13) were used without further purification. Ten mole \% (equivalent to approximately 5-6 volume \%) of each additive was added based on dodecane. Thermal stressing was performed at $425^{\circ} \mathrm{C}$ in $25 \mathrm{~mL}$ type 316 stainless steel microreactors under $0.69 \mathrm{MPa}$ of UHP-grade $\mathrm{N}_{2}$. The microreactor containing the sample was purged five times with UHP-grade $\mathrm{N}_{2}$ at $7.0 \mathrm{MPa}$ to minimize the presence of dissolved oxygen and finally pressurized with $0.69 \mathrm{MPa}$ of $\mathrm{N}_{2}$. It was then placed in a preheated sand bath at $425^{\circ} \mathrm{C}$ for 6 hours, followed by quenching into cold water. The liquid products were analyzed by using a Perkin-Elmer GC with a FID detector. The column used was DB-17. The column temperature was programmed $40^{\circ} \mathrm{C}$ to $280^{\circ} \mathrm{C}$ at a heating rate of $4^{\circ} \mathrm{C} / \mathrm{min}$ after $5 \mathrm{~min}$ isothermal period at $40^{\circ} \mathrm{C}$, followed by $10 \mathrm{~min}$ isothermal period at $280^{\circ} \mathrm{C}$. The split mode of injection was used. The side products were analyzed by using GC/MS.

\section{Results and Discussion}

Shown in Figure 59 are the results from the $6 \mathrm{~h}$ thermal stressing of dodecane at $425^{\circ} \mathrm{C}$ in the presence of additives 1-6,8,10-12. Compounds 7 and 9 were insoluble in dodecane even after stressing at $425^{\circ} \mathrm{C}$ for $6 \mathrm{~h}$, and resulted in the formation of various solids.

The molar yields of dodecane when stressed with compounds 5 and 6 were $30 \%$ and $27 \%$ respectively. The inability of these compounds to act as efficient radical scavengers was evidenced by the formation of benzene, toluene, chlorobenzene, and chloromethylbenzene, the products of additive degradation. This appears to suggest that the presence of electron-withdrawing substituents on the aromatic ring facilitates and accelerates side group cleavage. 
When compound 10 was stressed with dodecane the molar yield of dodecane increased somewhat, although not substantially. The byproducts from this reaction were fluorene from loss of $\mathrm{OH}$, and fluorenone, the product of oxidation. The stressing of dodecane with compound 3 resulted in a molar yield of $35 \%$ with the byproducts being benzyl alcohol, benzene and toluene. What we had discovered up to this point was that any side groups on additives will undergo thermal cleavage at $425^{\circ} \mathrm{C}$, which in turn results in degradation of the additive and thus decreases stabilization of dodecane.

The presence of electron-donating groups within the additives 1 and $\mathbf{2}$ resulted in a relative increase in the molar yields of dodecane. However, the byproducts pyridine, methylpyridine and pyridinecarboxaldehyde again suggest an acceleration in side group cleavage when compared to that of benzyl alcohol, 13.

The effect of an increase in radical resonance energy (and thus radical stability) was evaluated with compounds $4,8,11$, and 12 . Compounds 8 and 11 had a relative increase in the molar yields of dodecane, but compound 8 produced naphthalene and methyl naphthalene while compound 11 produced unidentified reaction products, again the result of additive decomposition.

Compound 12 produced a similar molar yield of dodecane compared to benzyl alcohol after stressing at $425^{\circ} \mathrm{C}$. The only byproduct formed from this reaction was phenanthrene. However, a major drawback to compound 12 is that after stressing at $425^{\circ} \mathrm{C}$ for $6 \mathrm{~h}$ only $20 \%$ of the additive remains. In contrast, stressing with benzyl alcohol under the same conditions, $48 \%$ of the additive remains. Accordingly, there appears to be a definitive correlation between "additive efficiency" and the overall thermal stability of the additive. Further evidence for this conclusion was determined with compound 4.

The molar yield of dodecane when stressed under standard conditions with compound 4 was 93\%. This is a dramatic improvement over benzyl alcohol. Furthermore, the amount of additive 4 remaining after thermal stressing at $425^{\circ} \mathrm{C}$ for $6 \mathrm{~h}$ was $78 \%$, a marked increase relative to that of benzyl alcohol (48\%). The major byproduct from the stressing of additive 4 was quinoline. A plausible mechanism for this transformation is shown in scheme II. At $425^{\circ} \mathrm{C}$, initial abstraction of the $\mathrm{N}-\mathrm{H}$ hydrogen by a dodecane radical leads to intermediate $\mathrm{A}$. This radical can then be resonance stabilized by delocalization through the aromatic ring. Subsequent abstraction of a second hydrogen atom leads to a diradical intermediate, $\mathrm{B}$, which again enjoys resonance stabilization. This then leads to dihydroquinoline, $\mathbf{C}$. Abstraction of an additional two hydrogen atoms leads to a second diradical species, $\mathrm{D}$, which again benefits from resonance stabilization. The diradical $\mathbf{D}$ presumably then rapidly aromatizes to quinoline. Hence, there are two main reasons for the dramatic efficiency of tetrahydroquinoline, 4, relative to benzyl alcohol. First, compound 4 exhibits superior thermal stability at $425^{\circ} \mathrm{C}$ that infers an increased lifetime of the 
additive. Second, compound 4 has four hydrogen atoms available for abstraction instead of the two available with benzyl alcohol.

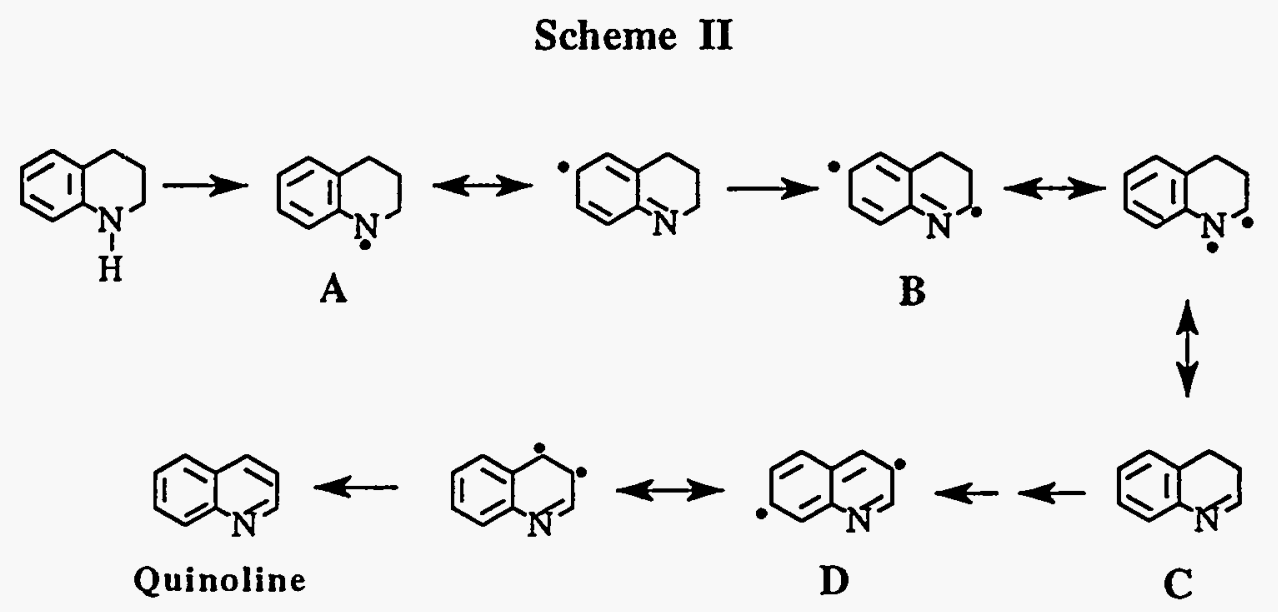

From this study we have developed a set of parameters to predict the effectiveness of organic additives that can be used to thermally stabilize hydrocarbon fuels and prevent the formation of carbonaceous solids. The properties of a good additive are summarized as follows:

1. The additives must be thermally stable at temperatures above $400^{\circ} \mathrm{C}$. In other words, it must not possess any side groups which could undergo cleavage and therefore promote degradation.

2. The additive must have hydrogen atoms that can be transferred or abstracted by hydrocarbon radicals. The greater the number of hydrogen atoms available for abstraction the better.

3. The radicals generated from hydrogen atom abstraction should be stabilized by resonance.

Future work will focus on improving the effectiveness of compound 4, possibly through the addition of ethanol, which we have previously shown to increase the lifetime of benzyl alcohol at $425^{\circ} \mathrm{C}$. 


\section{Task 5. Exploratory Studies on the Direct Conversion of Coal to High-Quality Jet Fuels.}

Shape-Selective Naphthalene Hydrogenation for Production of Thermally Stable Jet Fuels. (Contributed by Andrew D. Schmitz, Grainne Bowers and Chunshan Song)

\section{Introduction}

Previous work in this laboratory has shown that for jet fuels, cyclic alkanes have higher thermal stability than normal alkanes. Cycloalkane conformation also affects high temperature (eg. $450^{\circ} \mathrm{C}$ ) stability. For example, trans-decalin (t-DeHN) was found to be more stable than cisdecalin (c-DeHN) . Furthermore, a jet fuel's carbon-forming propensity can be reduced by limiting its aromatic content as in the complete hydrogenation of naphthalene (Nap). Tests on the thermal stressing of petroleum-derived fuels and model compounds have shown that addition of $t-D e H N$ can significantly retard the rate of carbon deposition. The challenge, then, is to hydrogenate Nap, selectively, to produce $t$-DeHN.

Shape-selective hydrogenation of naphthalene to t-DeHN may be accomplished over metalloaded zeolite molecular sieves. Zeolites are high surface area crystalline aluminosilicates, having regular channel structures of narrow size distribution. They can mediate the course of reaction by controlling diffusion, and the shape and size of products produced within their channels. We examined two types of zeolites: mordenite and zeolite Y. Mordenite has a two-dimensional channel structure, with elliptically shaped channels of diameter $6.7 \times 7.0 \AA$. The molecular diameter of the Nap is very close to the dimensions of the channel, which limits the types of reactions that Nap can undergo, and governs regioselectivity in the products. On the other hand, zeolite $\mathrm{Y}$ has a cage structure with large cavities in its interior, and narrow channel openings. A reactant that has entered the channel structure may reorient itself freely and react at catalyst sites on the walls of the cavity. However, because of restricted diffusion at the channel openings, only molecules of appropriate diameter can exit the catalyst's interior.

Zeolite supports may also give better catalyst longevity. Zeolites have very high thermal stability, so they can be subjected to oxidative regeneration procedures without undergoing sintering. It is also believed that the high area and acidity of the zeolite surfaces will prevent or retard catalyst deactivation caused by sulfur poisoning.

We have prepared and tested eight catalysts in our preliminary effort to selectively convert Nap to t-DeHN, using four different commercial zeolites: HY, and three hydrogen-mordenites having different silica/alumina ratios. To each zeolite was added an approximate $6 \mathrm{wt} \%$ loading of platinum or palladium by impregnation of a corresponding metal chloride salt. Following drying and calcination, the catalysts were tested in batch tubing-bomb reactors at $200^{\circ} \mathrm{C}$, for $0.25-1.0 \mathrm{~h}$. Reduction of the metal occurs in situ under the hydrogen pressure used for reaction. 
Catalysts based on HM38 gave the highest t-DeHN selectivity, and catalysts with palladium gave higher selectivity than those with platinum. Under the chosen test conditions, $100 \%$ of the Nap was converted in all cases, almost exclusively to a mixture of cis-and trans-decalins. Therefore, it is not possible to rank catalyst activity at this time.

$\mathrm{X}$-ray powder diffraction (XRD) was used to examine the state of the metal on the zeolite after the catalysts were recovered from the reactors. For the metals, only lines indicative of zerovalency were observed. Line broadening was used to measure average metal particle sizes. There are striking differences in metal particle sizes between the samples. HM38 catalyst generally showed the highest metal dispersions (smallest particle sizes).

Also addressed in this report is a peculiar behavior of this series of catalysts that seems to be a consequence of ageing. The catalysts were originally prepared and tested in June-July of 1993 by G. Bowers. These samples were further tested by A. Schmitz beginning August, 1994, after having been stored in a desiccator. The objective of this second series of tests was to examine the product distribution in short-duration runs. The procedures used were nearly identical to those of Bowers. Schmitz observed marked differences from what was expected for short runs and observed in $1 \mathrm{~h}$ runs by Bowers. We do not yet have an explanation for the discrepancies.

\section{Experimental}

The zeolites were supplied in $\mathrm{NH}_{4}$-form and used as received. Table 15 lists their properties. Zeolite-supported metal catalysts were prepared by incipient wetness impregnation of either aqueous $\mathrm{H}_{2} \mathrm{PtCl}_{6}$, or $\mathrm{PdCl}_{2}$ dissolved in hydrochloric acid. Following drying in vacuo, the catalysts were calcined in air at $450^{\circ} \mathrm{C}$ for $2 \mathrm{~h}$.

Initial tests by Bowers were done with little delay. However, Schmitz used these same catalysts following storage in a desiccator, over anhydrous $\mathrm{CaSO}_{4}$, for up to one year. In either case, a $30 \mathrm{~mL}$, stainless steel tubing-bomb, batch reactor was used for catalyst tests. The reactor was charged with $0.4 \mathrm{~g}$ catalyst, $1.0 \mathrm{~g}$ (7.8 mmol) naphthalene (Aldrich, 99\%), $4.0 \mathrm{~g} n$-tridecane reaction solvent, and $0.35 \mathrm{~g} n$-nonane internal standard. The charged reactor was then sealed and leak-tested by pressurizing with $\mathrm{H}_{2}$. Finally, the hydrogen pressure was adjusted to $1500 \mathrm{psig}$, (cold), ca. $0.2 \mathrm{~g}$ ( $20 \mathrm{mmol})$, as determined by difference in the reactor weight.

The reactor was affixed to a holder so that approximately two-thirds of the length of the reactor assembly was immersed in the fluidized sand-bath heater. Vertical agitation at 240 cycle/min was used to provide mixing. Experiments were done at $200^{\circ} \mathrm{C}$ for $0.25-1 \mathrm{~h}$. At the end of the test, the reaction was quenched in cold water. After cooling, the gas headspace was collected for analysis and the reactor was opened. Acetone was used to wash the contents of the reactor onto a $0.45 \mu \mathrm{m}$ polypropylene filtering disk. The filtrate and washings were combined for GC analysis, while the solid was dried for XRD examination. 
GC and GC-MS analyses were performed using a $30 \mathrm{~m} \times 0.25 \mathrm{~mm}$ o.d. $\times 0.25 \mu \mathrm{m}$ coating thickness DB-17 capillary open-tubular column (J\&W Scientific). The GC oven temperature program was 100 to $280^{\circ} \mathrm{C}$ at $15^{\circ} / \mathrm{min}$, with a $3 \mathrm{~min}$ hold at $280^{\circ} \mathrm{C}$. Products were quantitated by an internal standard method using FID calibration factors determined from standard solutions.

$\mathrm{X}$-ray powder diffraction analyses (XRD) were done on a Scintag 3100 diffractometer using $\mathrm{Cu} \mathrm{K}_{\alpha}$ radiation and continuous scans at 1 or $2 \% \mathrm{~min}$. Diffraction peak profiles were measured by an automatic profile-fitting/deconvolution routine whenever possible. This routine calculates a smooth-peak profile, with shape intermediate between Gaussian and Cauchy, to fit the experimental data. Accuracy is judged statistically by a goodness-of-fit parameter, and visually by a zoomed-view window of the calculated profile overlaid on the actual pattern. Manual measurements were always used to check calculated results, especially for very broad, weak lines where the computer routine often fails.

Mean metal crystallite size was calculated by application of the Scherrer equation according to procedures described elsewhere for profile shapes intermediate between Gaussian and Cauchy . For most of the catalysts, only the (111) reflection was suitable for profile analysis since other, less intense lines were not clearly resolved from weak lines due to the zeolite. Silicon powder (325 mesh) was used as an external standard for measuring instrumental and spectral broadening.

\section{Results and Discussion}

Tables 16 and 17 compare the results for platinum and palladium catalysts, respectively, in $1 \mathrm{~h}$ runs $200^{\circ} \mathrm{C}$. The products of Nap hydrogenation are almost exclusively isomeric DeHN's. In some cases, a small amount of tetralin (THN) is observed. Gas headspace analyses show predominately unreacted hydrogen with approximate ppm levels of $\mathrm{C}_{1}-\mathrm{C}_{4}$ hydrocarbons. Every catalyst gives ca. $100 \%$ Nap conversion in $1 \mathrm{~h}$ tests at $200^{\circ} \mathrm{C}$, so it is not possible to rank catalyst activity. Yet, the trans/cis DeHN ratio is highly dependent on zeolite composition and noble metal identity. Catalysts based on HM38 gave the highest $t-D e H N$ selectivity. Palladium gives higher $\mathrm{t}$-DeHN selectivity than platinum on the same zeolite.

Because HM38-based catalysts show particular promise, we further investigated their performance in 0.25 and $0.5 \mathrm{~h}$ runs. These data are shown in Tables 18 and 19, together with the $1 \mathrm{~h}$ test data from the previous tables. Complete conversion of Nap occurs within the first $0.25 \mathrm{~h}$. The trans/cis DeHN ratio increases markedly over time in keeping with the higher thermodynamic stability of trans-compared to cis-DeHN. A comparison of trans/cis ratios over time from the present and Bowers' studies is shown in Figure 60. Especially apparent in the AS data is that not only does palladium have a higher initial selectivity for $t$-DeHN, but palladium also isomerizes $c$-DeHN to $t-D e H N$ at a higher rate than platinum (comparing the slopes of the linear line-fits). 
This figure also shows a significant discrepancy between the two sets of data. The selectivity for $\mathrm{t}$-DeHN is much higher in the present work than that recorded by Bowers. For example, $\mathrm{Pd}(\mathrm{GB}) / \mathrm{HM} 38$ requires $2 \mathrm{~h}$ reaction time to reach the same trans/cis ratio obtained in $0.25 \mathrm{~h}$ with $\mathrm{Pd}(\mathrm{AS}) / \mathrm{HM} 38$, Nap conversion being approximately $100 \%$ to DeHN's in both cases. We speculated that the difference between the data was due to moisture adsorption by the hygroscopic zeolite during storage-freshly calcined samples may give results that mimic Bowers' data. A comparison study was necessary.

We chose to run a comparison study with HM17-based catalysts so that we could also examine a further discrepancy. Bowers consistently observed THN as an intermediate product in 2 and $4 \mathrm{~h}$ runs with these catalysts; whereas, THN was not observed at significant levels in any of the current tests. For the experiment, portions of $\mathrm{Pt} / \mathrm{HM} 17$ and $\mathrm{Pd} / \mathrm{HM} 17$ that had been stored for approximately one year in the desiccator were calcined $3 \mathrm{~h}$ at $450^{\circ} \mathrm{C}$. Calcination resulted in ca. $13 \%$ weight loss for each sample. If discrepancies between the data sets are due to adsorbed water, $1 \mathrm{~h} / 200^{\circ} \mathrm{C}$ tests of freshly calcined HM17-based catalysts should give measurable yields of THN, and trans/cis DeHN ratios should be in accord with Bowers' data.

Tables 20 and 21 list results for all tests of the HM17-based catalysts: (1) the original data from Bowers; (2) Schmitz's first test after samples stored 1 year; and (3) stored samples, recalcined. Considering first the platinum catalysts, Figure 61 shows that the trend in trans/cis DeHN ratio over time is approximately linear, as expected, when comparing the Bowers 2 and $4 \mathrm{~h}$ data with that for the stored sample in a $1 \mathrm{~h}$ run. But THN is not produced over the stored sample. Even after re-calcination, no THN was observed, and the trans/cis ratio increased remarkablyover $300 \%$. No THN was observed in the products for stored Pd/HM17, or stored and re-calcined $\mathrm{Pd} / \mathrm{HM} 17$, either. Trans/cis DeHN ratios for the 2 and $4 \mathrm{~h}$ tests of Pd/HM17 are inconsistent: the ratio should increase with time. Nevertheless, re-calcination of the stored sample causes a marked increase in t-DEC selectivity (ca. 140\%).

Perhaps preadsorbed water acts to increase metal dispersion during thermal treatment (reductive or oxidative). However, it is generally observed that supported noble metal microcrystallites sinter during hydrothermal treatment. It may be that the greatest effect of hydrothermal treatment is on the acidic surface of the zeolite. Since the moisture content significantly effects catalyst performance, we are planning the following sequence of experiments for one or two catalysts to resolve this issue:

(1) determine moisture content of the stored catalyst by thermal gravimetric analysis (TGA);

(2) calcine and re-test a portion of the stored catalyst;

(3) store the remaining re-calcined catalyst for a period of time, allowing it to re-adsorb water;

(4) determine adsorbed water by TGA, re-calcine, and re-test. 
XRD and transmission electron microscopy will provide information on changes in metal dispersion during the different stages of treatment.

XRD line widths for (111) and other reflections of platinum and palladium are compared for all catalysts tested $1 \mathrm{~h}$ at $200^{\circ} \mathrm{C}$ (A. Schmitz data) in Figures 62 and 63 . In every case, the only phases observable other than the support are attributed to zero-valent metal. Therefore, in situ hydrogen treatment is adequate for complete metal reduction. Differences between the samples are striking, especially for the platinum catalysts. $\mathrm{P} / \mathrm{HY}$ shows very sharp and intense platinum diffraction lines (large Pt particles), but Pt/HM38 and Pt/HM17 show very broad, diffuse lines indicative of small $\mathrm{Pt}$ particles. Pt/M21 is intermediate. Further examination of $\mathrm{Pt} / \mathrm{HM} 38$ shows that the $\mathrm{Pt}$-phase is bi-disperse, Figure 64. A sharp line appears superimposed over a very broad band, both arising from reduced platinum. Figure 64 also shows what is generally observed: the diffraction signal arising from the zeolite is very weak in the region of $\mathrm{Pt}(111)$ or $\mathrm{Pd}(111)$ and does not significantly interfere with (111) profile measurements. Palladium catalysts, Figure 63, all show significant line-broadening. The trend in line width increase on going from metal/HY to metal/HM17 is also observed for Pd, but is less pronounced. Particle size estimates determined from the profiles of Figures 62 and 63 using the Scherrer equation are summarized in Table 22. There does seem to be a loose correlation between metal crystallite size and t-DeHN selectivity. The trans/cis ratio generally increases with decreasing crystallite size, but HM17 catalysts do fit the trend.

Accuracy of the XRD particle size technique is generally accepted to be $\pm 10-20 \%$, increasing significantly as the dimension approaches $2000 \AA$. Similarly, when XRD lines become very broad and diffuse, accurate line-width measurements are impossible. Under ideal conditions, particle size can be measured down to $20 \AA$ by XRD. Below $20 \AA$, the very broad lines fade into the baseline. However, the baseline zeolite signals from HM38 and HM17 cloud the Pd (111) reflection enough that accurate measurements in the 50-100 $\AA$ region are not possible. The corresponding values in Table 22 are then best guesses from poorly defined $\mathrm{Pd}(111)$ lines.

\section{Conclusions}

Catalysts based on HM38 gave the highest t-DeHN selectivity. Palladium gives higher t-DeHN selectivity than platinum on the same zeolite. Not only does palladium have a higher initial selectivity for t-DeHN, but palladium also isomerizes c-DeHN to t-DeHN at a higher rate than platinum. Metal crystallite sizes are highly dependent on the zeolite. Palladium generally had a higher dispersion than did platinum on a given zeolite. There is a loose correlation between decreasing particle size and increasing t-DeHN selectivity. Continued use of XRD line-broadening and transmission electron microscopy will allow us to further probe this correlation and engineer better catalysts. Since a high metal dispersion means a proportionately high number of active metal 
sites, improved sulfur tolerance will likely also be observed for small metal crystallites. Complete conversion of Nap occurs within the first $0.25 \mathrm{~h}$ in tests with $\mathrm{Pt} / \mathrm{HM} 38$ and $\mathrm{Pd} / \mathrm{HM} 38$. In future work, we will decrease the metal loading on the zeolite to $2 \mathrm{wt} \%$ and decrease the catalyst charge in the reactor to moderate Nap conversion. We can then establish an activity scale for the catalysts and possibly observe better t-DeHN selectivity. Ultimately, we endeavor to develop a catalyst with high sulfur tolerance which may require metal loading greater than $2 \%$. Thiophene added as reactor charge will allow us to investigate sulfur tolerance. Our previous work with mordenites has taught us that regioselectivity for reactions involving naphthalene can be enhanced by mordenite dealumination. At some point we will apply this technology in attempt to engineer better molecular sieve supports.

\section{References:}

1. Song, C., Eser, S.; Schobert, H.H.; Hatcher, P.G. Energy \& Fuels, 1993, 7, 243.

2. Song, C.; Lai,W.-C., Schobert, H.H. Am. Chem. Soc. Div. Fue. Chem. Prepr. 1992, 37, 1655.

3. Klug, H.P.; Alexander, L.E., "X-ray Diffraction Procedures for Polycrystalline and Amorphous Materials;" Wiley: New York, 1974. (See example calculations on p. 699).

4. Schmitz, A.D,; Song, C. Advanced Thermally Stable Jet Fuels, Technical Progress Report 92PC92104-TPR-6, p. 18. 
APPENDIX I

\section{Tables}


Table.1. Kinetic parameters of reactions related to the pyrolysis of ethylbenzene and $n$-propylbenzene (references in text)

\begin{tabular}{ccccc}
\hline $\begin{array}{c}\text { Reaction } \\
\text { No. }\end{array}$ & $\begin{array}{c}\mathrm{E}_{\mathrm{a}} \\
(\mathrm{kJ} / \mathrm{mol})\end{array}$ & $\begin{array}{c}\log \mathrm{A} \\
\left(\mathrm{s}^{-1} \text { or m } 3 / \mathrm{s} \cdot \mathrm{kmol}\right)\end{array}$ & $\begin{array}{c}\mathrm{k}\left(800^{\circ} \mathrm{C}\right) \\
\left(\mathrm{s}^{-1} \text { or m } \mathrm{m}^{3} / \mathrm{s} \cdot \mathrm{kmol}\right)\end{array}$ & $\begin{array}{c}\mathrm{k}\left(450^{\circ} \mathrm{C}\right) \\
\left(\mathrm{s}^{-1} \text { or m } 3 / \mathrm{s} \cdot \mathrm{kmol}\right)\end{array}$ \\
\hline 1 & 304.39 & 15.30 & 3.03 & $2.00 \times 10^{-7}$ \\
2 & 207.31 & 14.18 & $1.23 \times 10^{4}$ & 0.015 \\
3 & 288.48 & 15.32 & $1.88 \times 10$ & $3.00 \times 10^{-7}$ \\
4 & 206.95 & 13.61 & $3.47 \times 10^{3}$ & 0.046 \\
5 & 157.40 & 14.70 & $1.10 \times 10^{7}$ & $2.14 \times 10^{3}$ \\
\hline
\end{tabular}

Table.2. Yields of gaseous and liquid and solid products from $n$-amylbenzene pyrolysis

\begin{tabular}{lcccc}
\hline $\begin{array}{l}\text { Temperature } \\
\left({ }^{\circ} \mathrm{C}\right)\end{array}$ & $\begin{array}{c}\text { Time } \\
(\mathrm{hr})\end{array}$ & $\begin{array}{c}\text { Gas } \\
(\mathrm{wt} \%)\end{array}$ & $\begin{array}{c}\text { Solid } \\
(\mathrm{wt} \%)\end{array}$ & $\begin{array}{c}\text { Liquid } \\
(\mathrm{wt} \%, \text { by diff.) }\end{array}$ \\
\hline \hline $425^{\circ} \mathrm{C}$ & 0.25 & 0.86 & 0.00 & 99.14 \\
& 0.50 & 1.51 & 0.00 & 98.49 \\
& 1.00 & 3.01 & 0.00 & 96.99 \\
& 2.00 & 6.88 & 0.00 & 93.12 \\
& 4.00 & 10.79 & 1.29 & 87.92 \\
\hline $450^{\circ} \mathrm{C}$ & 0.08 & 1.17 & 0.00 & 98.83 \\
& 0.13 & 1.17 & 0.00 & 98.83 \\
& 0.25 & 1.72 & 0.00 & 98.28 \\
& 0.50 & 4.42 & 0.00 & 95.58 \\
& 1.00 & 8.19 & 0.50 & 91.31 \\
& 2.00 & 15.13 & 2.88 & 81.99 \\
\hline $475^{\circ} \mathrm{C}$ & 0.08 & 0.21 & 0.00 & 99.79 \\
& 0.17 & 1.69 & 0.00 & 98.31 \\
& 0.25 & 4.64 & 0.15 & 95.21 \\
& 0.50 & 9.92 & 5.19 & 98.89 \\
& 1.50 & 18.32 & 5.20 & 76.48 \\
\hline
\end{tabular}


Table 3. Molar yields (mol\%) of major products formed for $n$-amylbenzene pyrolysis at $425^{\circ} \mathrm{C}$

\begin{tabular}{lccccc}
\hline \multirow{2}{*}{ Compound Name } & \multicolumn{5}{c}{ Reaction Time (hr) } \\
\cline { 2 - 6 } & 0.25 & 0.50 & 1.00 & 2.00 & 4.00 \\
\hline \hline methane & 0.18 & 0.41 & 1.30 & 3.27 & 7.31 \\
ethane & 0.51 & 0.95 & 2.18 & 5.20 & 9.75 \\
ethylene & 0.14 & 0.22 & 0.28 & 0.42 & 0.41 \\
propane & 2.53 & 4.12 & 5.82 & 17.66 & 24.12 \\
propylene & 0.37 & 0.59 & 0.73 & 1.97 & 1.72 \\
i-butane & 0.55 & 0.49 & 0.01 & 0.05 & 0.17 \\
$n$-butane & 1.36 & 2.26 & 1.56 & 1.98 & 3.14 \\
1-butene & 0.29 & 0.50 & 5.37 & 5.56 & 4.04 \\
hydrogen & 0.21 & 0.53 & 1.03 & 1.24 & 1.34 \\
benzene & 0.13 & 0.20 & 0.58 & 0.65 & 1.07 \\
toluene & 0.01 & 5.66 & 19.89 & 26.67 & 41.33 \\
ethylbenzene & 0.59 & 1.35 & 5.85 & 13.34 & 30.37 \\
styrene & 2.35 & 2.67 & 1.89 & 0.83 & 0.00 \\
methylethylbenzene & 0.00 & 0.07 & 0.87 & 2.08 & 5.62 \\
$n$-propylbenzene & 0.10 & 0.23 & 0.94 & 2.04 & 4.65 \\
1-ethenyl-2-methylbenzene & 0.23 & 0.20 & 0.33 & 0.21 & 0.00 \\
1-methylethenylbenzene & 0.22 & 0.38 & 0.61 & 0.30 & 0.16 \\
propenylbenzene & 0.04 & 0.04 & 0.11 & 0.13 & 0.04 \\
$n$-butylbenzene & 0.50 & 0.67 & 1.15 & 1.65 & 1.79 \\
indan & 0.20 & 0.23 & 0.59 & 0.55 & 0.33 \\
naphthalene & 0.01 & 0.04 & 0.17 & 0.69 & 0.00 \\
2-methylnaphthalene & 0.00 & 0.00 & 0.12 & 0.13 & 0.00 \\
1-methylnaphthalene & 0.00 & 0.00 & 0.00 & 0.99 & 0.00 \\
\hline
\end{tabular}


Table 4. Molar yields (mol\%) of major products formed for $n$-amylbenzene pyrolysis at $450^{\circ} \mathrm{C}$

\begin{tabular}{lccccc}
\hline Compound Name & \multicolumn{5}{c}{ Reaction Time (hr) } \\
\cline { 2 - 6 } & 0.08 & 0.13 & 0.25 & 0.50 & 1.00 \\
\hline \hline methane & 0.28 & 0.27 & 0.75 & 2.65 & 5.65 \\
ethane & 0.67 & 1.04 & 1.22 & 3.44 & 6.78 \\
ethylene & 0.28 & 0.20 & 0.34 & 0.73 & 0.47 \\
propane & 2.46 & 2.32 & 5.91 & 8.90 & 17.95 \\
propylene & 0.36 & 0.39 & 0.96 & 1.43 & 1.68 \\
i-butane & 0.00 & 0.02 & 0.00 & 0.01 & 0.09 \\
$n$-butane & 0.54 & 0.33 & 0.83 & 0.76 & 1.65 \\
1-butene & 0.63 & 0.81 & 2.79 & 2.50 & 2.48 \\
hydrogen & 0.34 & 0.39 & 0.60 & 1.25 & 1.10 \\
benzene & 0.03 & 0.06 & 0.27 & 0.42 & 0.66 \\
toluene & 0.73 & 1.23 & 7.61 & 16.15 & 21.26 \\
ethylbenzene & 0.23 & 0.37 & 2.33 & 6.76 & 16.63 \\
styrene & 1.22 & 1.69 & 4.14 & 3.81 & 1.00 \\
methylethylbenzene & 0.01 & 0.04 & 0.13 & 0.57 & 2.32 \\
$n$-propylbenzene & 0.00 & 0.00 & 0.38 & 1.13 & 2.50 \\
1-ethenyl-2-methylbenzene & 0.05 & 0.13 & 0.23 & 0.35 & 0.25 \\
1-methylethenylbenzene & 0.05 & 0.12 & 0.54 & 0.00 & 0.39 \\
propenylbenzene & 0.00 & 0.00 & 0.06 & 0.12 & 0.12 \\
$n$-butylbenzene & 0.00 & 0.00 & 0.81 & 1.23 & 1.59 \\
indan & 0.03 & 0.12 & 0.34 & 0.45 & 0.69 \\
naphthalene & 0.00 & 0.00 & 0.07 & 0.25 & 1.27 \\
2-methylnaphthalene & 0.00 & 0.00 & 0.03 & 0.00 & 0.20 \\
1-methylnaphthalene & 0.00 & 0.00 & 0.00 & 0.00 & 1.23 \\
\hline
\end{tabular}


Table 5. Molar yields (mol\%) of major products formed for $n$-amylbenzene pyrolysis at $475^{\circ} \mathrm{C}$

\begin{tabular}{lccccc}
\hline \multirow{2}{*}{ Compound Name } & \multicolumn{5}{c}{ Reaction Time (hr) } \\
\cline { 2 - 6 } & 0.08 & 0.17 & 0.25 & 0.33 & 0.50 \\
\hline \hline methane & 0.04 & 1.07 & 3.35 & 2.44 & 8.42 \\
ethane & 0.11 & 1.27 & 3.63 & 2.47 & 8.39 \\
ethylene & 0.04 & 0.47 & 0.84 & 0.43 & 0.79 \\
propane & 1.17 & 6.35 & 10.09 & 9.10 & 20.36 \\
propylene & 0.15 & 1.20 & 1.64 & 1.44 & 2.45 \\
i-butane & 0.00 & 0.00 & 0.04 & 0.03 & 0.13 \\
n-butane & 0.40 & 0.86 & 1.29 & 1.25 & 1.95 \\
1-butene & 0.51 & 2.73 & 2.22 & 2.69 & 2.59 \\
hydrogen & 0.04 & 0.48 & 1.05 & 0.49 & 1.25 \\
benzene & 0.06 & 0.25 & 0.34 & 0.51 & 0.75 \\
toluene & 0.92 & 7.80 & 11.52 & 14.97 & 20.55 \\
ethylbenzene & 0.29 & 3.14 & 6.18 & 10.45 & 17.26 \\
styrene & 1.61 & 4.09 & 3.18 & 2.46 & 1.56 \\
methylethylbenzene & 0.00 & 0.39 & 0.78 & 1.34 & 2.09 \\
$n$-propylbenzene & 0.04 & 0.59 & 1.10 & 1.56 & 2.32 \\
1-ethenyl-2-methylbenzene & 0.08 & 0.50 & 0.40 & 0.43 & 0.32 \\
1-methylethenylbenzene & 0.00 & 0.68 & 0.70 & 0.57 & 0.42 \\
propenylbenzene & 0.00 & 0.13 & 0.13 & 0.24 & 0.15 \\
$n$-butylbenzene & 0.00 & 0.93 & 1.17 & 1.15 & 1.07 \\
indan & 0.05 & 0.58 & 0.81 & 0.90 & 0.66 \\
naphthalene & 0.00 & 0.32 & 0.51 & 0.94 & 1.56 \\
2-methylnaphthalene & 0.00 & 0.08 & 0.28 & 0.06 & 0.18 \\
1-methylnaphthalene & 0.00 & 0.00 & 0.00 & 0.55 & 0.92 \\
\hline & & & & &
\end{tabular}


Table 6. Some kinetic data of hydrogen abstraction and $\beta$-scission reactions in $n$-amylbenzene pyrolysis

(kJ/mol)


Table 7. Comparison of kinetic parameters for $n$-alkylbenzene pyrolysis

\begin{tabular}{|c|c|c|c|c|c|c|}
\hline \multirow{2}{*}{$\begin{array}{l}\text { Compound } \\
\text { Name }\end{array}$} & \multicolumn{4}{|c|}{ Rate Constants x $10^{4}, \mathrm{~s}^{-1}$} & \multirow{2}{*}{$\begin{array}{c}\mathrm{E}_{\mathrm{a}} \\
\mathrm{kJ} / \mathrm{mol}\end{array}$} & \multirow{2}{*}{$\begin{array}{c}A \times 10^{6} \\
s^{-1}\end{array}$} \\
\hline & $400^{\circ} \mathrm{C}$ & $425^{\circ} \mathrm{C}$ & $450^{\circ} \mathrm{C}$ & $475^{\circ} \mathrm{C}$ & & \\
\hline$n$-amylbenzene & & 1.25 & 3.64 & 7.90 & 160.09 & 130 \\
\hline$n$-hexylbenzene & & 2.57 & 5.68 & 12.99 & 140.32 & 8.2 \\
\hline$n$-octylbenzene & 0.84 & 3.59 & 7.89 & & 131.98 & 2.8 \\
\hline
\end{tabular}


Table 8. Temperature Regimes in Oxygen/Dodecane Reactions.

\begin{tabular}{llll}
\hline Regime & Temp, ${ }^{\circ} \mathrm{F}\left({ }^{\circ} \mathrm{C}\right)$ & Reactions & Products \\
\hline Autoxidation & 500 and below (260) & $\mathrm{O}_{2}$ with $\mathrm{C}_{12}$ & $\begin{array}{l}\text { Hydroperoxides } \\
\text { (ROOH) }\end{array}$ \\
\hline Intermediate & $550-900(288-482)$ & $\begin{array}{l}\text { (1) } \mathrm{ROOH} \\
\text { decomposition }\end{array}$ & $\begin{array}{l}\text { Alcohols, Ketones + } \\
\end{array}$ \\
& & $\begin{array}{l}\text { CO } \mathrm{ROOH} \text { initiated } \\
\text { pyrolysis }\end{array}$ & $\begin{array}{l}\text { n-Alkanes, 1-alkenes } \\
+\mathrm{H}_{2}\end{array}$ \\
& & n-Alkanes, 1-alkenes \\
& & & $+\mathrm{H}_{2}$ \\
\hline
\end{tabular}

Table 9. Effect of Pressure on Olefin Formation

\begin{tabular}{lll}
\hline & \multicolumn{2}{c}{ Total pressure, p.s.i.g. } \\
\cline { 2 - 3 } & 0 & 100 \\
\hline Temperature, ${ }^{\circ} \mathrm{C}$ & 315 & 333 \\
\hline Feed composition, mole\% & & \\
Butane & 40 & 50 \\
Oxygen & 5 & 5 \\
$\quad$ Nitrogen & 55 & 45 \\
\hline Fraction of converted butane & & \\
appearing as butylenes, \% & 45 & Nil \\
\hline
\end{tabular}


Table 10. Effect of Temperature on Butane Oxidation

(Feed composition, \%: butane 50, oxygen 10, nitrogen 40, Pressure: $1 \mathrm{~atm}$.)

\begin{tabular}{|c|c|c|c|c|}
\hline \multirow[b]{2}{*}{ Product } & \multicolumn{4}{|c|}{ Reaction Temperature, ${ }^{\circ} \mathrm{C}$} \\
\hline & 350 & 400 & 550 & 650 \\
\hline \multicolumn{5}{|c|}{ Yield, $\%$ of Butane Oxidized } \\
\hline Liquid Products & 34 & 26 & 5 & nil \\
\hline Olefins & 51 & 61 & 77 & 80 \\
\hline Methane & 3 & 3 & 8 & 15 \\
\hline $\begin{array}{l}\text { Carbon oxides } \\
\text { and ethane }\end{array}$ & 12 & 10 & 10 & 5 \\
\hline \multicolumn{5}{|c|}{ Distribution of Carbon in Liquid Products, \% } \\
\hline Formaldehyde & 11 & 14 & 18 & - \\
\hline Acetaldehyde & 26 & 26 & 28 & - \\
\hline Methanol & 11 & 10 & 7 & - \\
\hline Other & 53 & 50 & 53 & - \\
\hline \multicolumn{5}{|c|}{ Olefin Composition, Mole \% } \\
\hline Butylenes & 86 & 55 & 14 & 2 \\
\hline Propylene & 2 & 18 & 35 & 37 \\
\hline Ethylene & 12 & 25 & 49 & 61 \\
\hline
\end{tabular}


Table 11. Influence of Initial Oxygen Concentration

\begin{tabular}{|c|c|c|c|c|c|c|c|c|c|c|c|c|c|}
\hline \multicolumn{14}{|c|}{$\mathrm{n}-\mathrm{C}_{4} \mathrm{H}_{10}$ initial pressure, $380 \pm 2 \mathrm{~mm}$.; reaction time, $30 \mathrm{sec}$. ; temperature, $500^{\circ}$} \\
\hline \multicolumn{14}{|c|}{ Products - moles $/ 100$ moles $\mathrm{n}-\mathrm{C}_{4} \mathrm{H}_{10}$ reacted } \\
\hline Expt. & Initial & Reaction & $\mathrm{O}_{2}$ & $\mathrm{CO}$ & $\mathrm{H}_{2}$ & $\mathrm{CH}_{4}$ & $\mathrm{C}_{2} \mathrm{H}$ & $\mathrm{C}_{2} \mathrm{H}$ & $\mathrm{C}_{3} \mathrm{H}$ & $\mathrm{C}_{3} \mathrm{H}$ & $\mathrm{C}_{4} \mathrm{H}$ & $\mathrm{H}_{2} \mathrm{O}$ & Moles of \\
\hline No. & $\begin{array}{l}\mathrm{O}_{2} \\
\text { Con.\% } \\
\text { by vol. }\end{array}$ & $\begin{array}{l}\% \mathrm{n}- \\
\mathrm{C}_{4} \mathrm{H}_{10} \\
\text { min. }\end{array}$ & & & & & 4 & 6 & 6 & 8 & 8 & & $\begin{array}{l}\mathrm{nC}_{4} \mathrm{H}_{10} \\
\text { reacted } \\
\text { per mole } \\
\mathrm{O}_{2} \\
\text { reacted }\end{array}$ \\
\hline $175 \mathrm{~S}$ & 0.00 & $2.22^{\mathrm{a}}$ & .. & 0 & 1 & 67 & 25 & 27 & 55 & 3 & 15 & 0 & .. \\
\hline $166 \mathrm{~S}$ & 0.48 & 8.8 & 100 & 0 & 0 & 32 & 16 & 15 & 39 & 0 & 43 & 11 & 15.5 \\
\hline $156 \mathrm{~S}$ & 2.03 & 13.4 & 100 & 0 & 0 & 52 & 22 & 21 & 42 & 1 & 34 & 25 & 6.3 \\
\hline $157 \mathrm{~S}$ & 5.10 & 18.2 & 100 & 0 & 3 & 46 & 28 & 13 & 38 & 4 & 36 & 52 & 3.3 \\
\hline $158 \mathrm{~S}$ & 8.57 & 21.3 & 100 & 0 & 3 & 49 & 29 & 13 & 38 & 3 & 35 & 79 & 2.2 \\
\hline $182 \mathrm{~S}$ & 12.29 & 27.9 & 100 & 5 & 0 & 44 & 28 & 12 & 39 & 6 & 28 & 95 & 2.0 \\
\hline $172 \mathrm{~S}$ & 15.73 & 34.3 & 100 & 12 & 5 & 42 & 32 & 13 & 37 & 3 & 27 & 98 & 1.8 \\
\hline 181S & 22.54 & 50.8 & 100 & 24 & 6 & 53 & 42 & 12 & 42 & 5 & 15 & 91 & 1.8 \\
\hline
\end{tabular}


Table 12. Comparison of Rates of oxidation and gum formation at $130^{\circ} \mathrm{C}$

\begin{tabular}{llllll}
\hline fuel & $\mathrm{R}_{\mathrm{O}}$ & fuel & $\mathrm{Rg}$ & fuel & $\mathrm{R}_{\mathrm{g}} / \mathrm{R}_{\mathrm{O}}$ \\
\hline NMP & 97 & $\mathrm{IND}$ & 1280 & $\mathrm{DOD}$ & 0.018 \\
IND & 91 & $\mathrm{NMP}$ & 680 & $1-\mathrm{PH}$ & 0.027 \\
TET & 69 & $\mathrm{EtN}$ & 42 & $\mathrm{TET}$ & 0.10 \\
EtN & 64 & $\mathrm{~B}$ & 13 & $\mathrm{BCH}$ & 0.21 \\
$1-\mathrm{PH}$ & 28 & $\mathrm{TET}$ & 6.9 & $\mathrm{PCH}$ & 0.21 \\
PCH & 27 & $\mathrm{PCH}$ & 5.7 & 14 & 0.38 \\
B & 22 & $\mathrm{C}$ & 5.0 & $\mathrm{~B}$ & 0.59 \\
BCH & 19 & $\mathrm{BCH}$ & 3.0 & $\mathrm{EtN}$ & 0.66 \\
DOD & 15 & 13 & 0.85 & $\mathrm{C}$ & 1.38 \\
$\mathrm{C}$ & 3.8 & $1-\mathrm{PH}$ & 0.75 & $\mathrm{~A}$ & 1.45 \\
14 & 0.77 & 14 & 0.30 & 10 & 1.47 \\
13 & 0.20 & 15 & 0.28 & 15 & 1.69 \\
15 & 0.17 & $\mathrm{DOD}$ & 0.27 & 1 & 3.0 \\
10 & 0.096 & 1 & 0.19 & 13 & 4.2 \\
1 & 0.063 & 10 & 0.14 & $\mathrm{NMP}$ & 7.1 \\
$\mathrm{~A}$ & 0.038 & $\mathrm{~A}$ & 0.055 & IND & 14.1
\end{tabular}


Table 13. Some Experimental Results from Stressing of Dodecane with 5 and 50\% Decalin and 50 , 150 and $250 \mathrm{mg} \mathrm{PX}-21$ at $450^{\circ} \mathrm{C}$ for $1 \mathrm{~h}$.

\begin{tabular}{|l|l|l|l|l|l|l|l|l|}
\hline \multicolumn{2}{|l|}{ Dodecane $+5 \%$ Decalin } \\
\hline $\begin{array}{l}0 \quad \mathrm{mg} \\
\text { PX-21 }\end{array}$ & $\begin{array}{l}50 \mathrm{mg} \\
\text { PX-21 }\end{array}$ & $\begin{array}{l}150 \mathrm{mg} \\
\text { PX-21 }\end{array}$ & $\begin{array}{l}250 \mathrm{mg} \\
\text { PX-21 }\end{array}$ & $\begin{array}{l}\text { O mg } \\
\text { PX-21 }\end{array}$ & $\begin{array}{l}50 \mathrm{mg} \\
\text { PX-21 }\end{array}$ & $\begin{array}{l}150 \mathrm{mg} \\
\text { PX-21 }\end{array}$ & $\begin{array}{l}\text { 250 mg } \\
\text { PX-21 }\end{array}$ \\
\hline Color & yellow & yellow & yellowish & yellowish & yellowish & colorless & colorless & colorless \\
\hline $\begin{array}{l}\text { Liquid, } \\
\mathrm{ml}\end{array}$ & 7.6 & 5.6 & 5.0 & 4.6 & 9.6 & 9.5 & 9.0 & 7.0 \\
\hline $\begin{array}{l}\text { Deposit, } \\
\mathrm{mg}\end{array}$ & 45 & - & - & - & 20 & - & - & - \\
\hline $\begin{array}{l}\text { Increase } \\
\text { of solid } \\
\text { weight,\% }\end{array}$ & - & 75 & 75 & 80 & - & 55 & 65 & 70 \\
\hline
\end{tabular}

Table 14. The Main Compounds Identified in the Liquids Obtained after Thermal Stressing of Dodecane+Decalin $50 \%$ Mixed with 50,150 and $250 \mathrm{mg} \mathrm{PX}-21$ at $450^{\circ} \mathrm{C}$ for $1 \mathrm{~h}$.

\begin{tabular}{|l|l|l|l|l|}
\hline $\begin{array}{l}\text { Compounds } \\
\text { identified }\end{array}$ & $\begin{array}{l}\text { Dodecane+ } \\
\text { Decalin 50\% }\end{array}$ & $\begin{array}{l}\text { Dodecane+ } \\
\text { Decalin 50\%+ } \\
50 \mathrm{mg} \text { PX-21 }\end{array}$ & $\begin{array}{l}\text { Dodecane+ } \\
\text { Decalin 50\% }+ \\
150 \mathrm{mg} \mathrm{PX-21}\end{array}$ & $\begin{array}{l}\text { Dodecane+ } \\
\text { Decalin 50\%+ } \\
250 \mathrm{mg} \mathrm{PX-21}\end{array}$ \\
\hline n butane+butene & 1.05 & 0.13 & 0.36 & 0.49 \\
\hline n pentane+pentene & 1.51 & 0.48 & 0.83 & 1.27 \\
\hline n hexane & 1.33 & 0.84 & 1.25 & 2.02 \\
\hline n heptane & 1.27 & 1.04 & 1.17 & 1.54 \\
\hline n octane & 1.41 & 1.26 & 1.26 & 1.58 \\
\hline n nonane & 1.24 & 1.23 & 1.29 & 1.63 \\
\hline n decane & 0.46 & 0.63 & 0.73 & 1.05 \\
\hline n undecane & 0.56 & 0.53 & 0.51 & 0.31 \\
\hline n dodecane & 28.68 & 35.11 & 35.39 & 36.50 \\
\hline cis decalin & 20.78 & 20.11 & 18.14 & 14.17 \\
\hline trans decalin & 30.96 & 29.35 & 29.55 & 27.78 \\
\hline naphthalene & 0.09 & 0.70 & 1.17 & 1.99 \\
\hline tetralin & 0.40 & 0.92 & 1.30 & 1.99 \\
\hline
\end{tabular}


Table 15. Properties of the Zeolite Starting Materials

\begin{tabular}{cccccc}
\hline zeolite id. & type & supplier & $\begin{array}{c}\mathrm{SiO}_{2} / \mathrm{Al}_{2} \mathrm{O}_{3}, \\
\text { molar }\end{array}$ & $\begin{array}{c}\mathrm{Na}_{2} \mathrm{O}, \\
\text { wt \% }\end{array}$ & $\begin{array}{c}\text { surface area, } \\
\mathrm{m}^{2} / \mathrm{g}\end{array}$ \\
\hline $\mathrm{HY}$ & zeolite $\mathrm{Y}$ & $\begin{array}{c}\text { Linde } \\
\text { LZ-Y62 }\end{array}$ & 5.0 & 2.5 & 948 \\
$\mathrm{HM} 17$ & mordenite & $\begin{array}{c}\text { Linde } \\
\text { LZ-M-8 }\end{array}$ & 17.0 & 0.05 & 480 \\
$\mathrm{HM} 21$ & mordenite & $\begin{array}{c}\text { PQ Corp. } \\
\text { CBV 20A } \\
\text { PQ Corp. } \\
\text { CBV 30A }\end{array}$ & 21.1 & 0.02 & 606 \\
\hline
\end{tabular}

Table 16. Nap Hydrogenation Over Platinum Catalysts in 1 hour $200^{\circ} \mathrm{C}$ Runs

\begin{tabular}{cccccccc}
\hline & & \multicolumn{5}{c}{ Product Distribution (mole percent) } \\
\cline { 4 - 6 } zeolite & run no. & $\begin{array}{c}\text { \%Nap } \\
\text { conv. }\end{array}$ & trans & cis & total & THN & $\begin{array}{c}\text { DeHN } \\
\text { trans/cis } \\
\text { DeHN }\end{array}$ \\
\hline HM38 & 160 & 100.00 & 70.10 & 29.90 & 100.00 & 0.00 & 2.34 \\
HM21 & 167 & 100.00 & 45.45 & 54.55 & 100.00 & 0.00 & 0.83 \\
HM17 & 168 & 100.00 & 36.76 & 63.23 & 100.00 & 0.00 & 0.58 \\
HY & 166 & 99.94 & 15.12 & 82.30 & 97.42 & 2.58 & 0.18 \\
\hline
\end{tabular}

Table 17. Nap Hydrogenation Over Palladium Catalysts in 1 hour $200^{\circ} \mathrm{C}$ Runs

\begin{tabular}{|c|c|c|c|c|c|c|c|}
\hline \multirow[b]{3}{*}{ zeolite } & \multirow[b]{3}{*}{ run no. } & \multirow[b]{3}{*}{$\begin{array}{l}\text { \%Nap } \\
\text { conv. }\end{array}$} & \multicolumn{4}{|c|}{ Product Distribution (mole percent) } & \multirow[b]{3}{*}{$\begin{array}{c}\text { trans/cis } \\
\text { DeHN }\end{array}$} \\
\hline & & & \multicolumn{3}{|c|}{ DeHN } & \multirow[b]{2}{*}{ THN } & \\
\hline & & & trans & cis & total & & \\
\hline HM38 & 163 & 100.00 & 81.56 & 18.44 & 100.00 & 0.00 & 4.42 \\
\hline HM21 & 169 & 100.00 & 74.97 & 25.03 & 100.00 & 0.00 & 3.00 \\
\hline HM17 & 170 & 99.95 & 64.81 & 35.16 & 99.97 & 0.03 & 1.84 \\
\hline HY & 171 & 100.00 & 72.94 & 27.06 & 100.00 & 0.00 & 2.69 \\
\hline
\end{tabular}


Table 18. Nap Hydrogenation Over PVHM38 Catalysts in 200.C Runs

\begin{tabular}{|c|c|c|c|c|c|c|c|}
\hline \multirow[b]{3}{*}{ time $(\mathrm{h})$} & \multirow[b]{3}{*}{ run no. } & \multirow[b]{3}{*}{$\begin{array}{l}\text { \%Nap } \\
\text { conv. }\end{array}$} & \multicolumn{4}{|c|}{ Product Distribution (mole percent) } & \multirow[b]{3}{*}{$\begin{array}{c}\text { trans/cis } \\
\text { DeHI }\end{array}$} \\
\hline & & & \multicolumn{3}{|c|}{ DeHN } & \multirow[b]{2}{*}{ THN } & \\
\hline & & & trans & cis & total & & \\
\hline 0.25 & 158 & 99.65 & 46.18 & 53.74 & 99.92 & 0.08 & $\overline{0.86}$ \\
\hline 0.50 & 159 & 99.98 & 55.69 & 44.29 & 99.98 & 0.02 & 1.26 \\
\hline 1.00 & 160 & 100.00 & 70.10 & 29.90 & 100.00 & 0.00 & 2.34 \\
\hline
\end{tabular}

Table 19. Nap Hydrogenation Over Pd/HM38 Catalysts in $200^{\circ} \mathrm{C}$ Runs

\begin{tabular}{cccccccc}
\hline & & \multicolumn{4}{c}{ Product Distribution (mole percent) } \\
\cline { 4 - 6 } & & & \multicolumn{3}{c}{ DeHN } & & \\
\cline { 4 - 7 } time (h) & run no. & $\begin{array}{l}\text { \%Nap } \\
\text { conv. }\end{array}$ & trans & cis & total & THN & $\begin{array}{c}\text { trans/cis } \\
\text { DeHN }\end{array}$ \\
\hline 0.25 & 161 & 100.00 & 65.35 & 34.64 & 100.00 & 0.00 & 1.89 \\
0.50 & 162 & 100.00 & 72.19 & 27.81 & 100.00 & 0.00 & 2.60 \\
1.00 & 163 & 100.00 & 81.56 & 18.44 & 100.00 & 0.00 & 4.42 \\
\hline
\end{tabular}


Table 20. Comparison Nap Hydrogenation Runs Over Pt/HM17 Catalysts at $200^{\circ} \mathrm{C}$

\begin{tabular}{|c|c|c|c|c|c|c|c|c|}
\hline \multirow[b]{3}{*}{ run } & \multirow[b]{3}{*}{ run } & \multirow[b]{3}{*}{ time $(\mathrm{h})$} & \multirow[b]{3}{*}{$\begin{array}{l}\text { \%Nap } \\
\text { conv. }\end{array}$} & \multicolumn{4}{|c|}{ Product Distribution (mole percent) } & \multirow[b]{3}{*}{$\begin{array}{c}\text { trans/cis } \\
\text { DeHN }\end{array}$} \\
\hline & & & & \multicolumn{3}{|c|}{ DeHN } & \multirow[b]{2}{*}{ THN } & \\
\hline & & & & trans & cis & total & & \\
\hline $\begin{array}{l}\text { original } \\
\text { GB data }\end{array}$ & G7 & 2 & 100.0 & 34.7 & 46.1 & 80.8 & $\begin{array}{c}15.5 \\
\text { (3.7 other) }\end{array}$ & 0.75 \\
\hline $\begin{array}{l}\text { original } \\
\text { GB data }\end{array}$ & G8 & 4 & 97.1 & 49.1 & 50.9 & 100.0 & trace & 0.96 \\
\hline $\begin{array}{l}\text { stored } \\
\text { sample }\end{array}$ & 168 & 1 & 100.0 & 36.8 & 63.2 & 100.0 & 0.0 & 0.58 \\
\hline $\begin{array}{l}\text { stored } \\
\text { sample, } \\
\text { re-calcined }\end{array}$ & 172 & 1 & 100.0 & 70.6 & 29.5 & 100.0 & 0.0 & 2.40 \\
\hline
\end{tabular}

Table 21. Comparison Nap Hydrogenation Runs Over Pd/HM17 Catalysts at $200^{\circ} \mathrm{C}$

\begin{tabular}{|c|c|c|c|c|c|c|c|c|}
\hline \multirow[b]{3}{*}{ run } & \multirow[b]{3}{*}{ run } & \multirow[b]{3}{*}{ time (h) } & \multirow[b]{3}{*}{$\begin{array}{l}\text { \%Nap } \\
\text { conv. }\end{array}$} & \multicolumn{4}{|c|}{ Product Distribution (mole percent) } & \multirow[b]{3}{*}{$\begin{array}{c}\operatorname{trans} / c i s \\
\mathrm{DeHN}\end{array}$} \\
\hline & & & & & $\overline{\mathrm{DeHN}}$ & & & \\
\hline & & & & trans & cis & total & THN & \\
\hline $\begin{array}{l}\text { original } \\
G B \text { data }\end{array}$ & G15 & 2 & 98.4 & 53.4 & 14.9 & 68.3 & $\begin{array}{c}31.1 \\
(0.6 \text { other })\end{array}$ & 3.58 \\
\hline $\begin{array}{l}\text { original } \\
\text { GB data }\end{array}$ & G16 & 4 & 99.5 & 64.1 & 18.3 & 82.4 & $\begin{array}{c}17.1 \\
(0.1 \text { other })\end{array}$ & 3.50 \\
\hline $\begin{array}{l}\text { stored } \\
\text { sample }\end{array}$ & 170 & 1 & 99.95 & 64.81 & 35.16 & 99.97 & 0.03 & 1.84 \\
\hline $\begin{array}{l}\text { stored } \\
\text { sample, } \\
\text { re-calcined }\end{array}$ & 173 & 1 & 100.0 & 81.4 & 18.6 & 100.0 & 0.0 & 4.37 \\
\hline
\end{tabular}




\begin{tabular}{|cc|}
\hline $\begin{array}{c}\text { Table 22. Mean Crystallite Size Determined } \\
\text { from XRD Line-Broadening }\end{array}$ \\
\hline \hline Catalyst Sample & $\mathrm{L}(\AA)$ \\
\hline \hline $\mathrm{Pt} / \mathrm{HM} 17$ & 120 \\
$\mathrm{Pt} / \mathrm{HM} 38$ & sharp line: 750 \\
& broad line: 50 \\
$\mathrm{Pt} / \mathrm{HM} 21$ & 590 \\
$\mathrm{Pt} / \mathrm{HY}$ & 1700 \\
$\mathrm{Pd} / \mathrm{HM} 17$ & $<80$ \\
$\mathrm{Pd} / \mathrm{HM} 38$ & $<60$ \\
$\mathrm{Pd} / \mathrm{HM} 21$ & 310 \\
$\mathrm{Pd} / \mathrm{HY}$ & 310 \\
\hline
\end{tabular}


APPENDIX II

Figures 


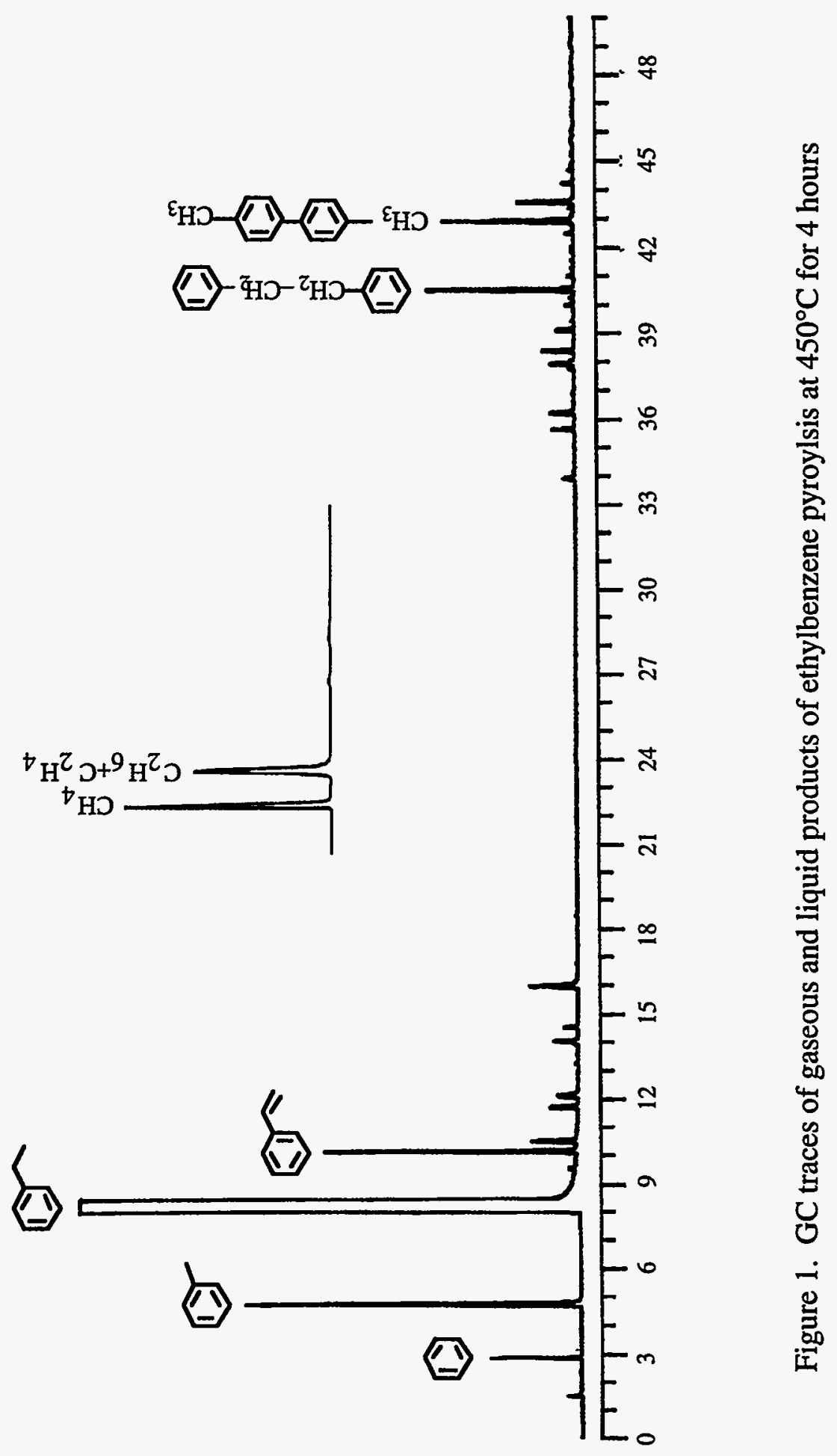




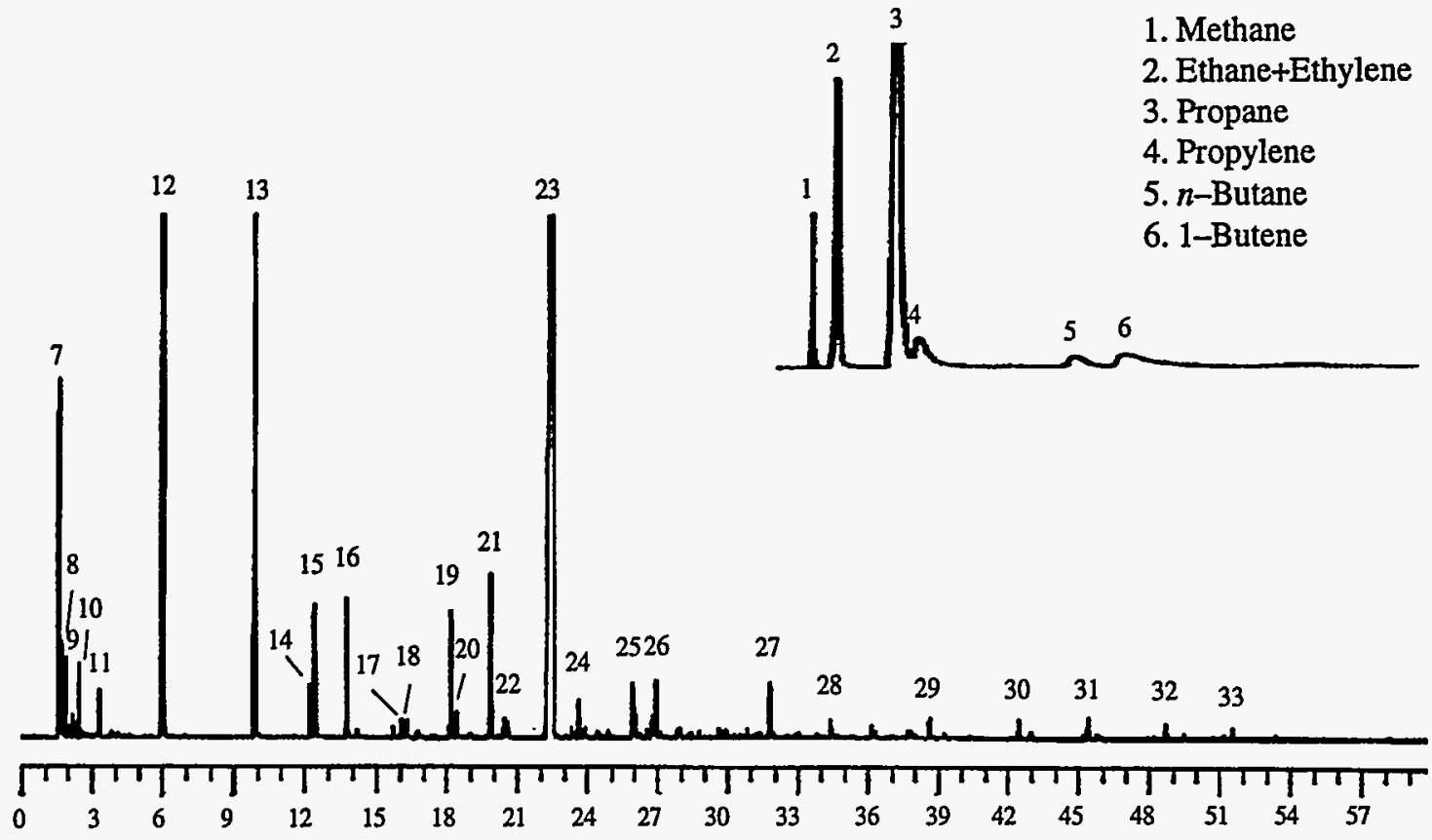

7. n-Butane+1-Butene

8. n-Pentane+1-Pentene

9. $n$-Hexane+1-Hexene

10. $n$-Heptane +1 -Heptene

11. Benzene

12. Toluene

13. Ethylbenzene

14. Styrene

15. Methylethylbenzene

16. n-Propylbenzene

17. s-Butylbenzene

18. Allylbenzene

19. n-Butylbenzene
20. Propenylbenzene

21. 1-Methylbutylbenzene

22. $\mathrm{C}_{5}$-Benzene (two isomers)

23. $n$-amylbenzene

24. 1-Methylpentylbenzene

25. Propenylbenzene $+n-H e x y l b e n z e n e$

26. naphthalene

27. 1-Methylnaphthalene

28. Biphenyl

29. Bibenzyl

30. 1,3-Diphenylpropane

31. 1,4-Diphenylbutane

32. Diphenylheptane*

33. Diphenylheptane*

Figure 2. GC traces of gaseous and liquid products of $n$-amylbenzene pyroylsis at $425^{\circ} \mathrm{C}$ for 2 hours and possible peak identification (*: tentative assignments) 
Molar Yield (\%)

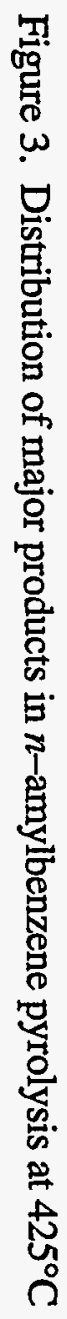

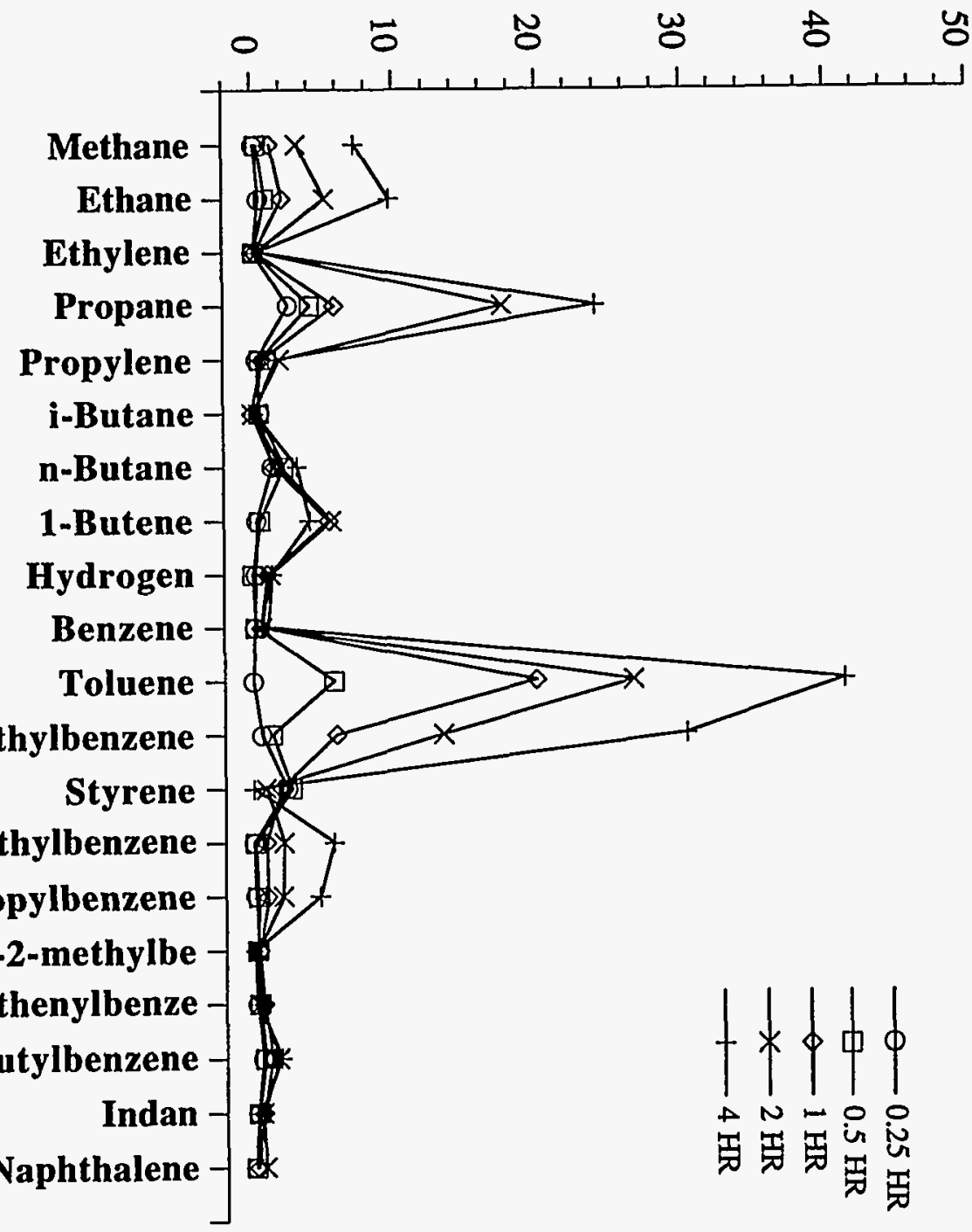




\section{Molar Yield (\%)}

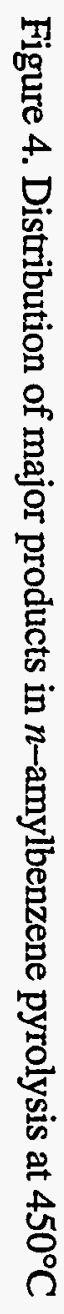

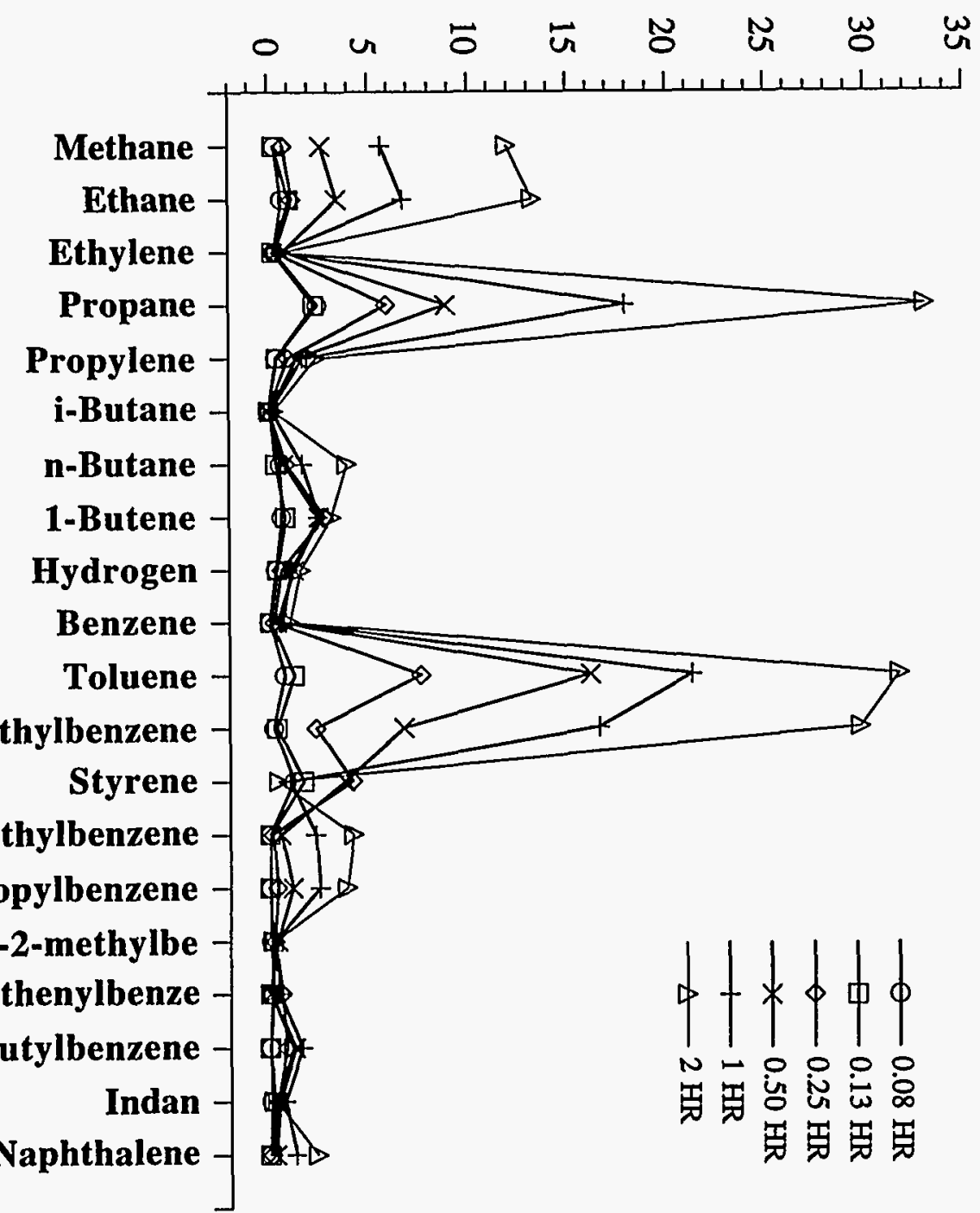

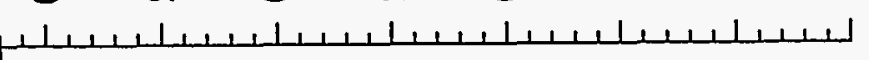


Molar Yield (\%)

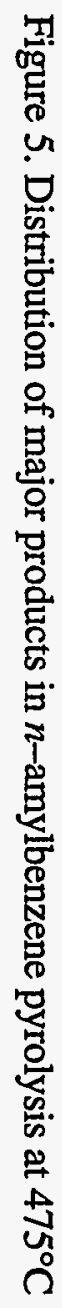

- u

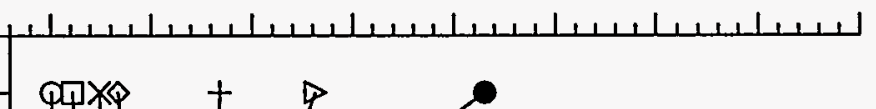

Ethane

Ethylene

Propane

Propylene

i-Butane

n-Butane

1-Butene

Hydrogen

Benzene

Toluene

Ethylbenzene

Styrene

Methylethylbenzene

n-Propylbenzene

1-Ethenyl-2-methylbe

1-Methylethenylbenze

n-Butylbenzene

Indan

Naphthalene

2-Methylnaphthalene

1-Methylnaphthalene

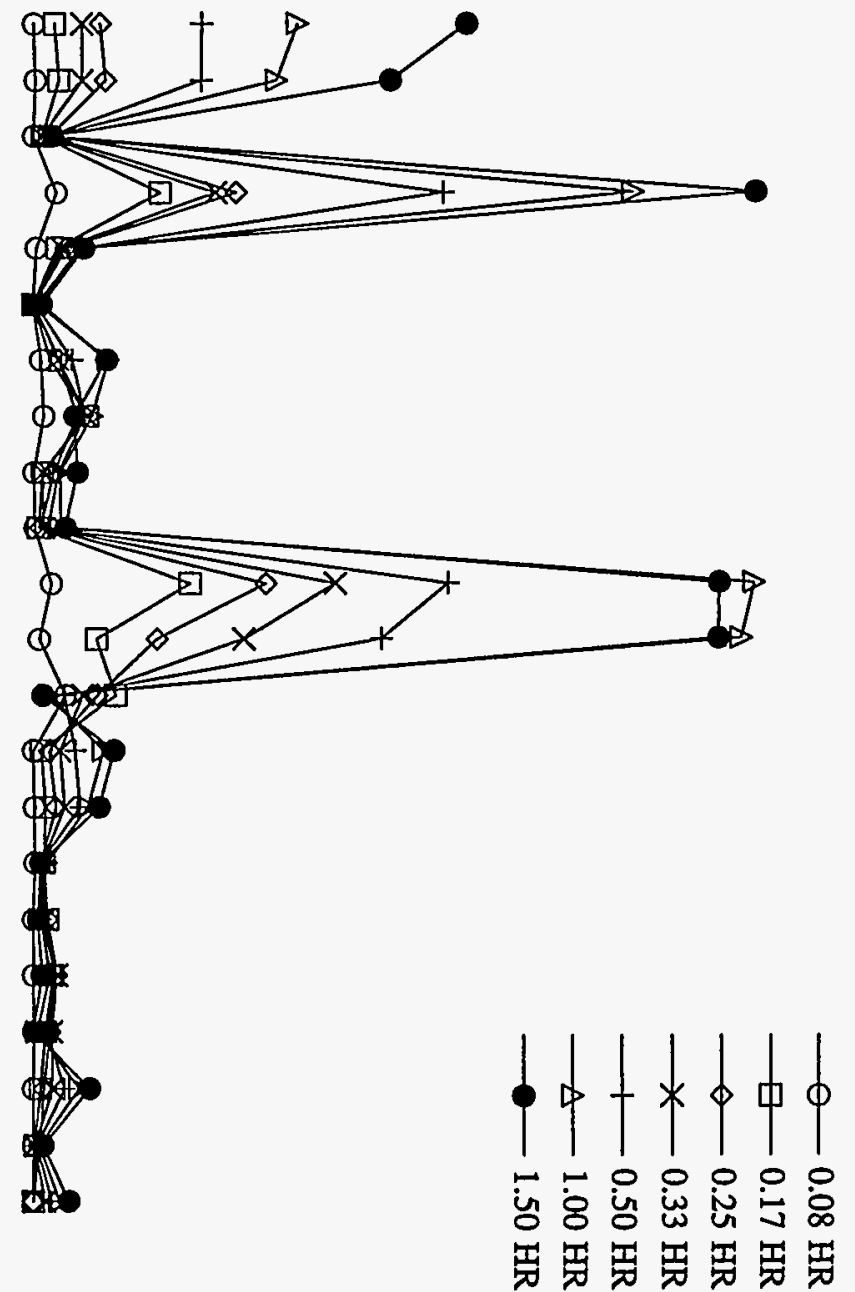




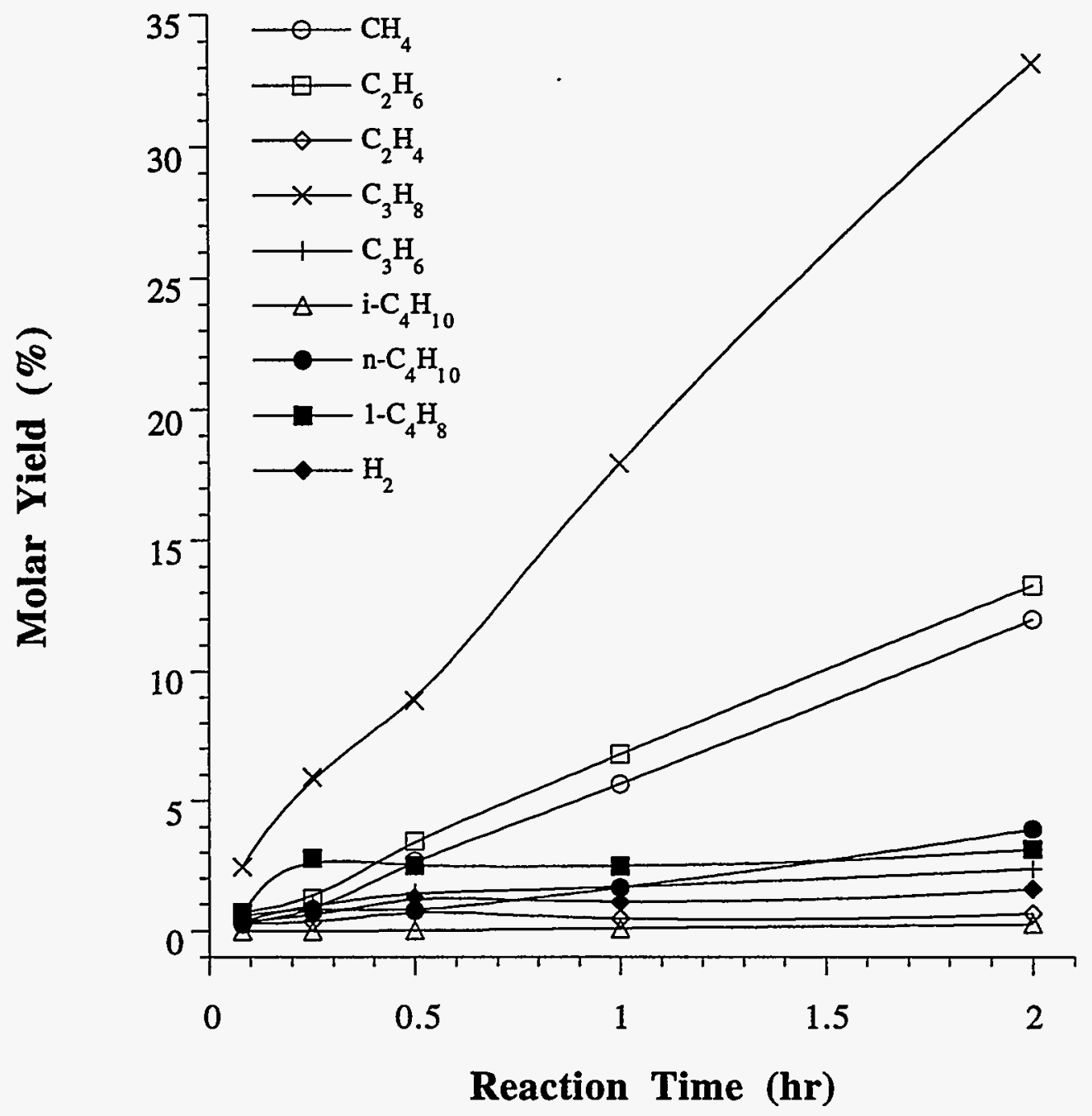

Figure 6. Temporal variations of some gaseous products from $n$-amylbenzene pyrolysis at $450^{\circ} \mathrm{C}$ 


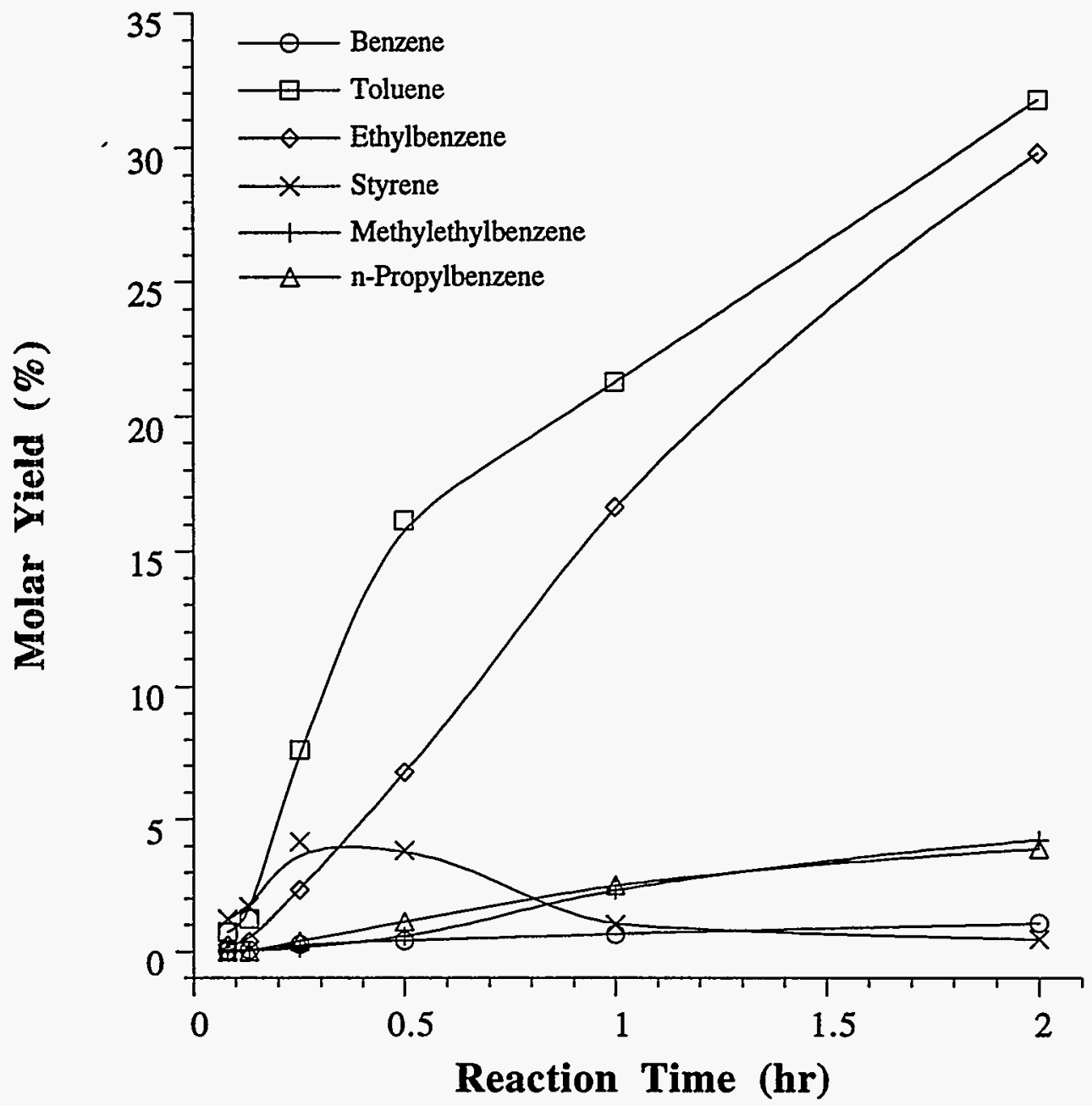

Figure 7. Temporal variations of some major liquid products from $n$-amylbenzene pyrolysis at $450^{\circ} \mathrm{C}$ 


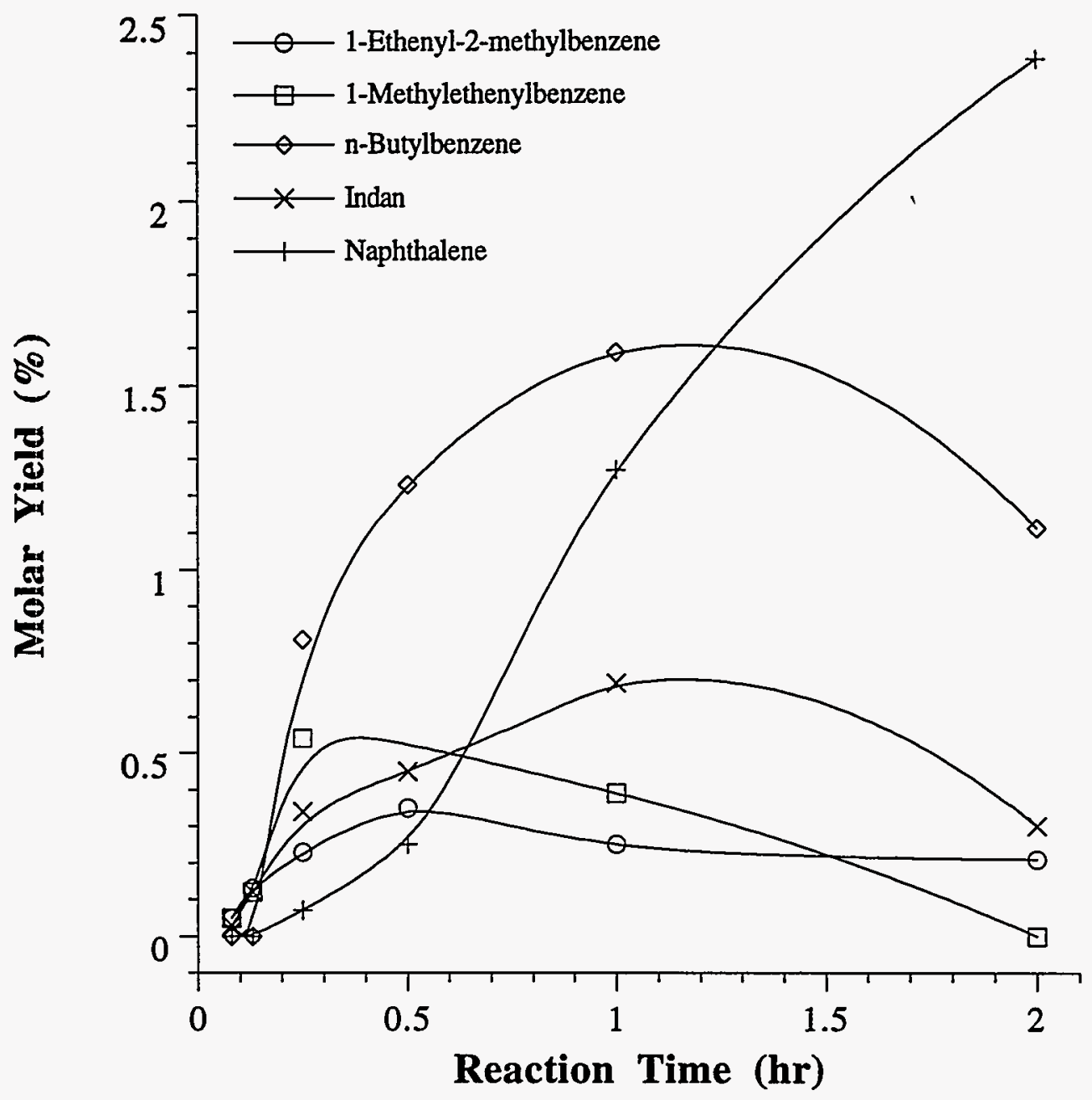

Figure 8. Temporal variations of some liquid products from $n$-amylbenzene pyrolysis at $450^{\circ} \mathrm{C}$ 

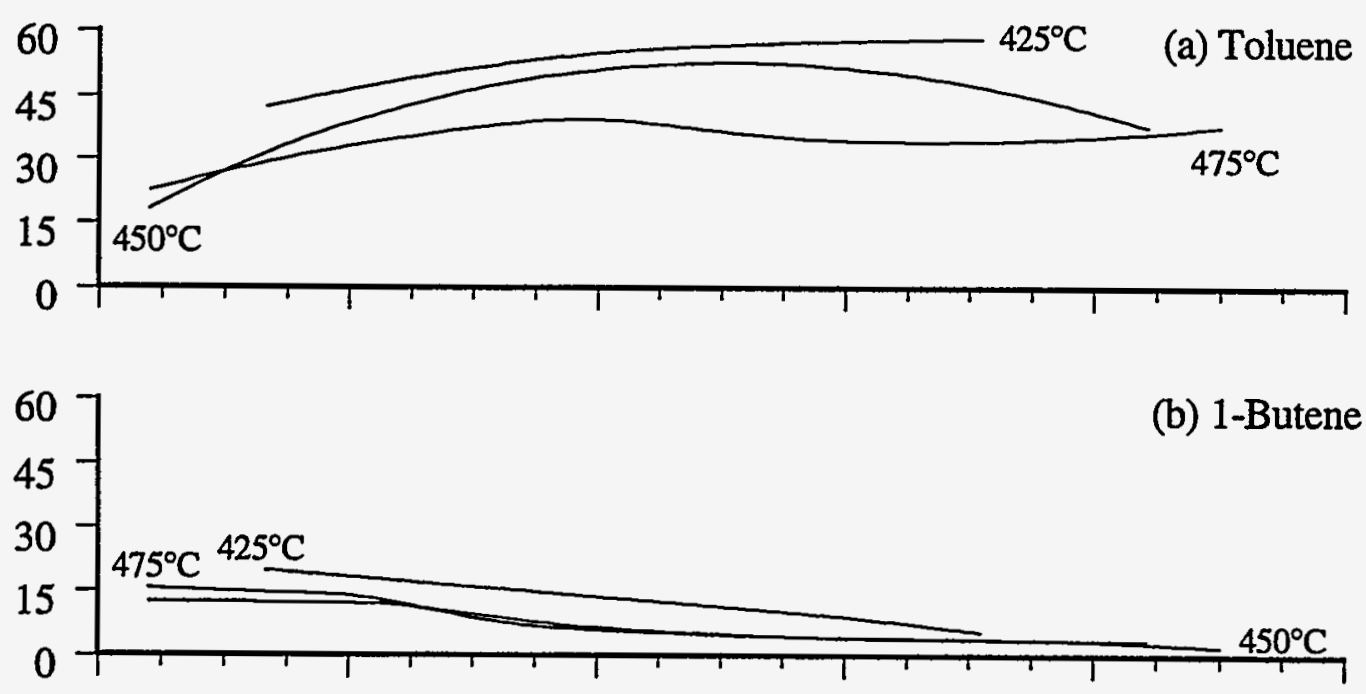

일
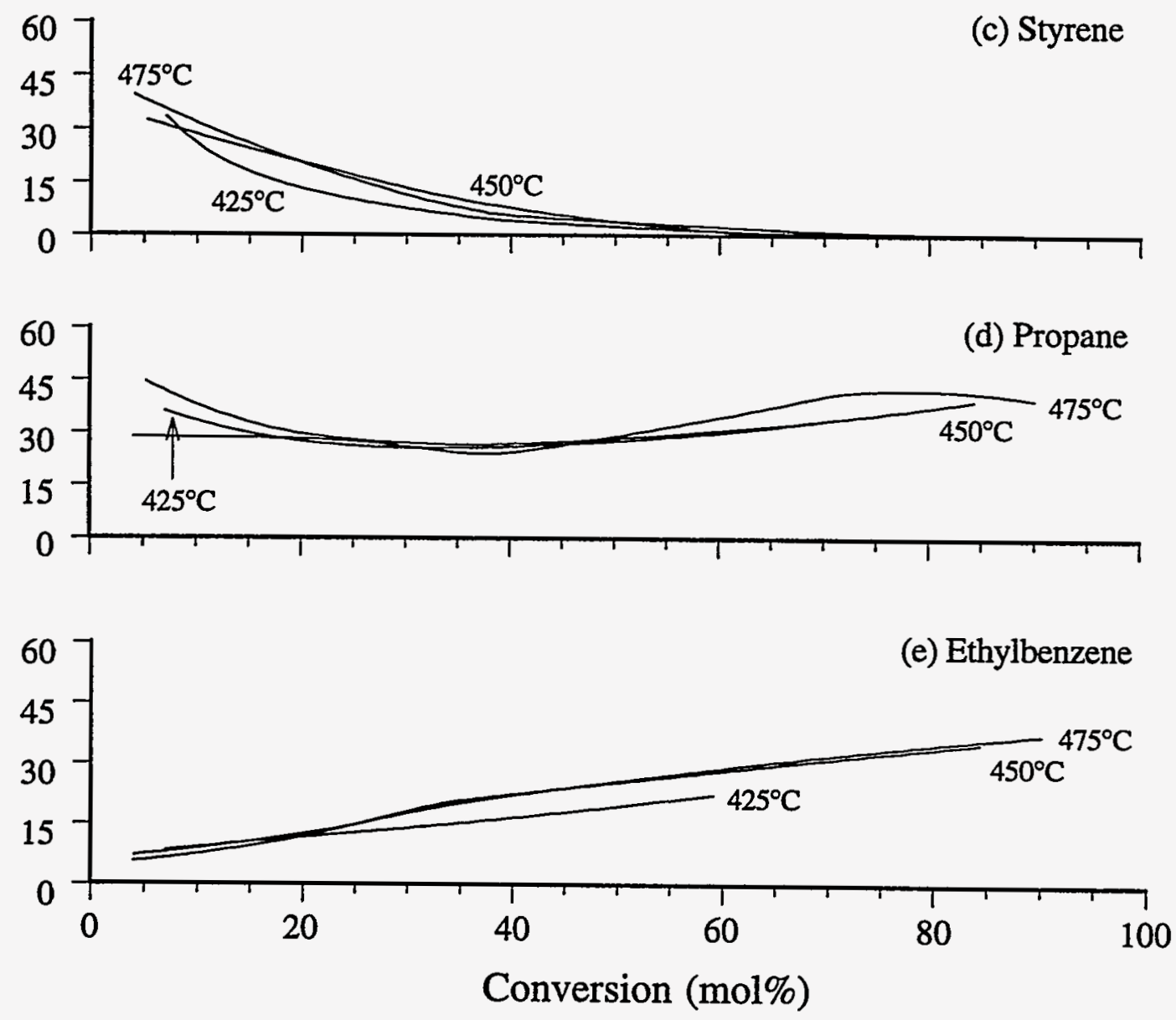

Figure 9. Selectivity diagrams for products in $n$-amylbenzene pyrolysis 

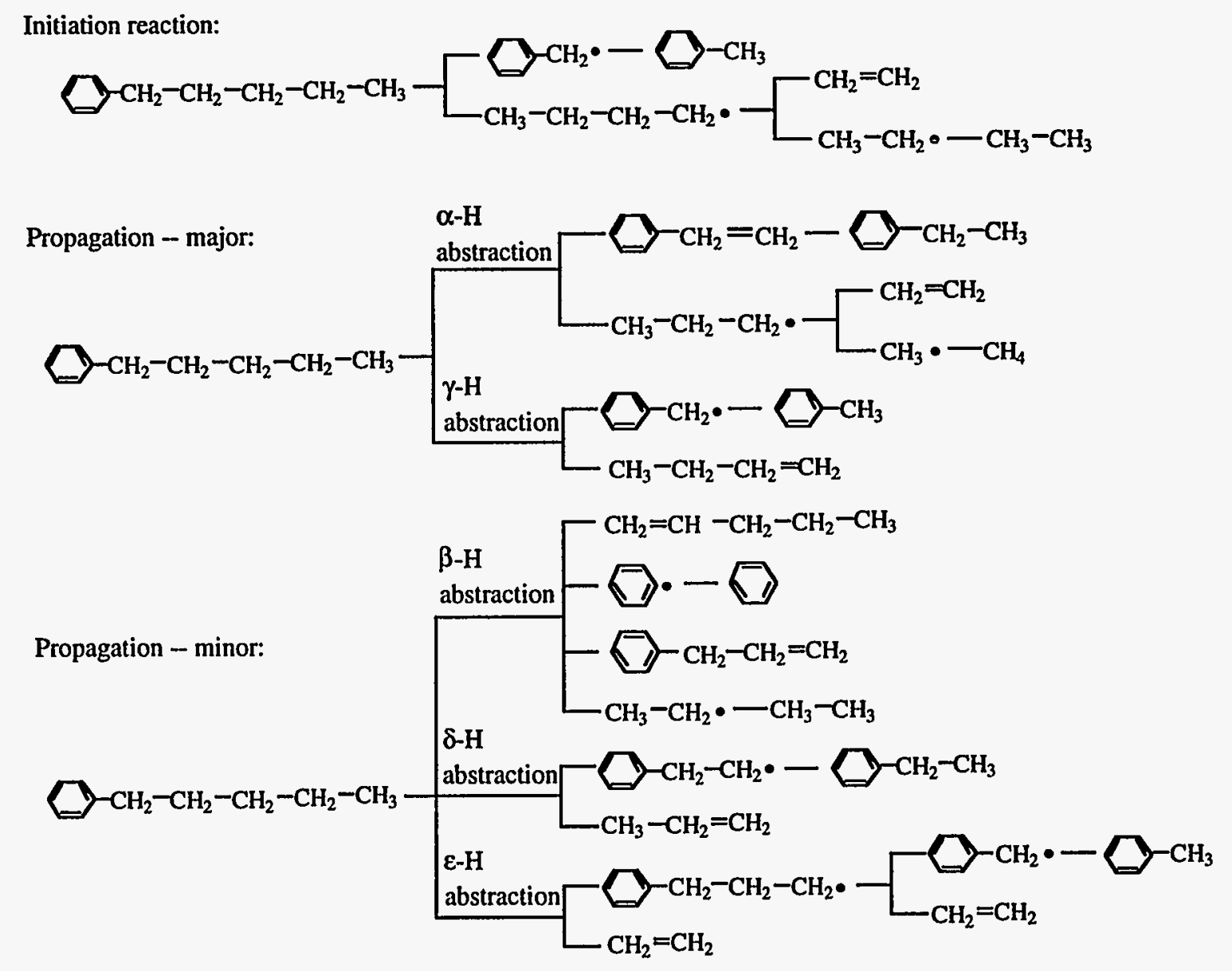

Recombination: can happen between any two radicals

Figure 10. Possible pathways to the formation of major products from $n$-amylbenzene pyrolysis 


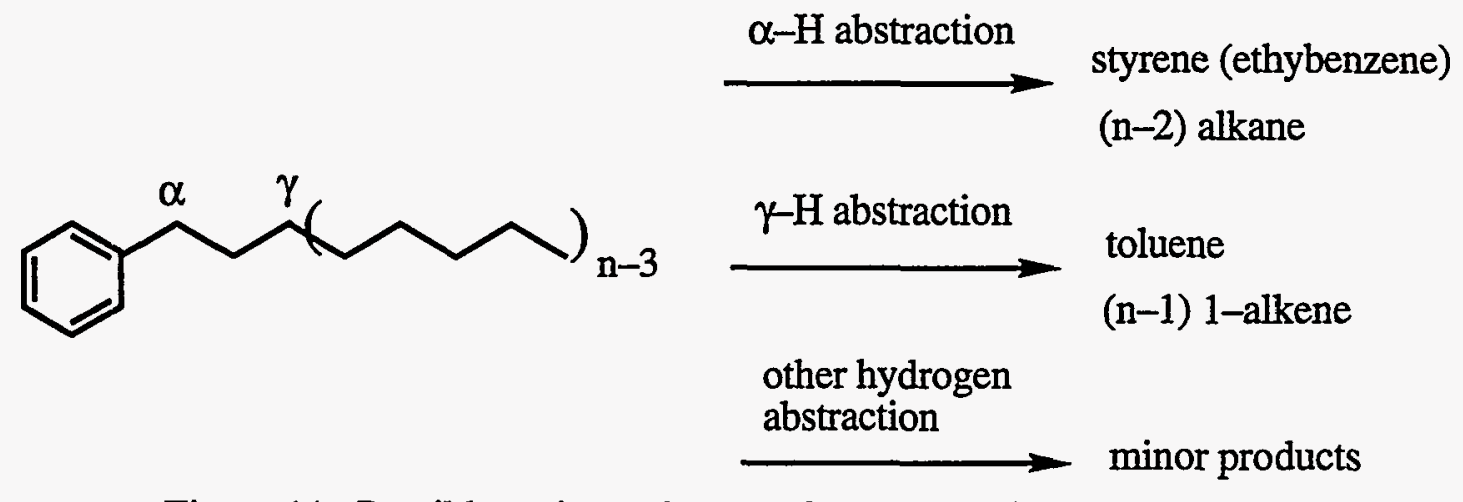

Figure 11. Possible major pathways of pyrolysis of $n$-alkylbenzenes 


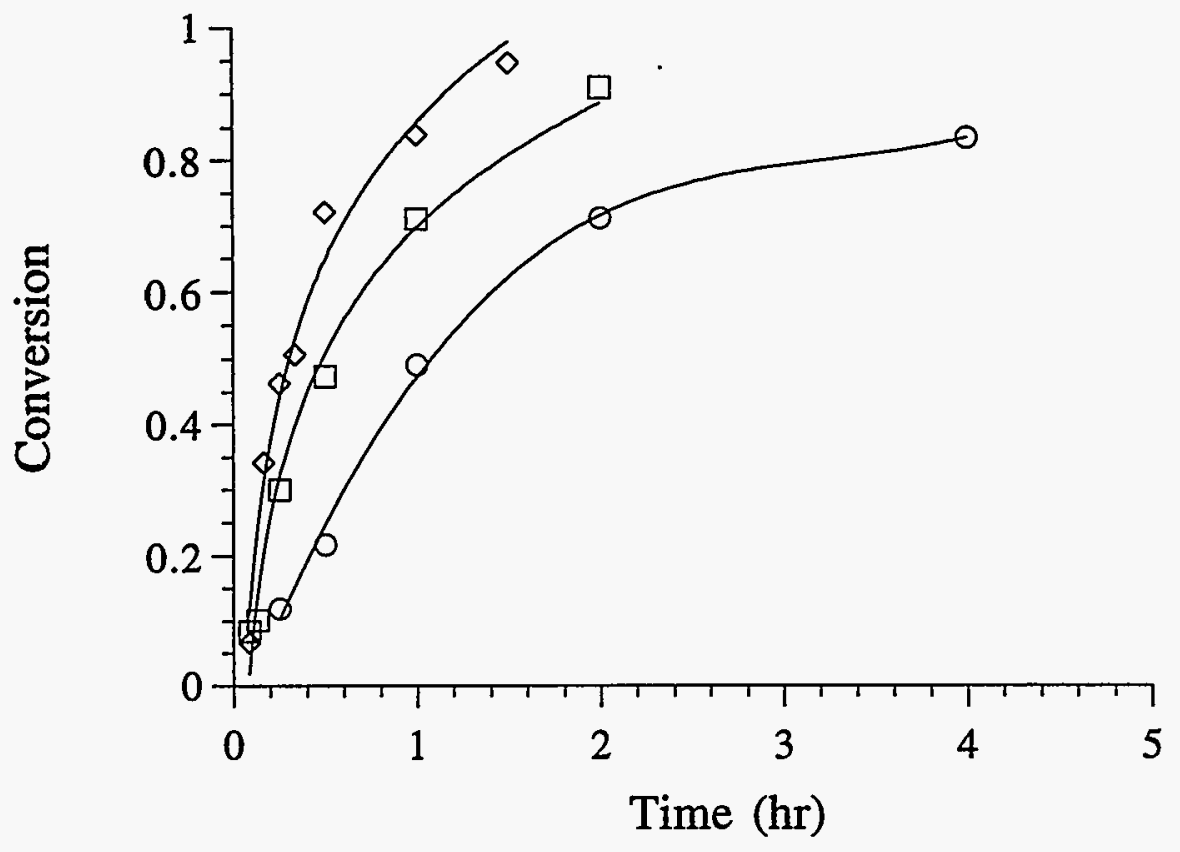

Figure 12. Conversion-time plot for n-amylbenzene pyrolysis 


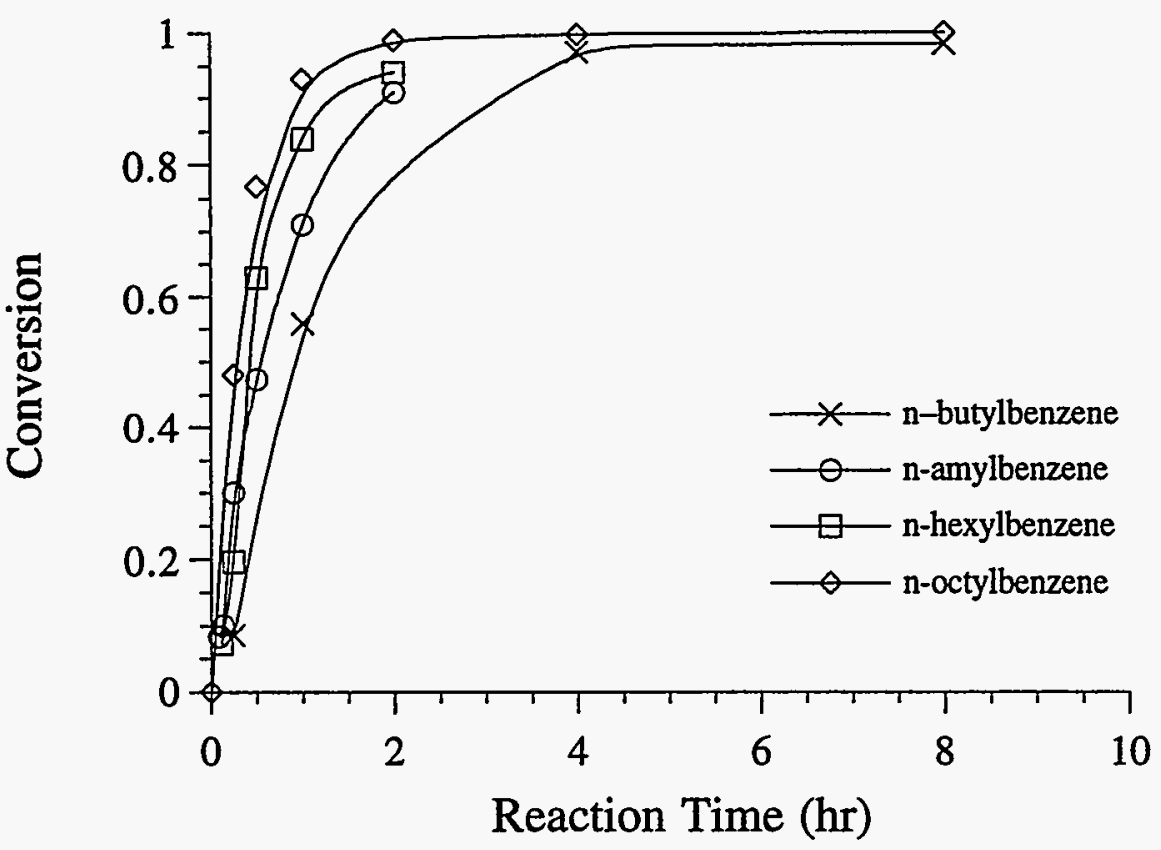

Figure 13. Comparison of conversion of $n$-alkylbenzene at $450^{\circ} \mathrm{C}$ 

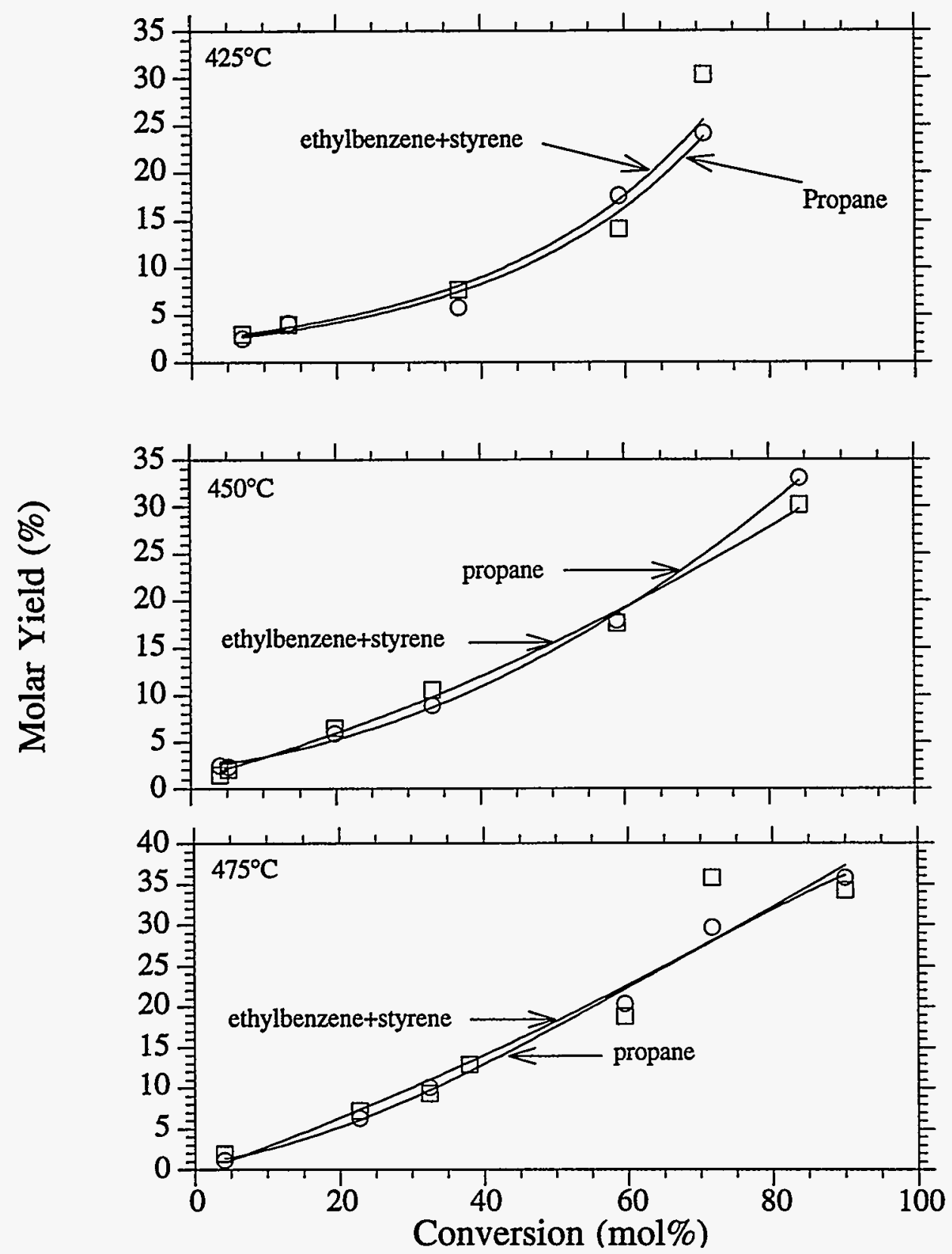

Figure 14. Products from $\alpha$-hydrogen abstraction for $n$-amylbenzene pyrolysis 

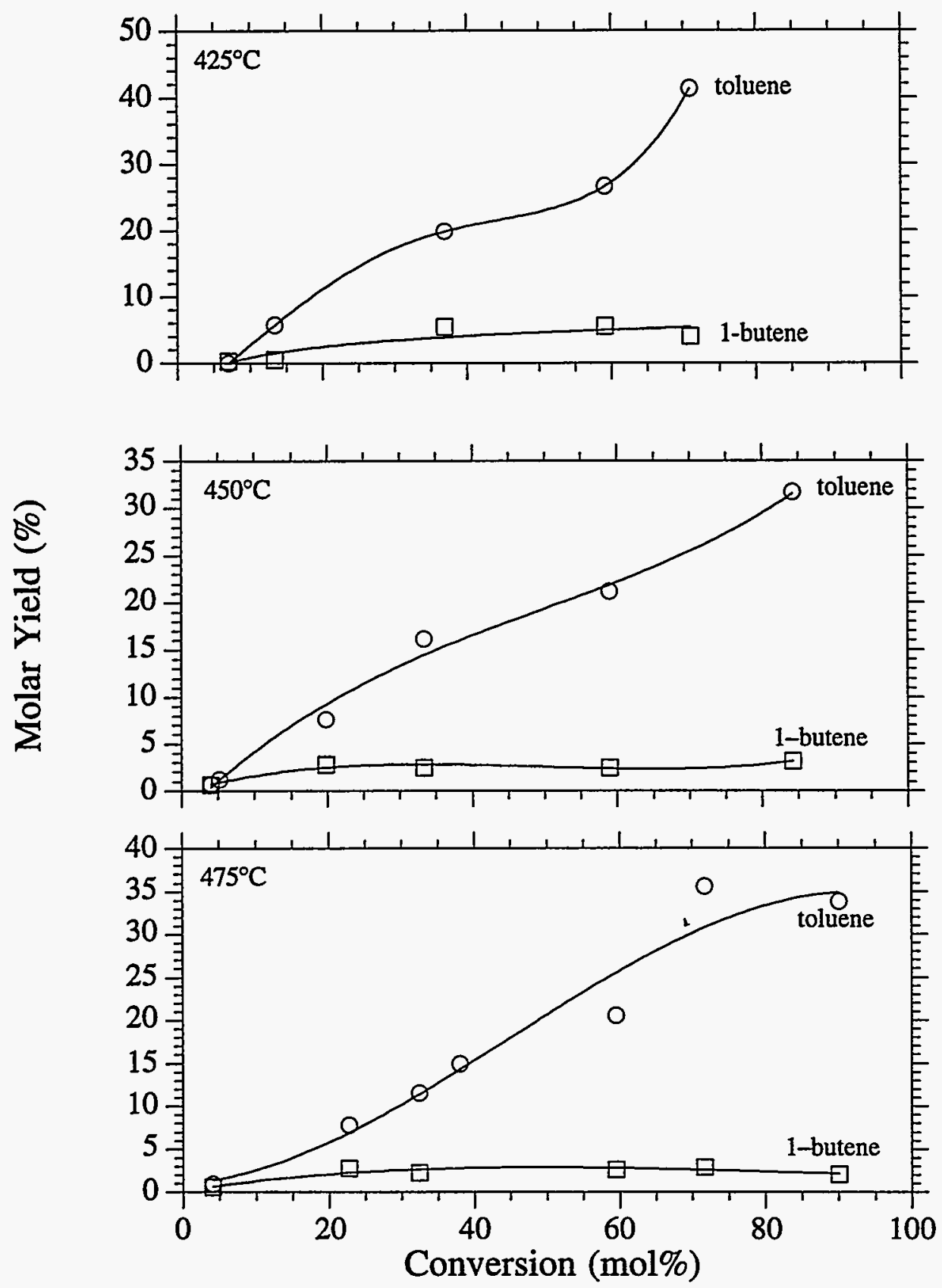

Figure 15. Products from $\gamma$-hydrogen abstraction for $n$-amylbenzene pyrolysis 

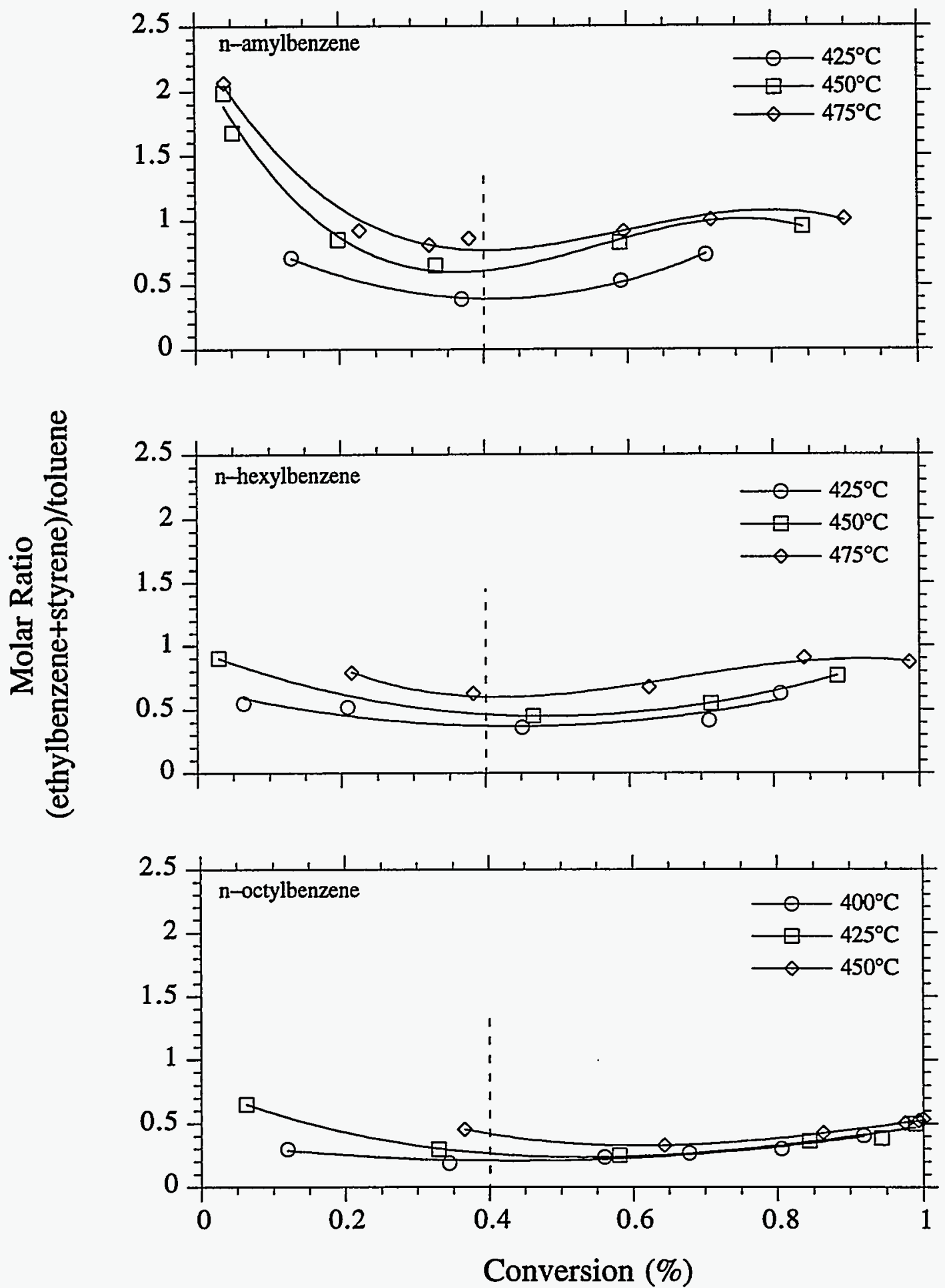

Figure 16. Comparison of relative importance of $\alpha$ - and $\gamma$-hydrogen abstraction 


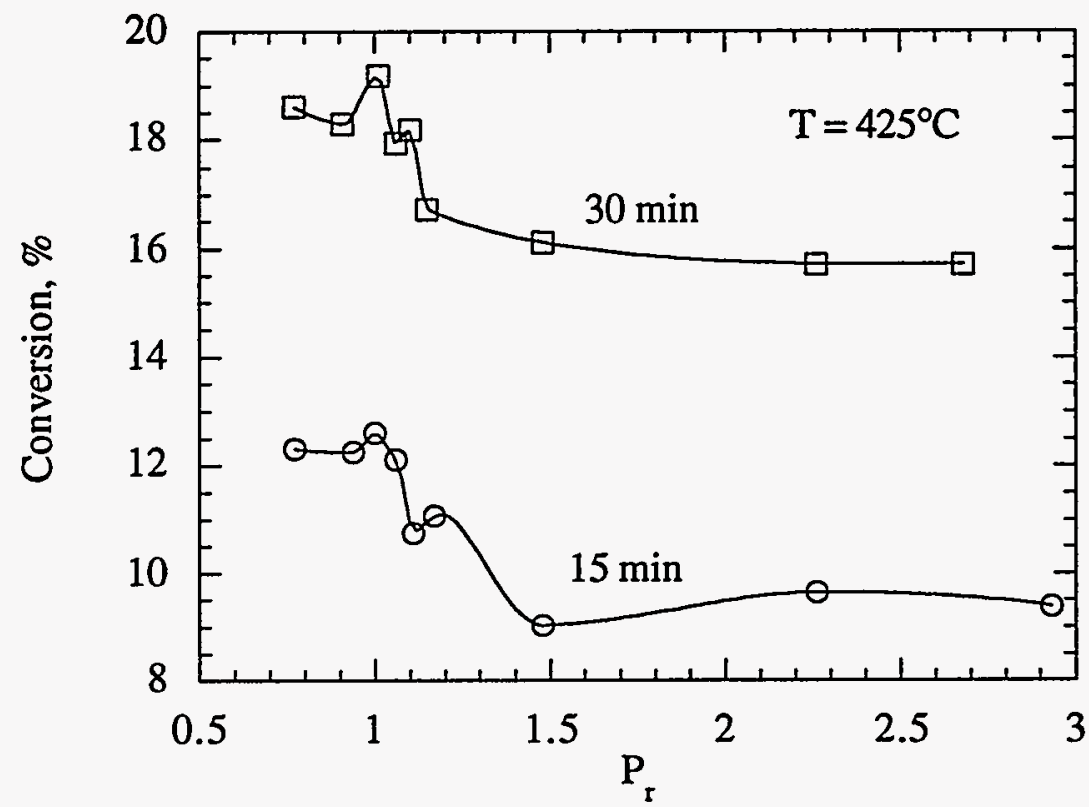

Figure 17. Change in Conversion of n-Tetradecane with Initial Reduced Pressure at $425^{\circ} \mathrm{C}$ for 15 and $30 \mathrm{~min}$. 


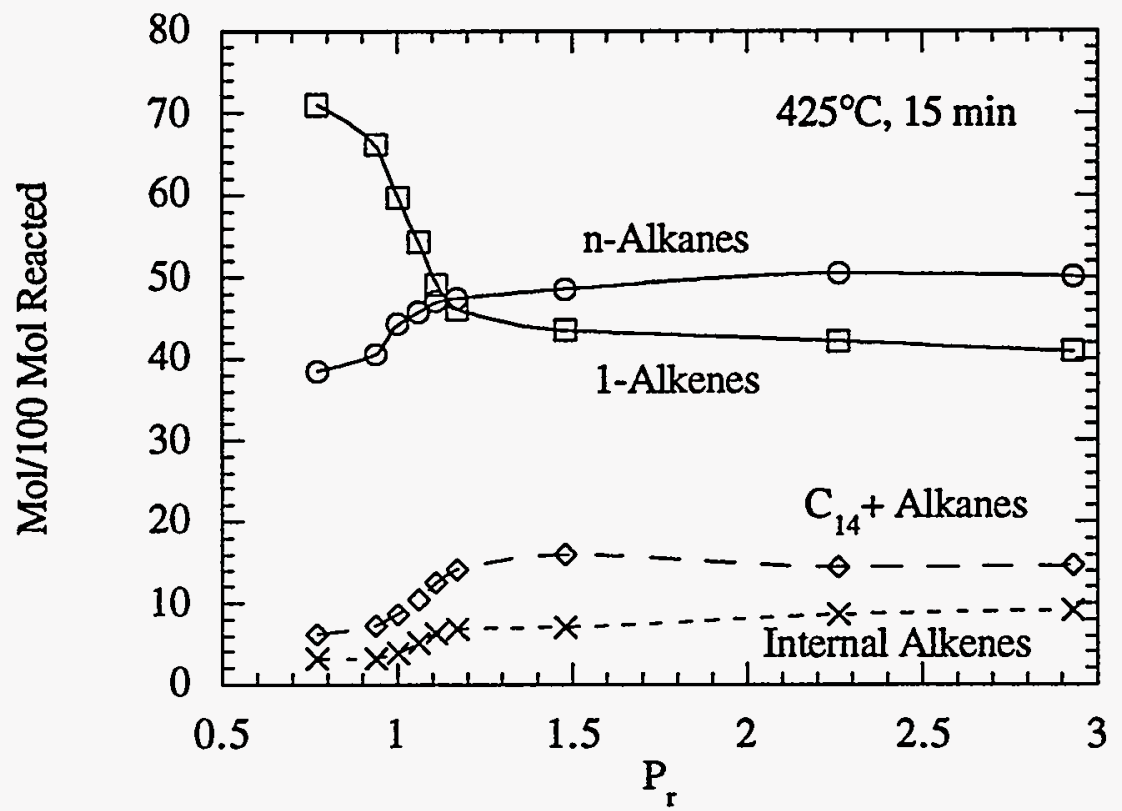

Figure 18. Changes in Molar Yields of $\mathrm{C}_{6}$ - $\mathrm{C}_{13}$ n-Alkanes, 1-Alkenes, and Internal Alkenes as well as $\mathrm{C}_{14}+$ Alkanes with Initial Reduced Pressure at $425^{\circ} \mathrm{C}$ for $15 \mathrm{~min}$ from n-Tetradecane.

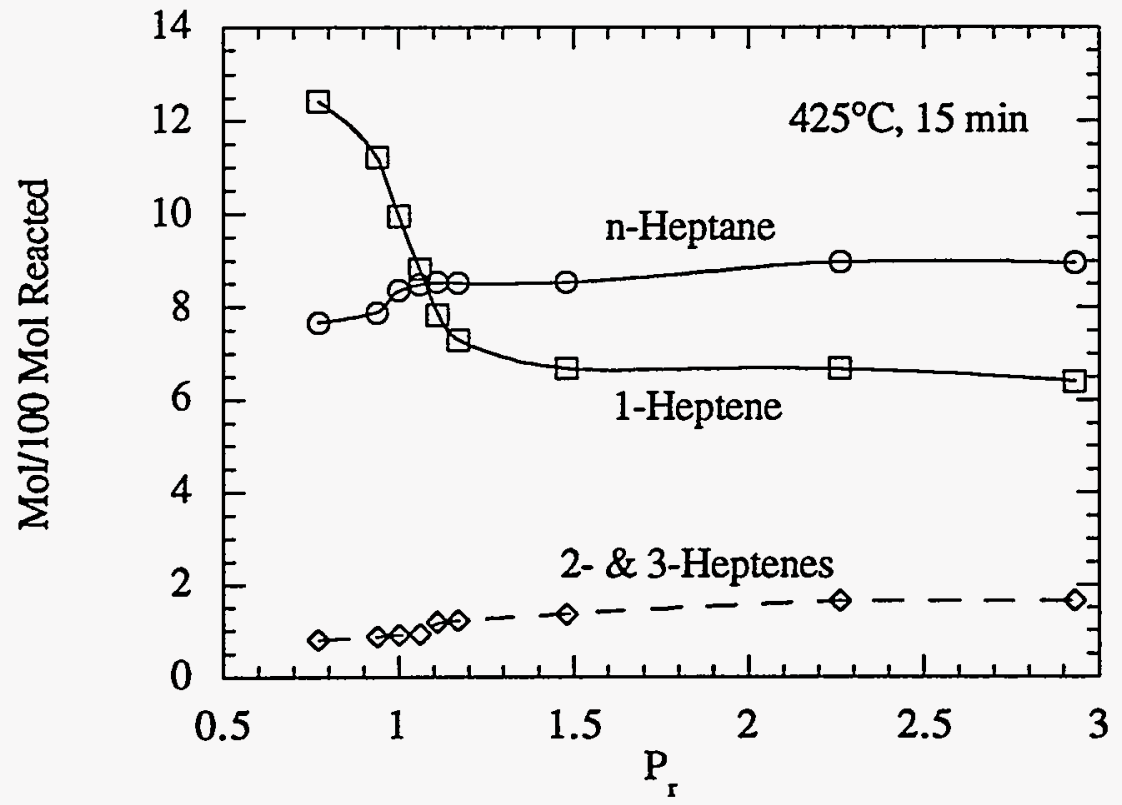

Figure 19. Changes in Molar Yields of $C_{7}$ Fractions with $P_{r}$ at $425^{\circ} \mathrm{C}$ for $15 \mathrm{~min}$ from n-Tetradecane. 

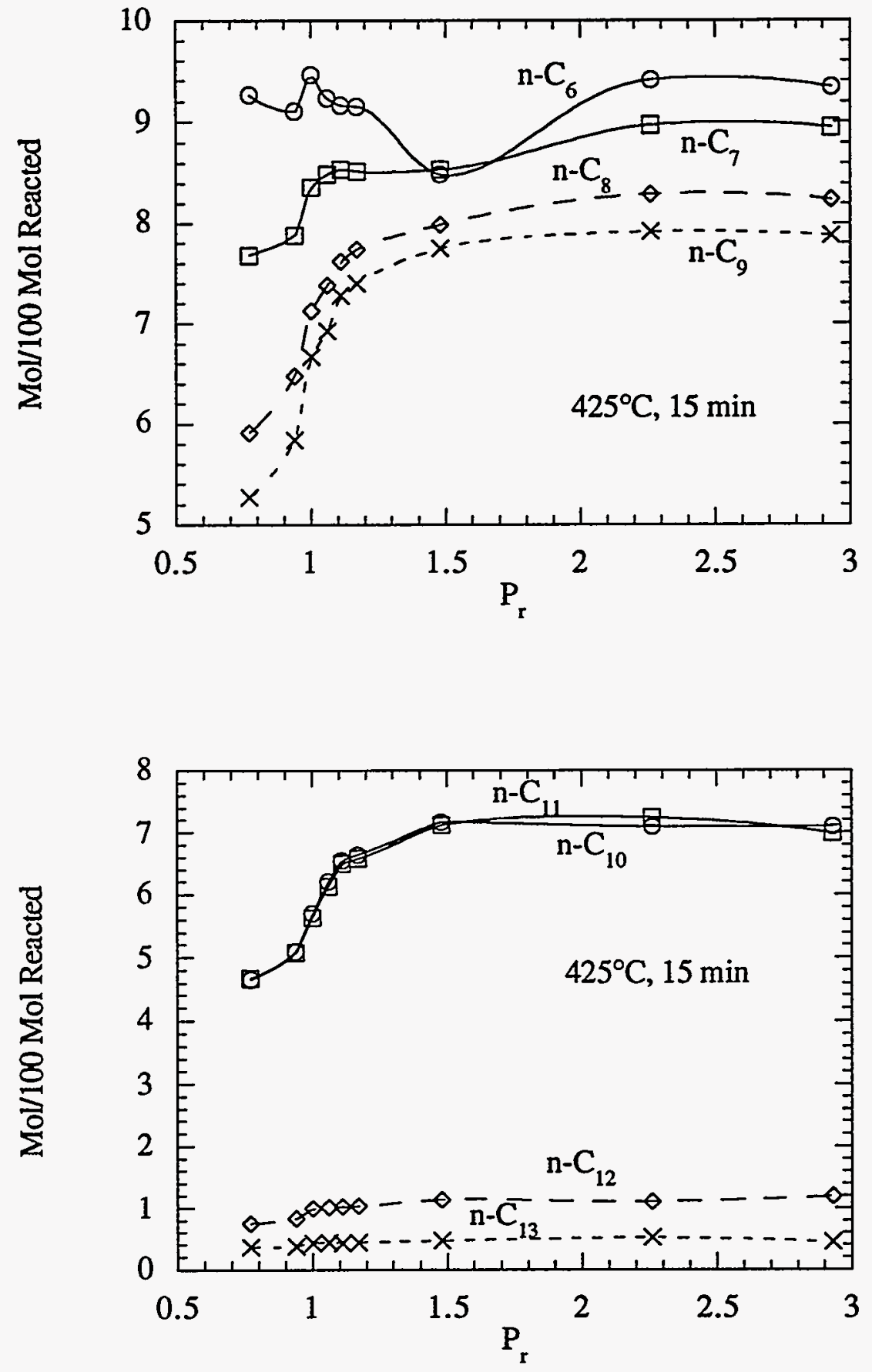

Figure 20. Changes in Molar Yields of $n$-Alkanes with $P_{\Gamma}$ at $425^{\circ} \mathrm{C}$ for $15 \mathrm{~min}$. from n-Tetradecane 

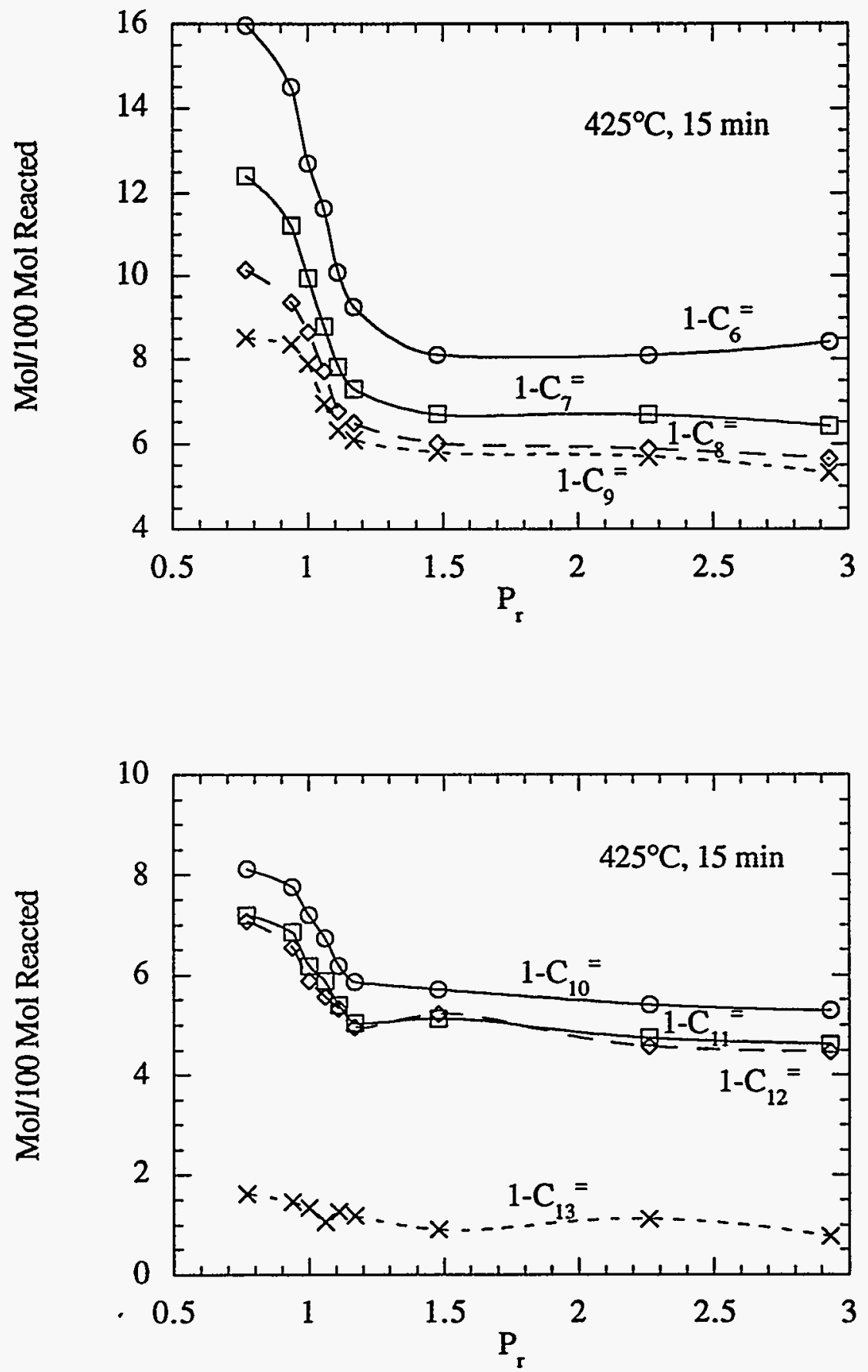

Figure 21. Changes in Molar Yields of 1-Alkenes with $\mathrm{P}_{\mathrm{r}}$ at $425^{\circ} \mathrm{C}$ for $15 \mathrm{~min}$. from n-Tetradecane. 


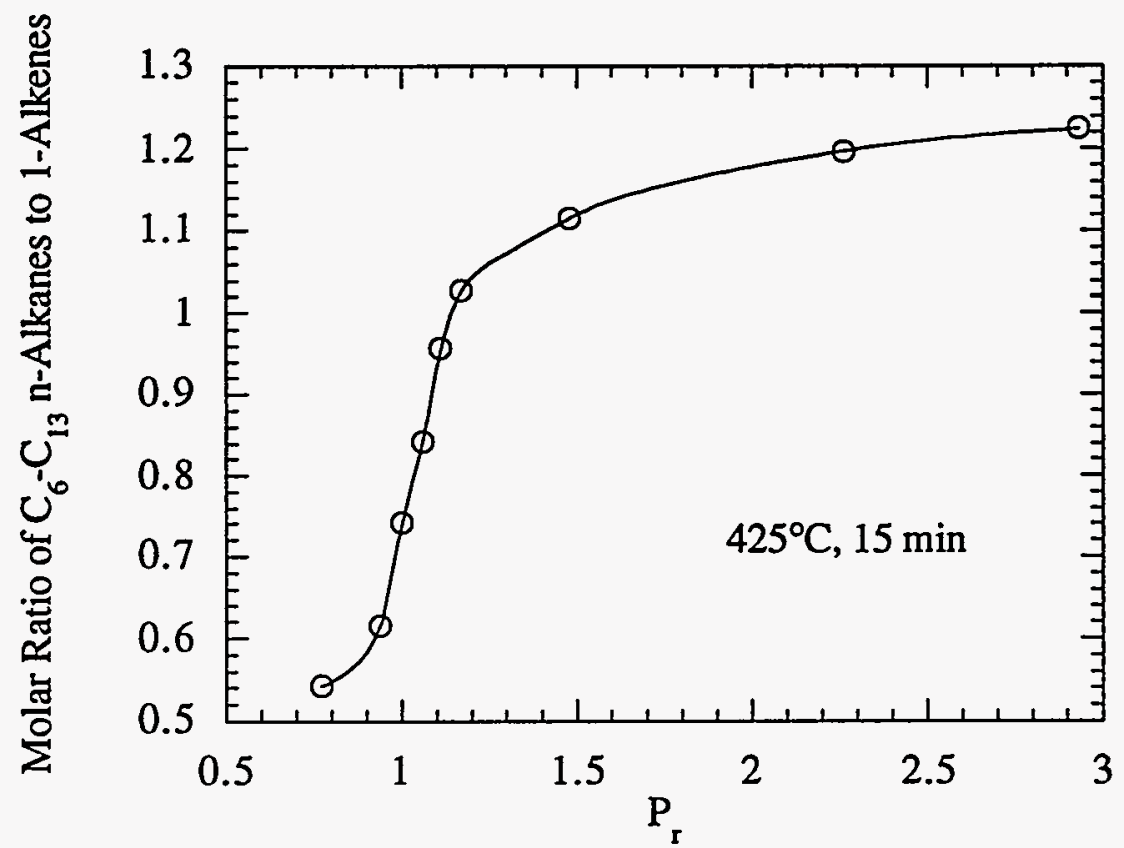

Figure 22. Change in Molar Ratio of $\mathrm{C}_{6}-\mathrm{C}_{13}$ n-Alkanes to 1-Alkenes with $P_{I}$ at $425^{\circ} \mathrm{C}$ for $15 \mathrm{~min}$. from $\mathrm{n}$-Tetradecane.

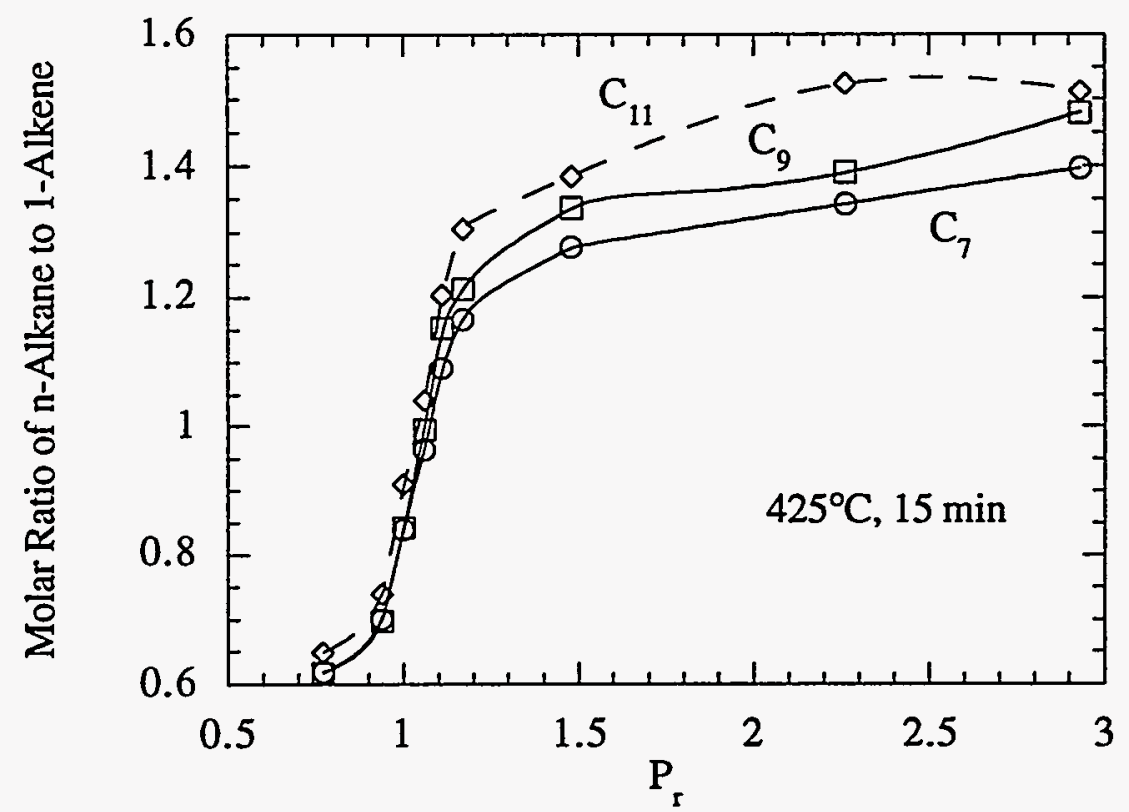

Figure 23. Change in Molar Ratio of $\mathrm{C}_{7}, \mathrm{C}_{9}$, and $\mathrm{C}_{11}$ n-Alkane to 1-Alkene with $\mathrm{P}_{\mathrm{r}}$ at $425^{\circ} \mathrm{C}$ for $15 \mathrm{~min}$. from n-Tetradecane. 


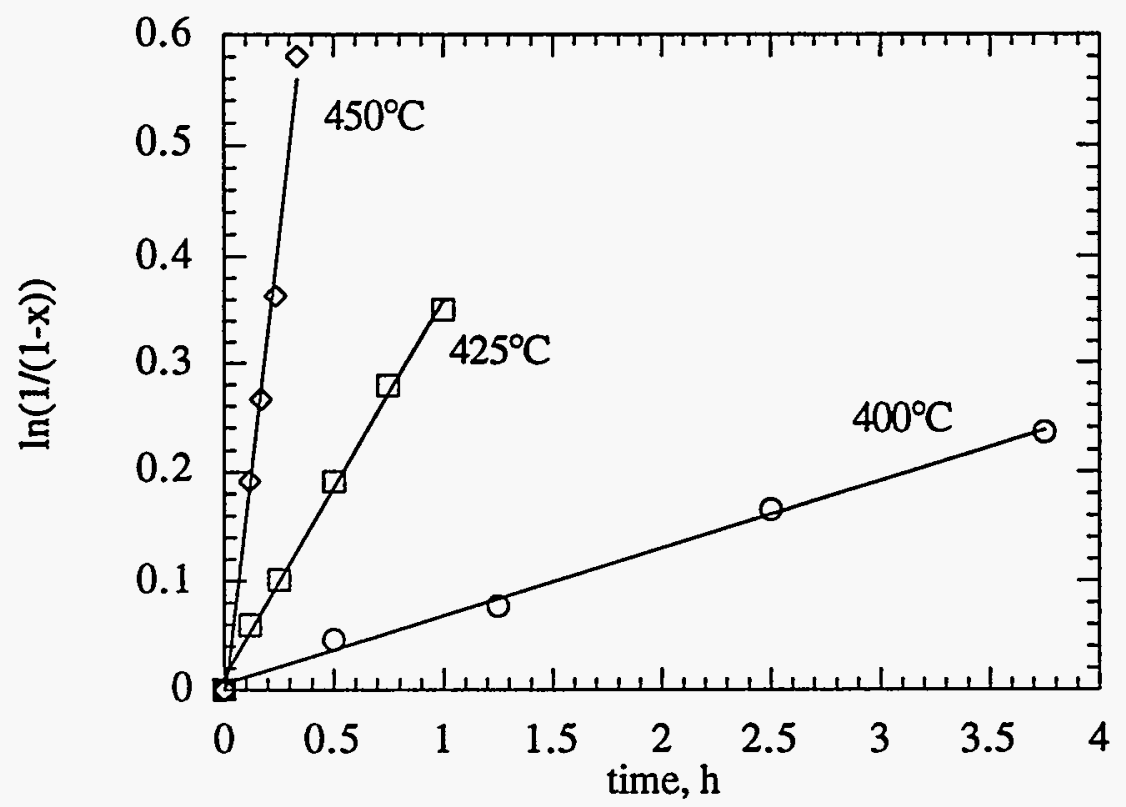

Figure 24. Relationship between $\ln [1 /(1-\mathrm{x})]$ and Time for Conversion of n-Tetradecane.

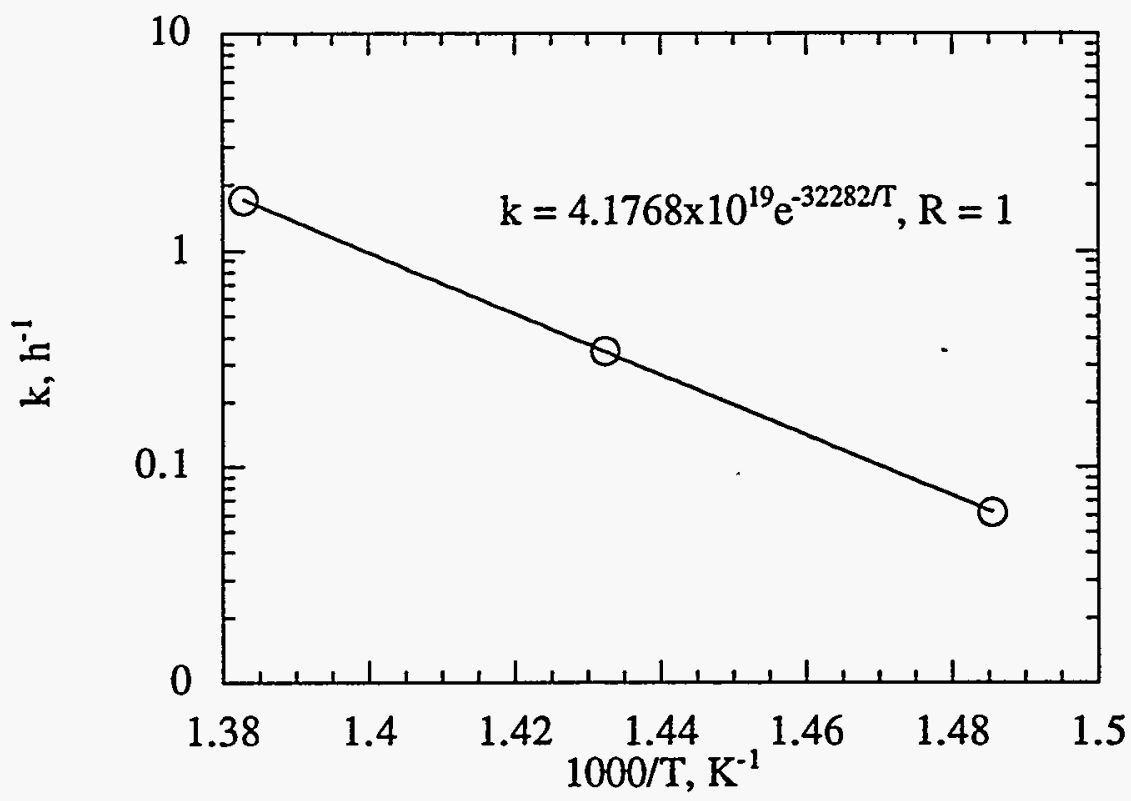

Figure 25. Relationship between Rate Constant and Temperature for $n$-Tetradecane Conversion. 


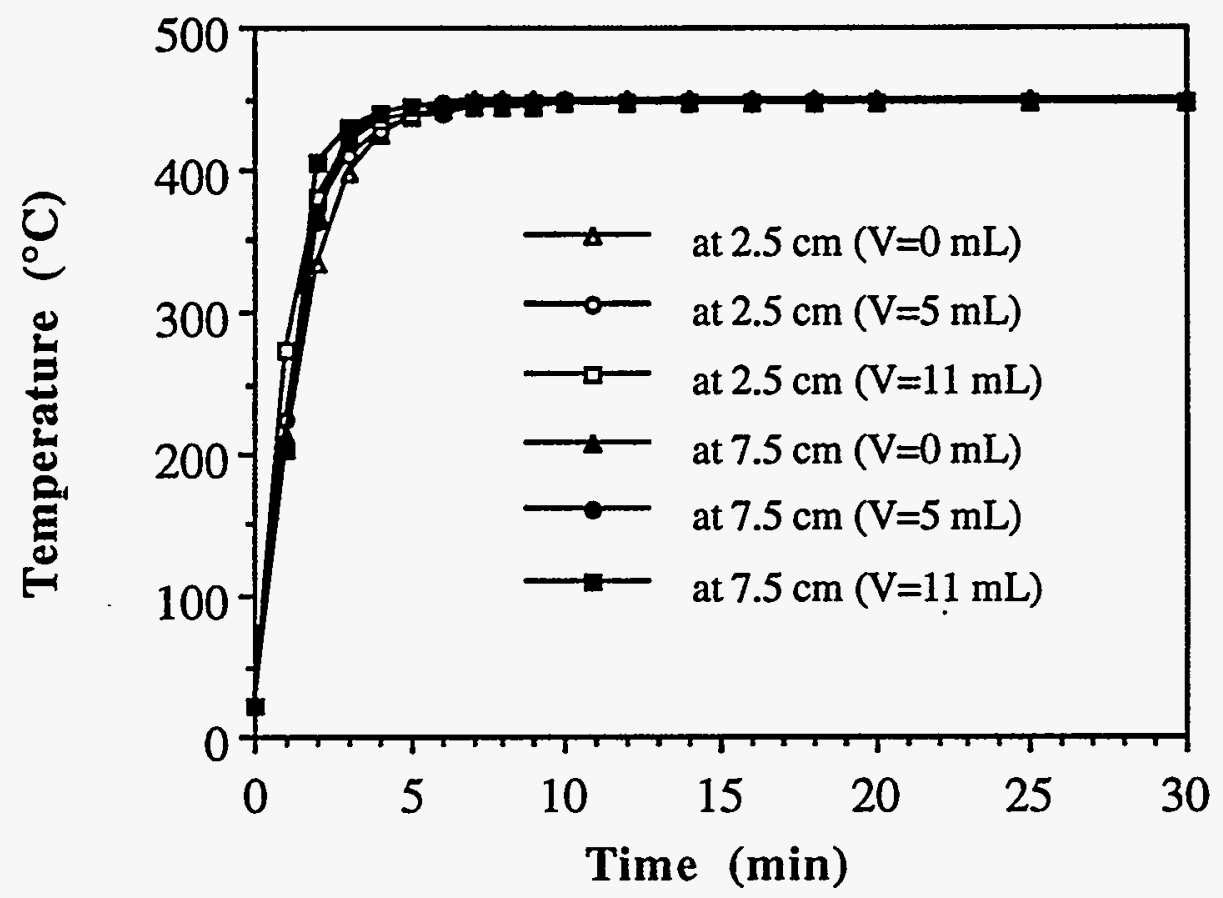

Figure 26. Temperature Profiles inside the Reactor at Two Positions $(2.5 \mathrm{~cm}$ and 7.5 $\mathrm{cm}$ from the Bottom of the Reactor) for Three $n$-C 14 Loadings $(0,5$, and 11 $\mathrm{mL}$ of $n-\mathrm{C}_{14}$ ) under an Initial $\mathrm{N}_{2}$ Pressure of $0.79 \mathrm{MPa}$. 


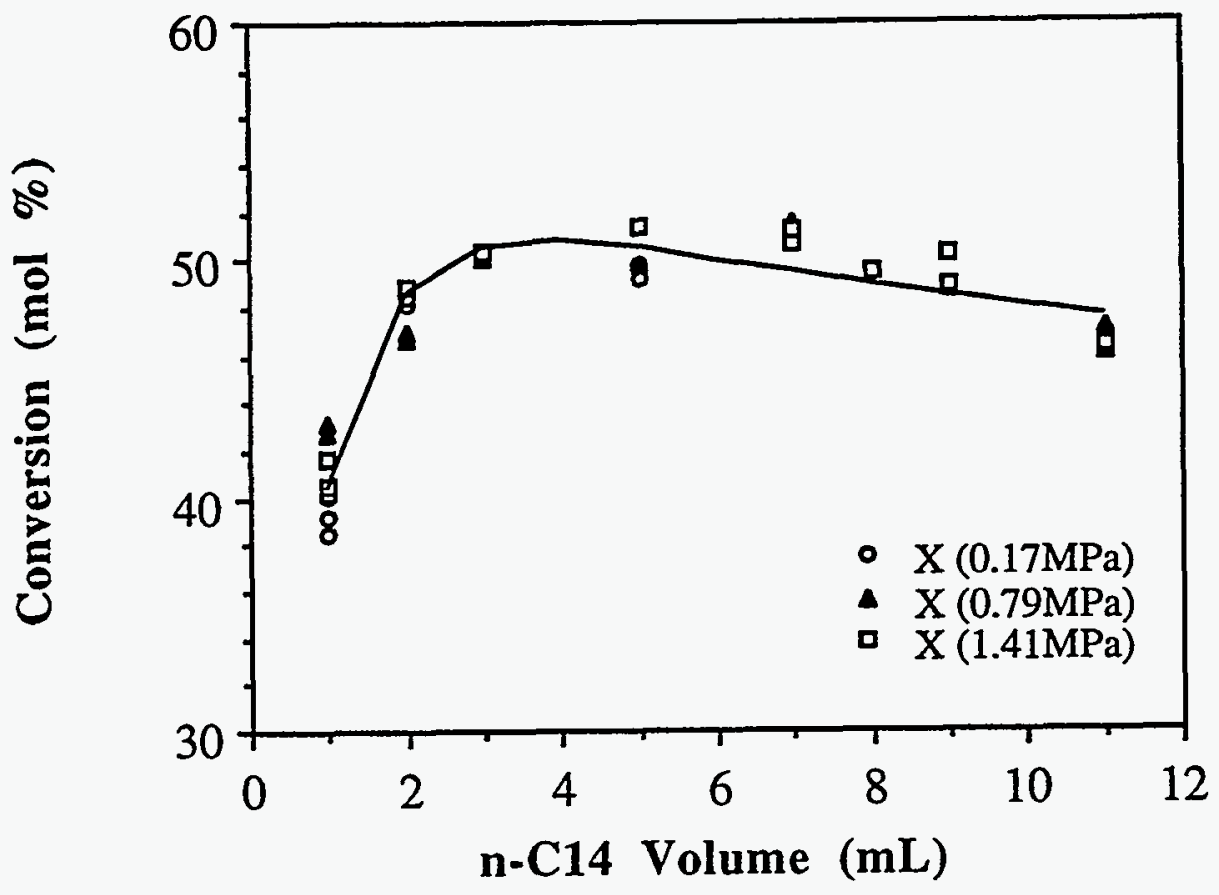

Figure 27. Effects of Initial Sample Volume of $n$-C14 (at Room Temperature) on its Pyrolytic Conversion at $450^{\circ} \mathrm{C}$ for 30 Minutes under Different Initial Pressure of $\mathrm{N}_{2}$ in 23.2-mL Microreactors. 


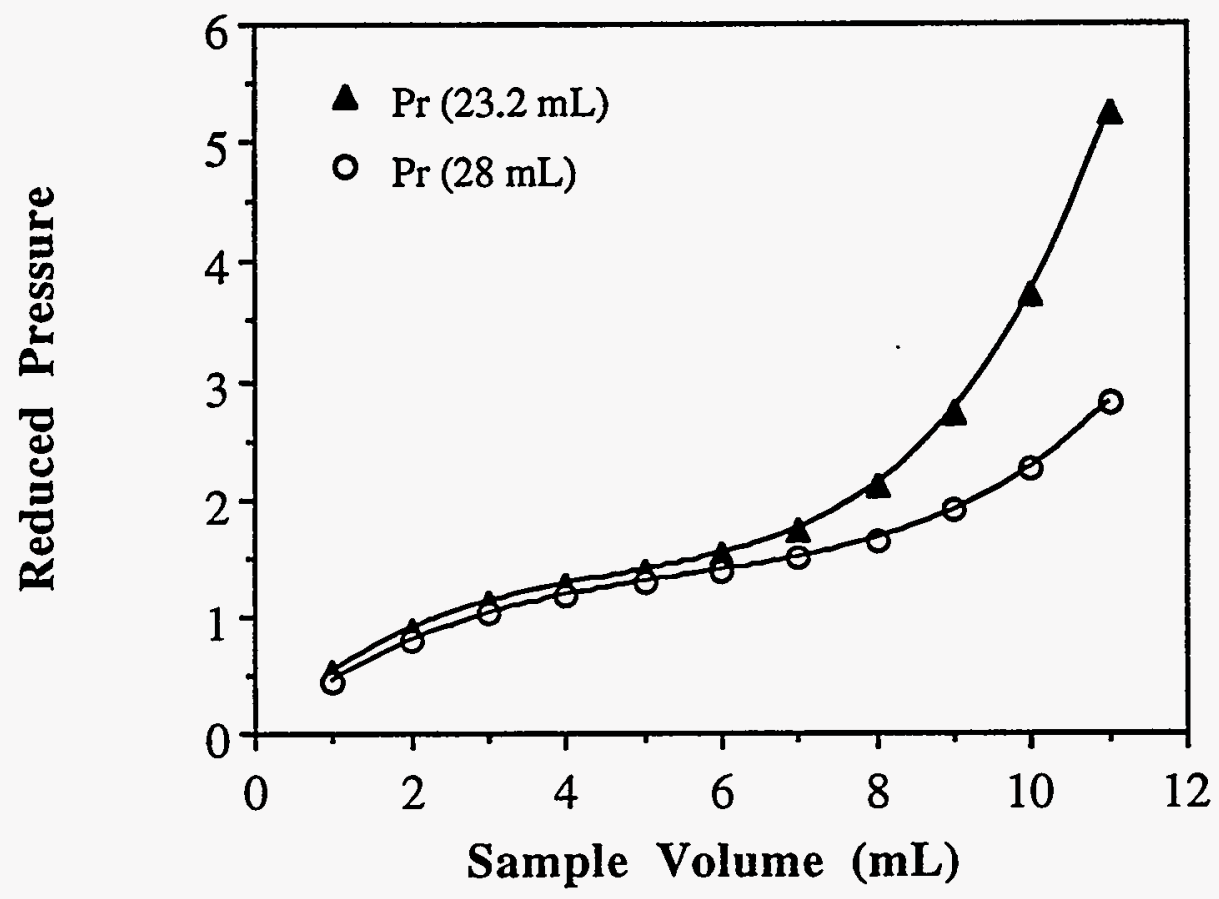

Figure 28. Estimated Reduced Pressure as a Function of the Initially Charged Volumes of $n-C_{14}$ under Vacuum Condition (without the Addition of $\mathrm{N}_{2}$ ) for Two Tubing Bombs with Different Capacities. 


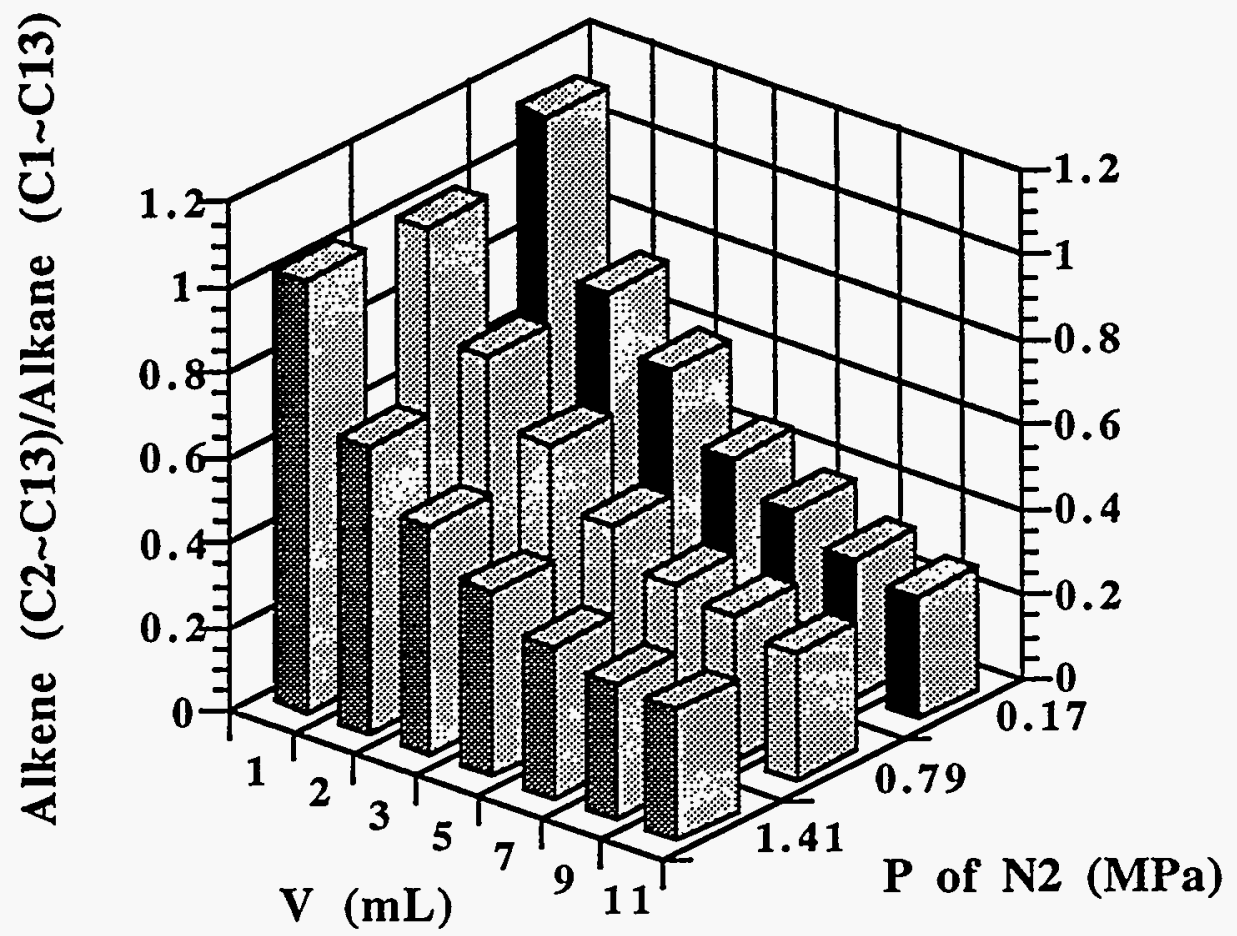

Figure 29. The Ratios of 1-Alkene $\left(C_{2}-C_{13}\right)$ to $n$-Alkanes $\left(C_{1}-C_{13}\right)$ Products from the Pyrolysis of $n-\mathrm{C}_{14}$ as a Function of the Initially Charged $n-\mathrm{C}_{14}$ Volume and $\mathrm{N}_{2}$ Pressure. 


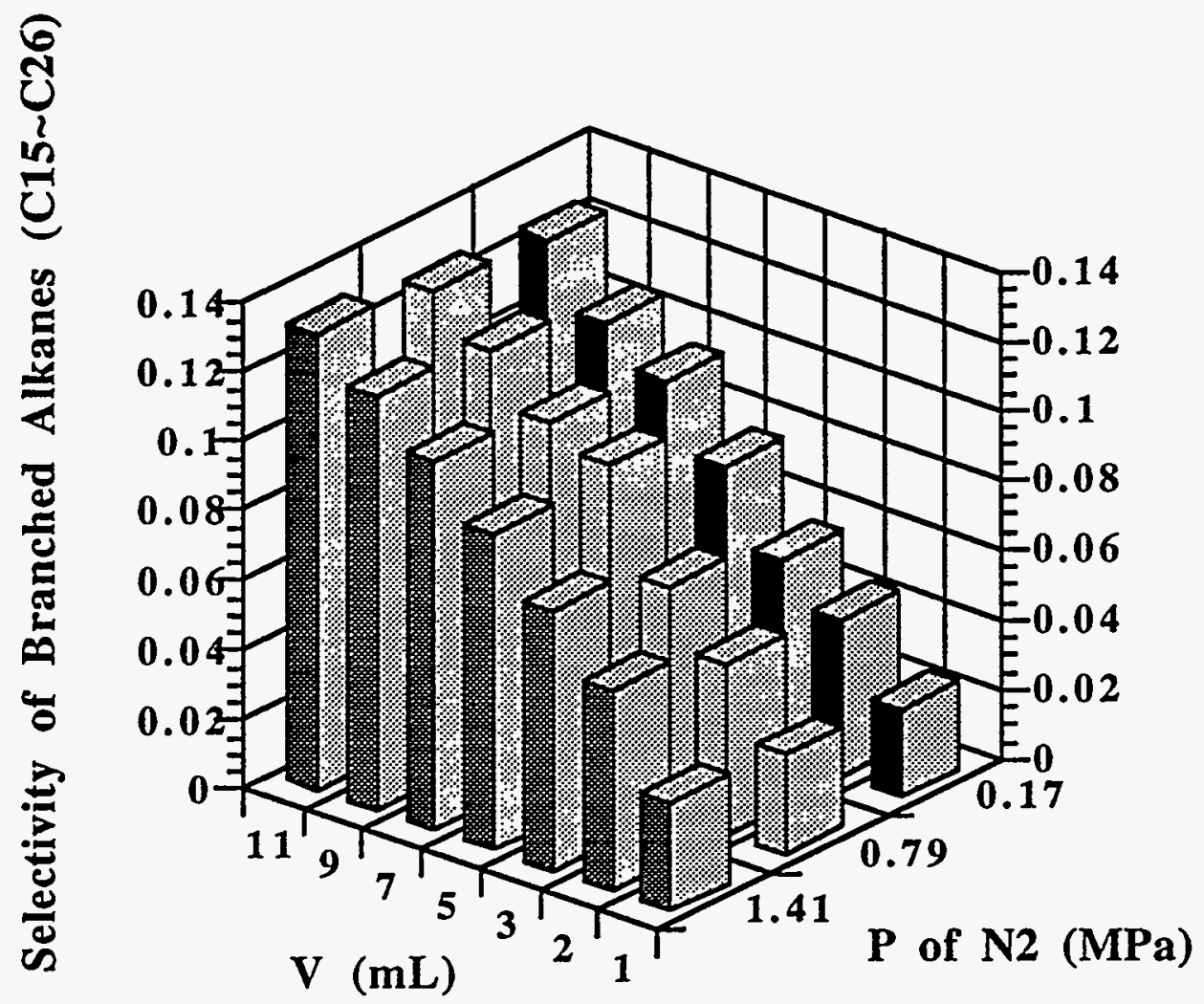

Figure 30. The Molar Selectivity of Lumped Branched Alkanes $\left(\mathrm{C}_{15}-\mathrm{C}_{26}\right)$ as a Function of the Initially Charged $n-\mathrm{C}_{14}$ Volume and $\mathrm{N}_{2}$ Pressure. 


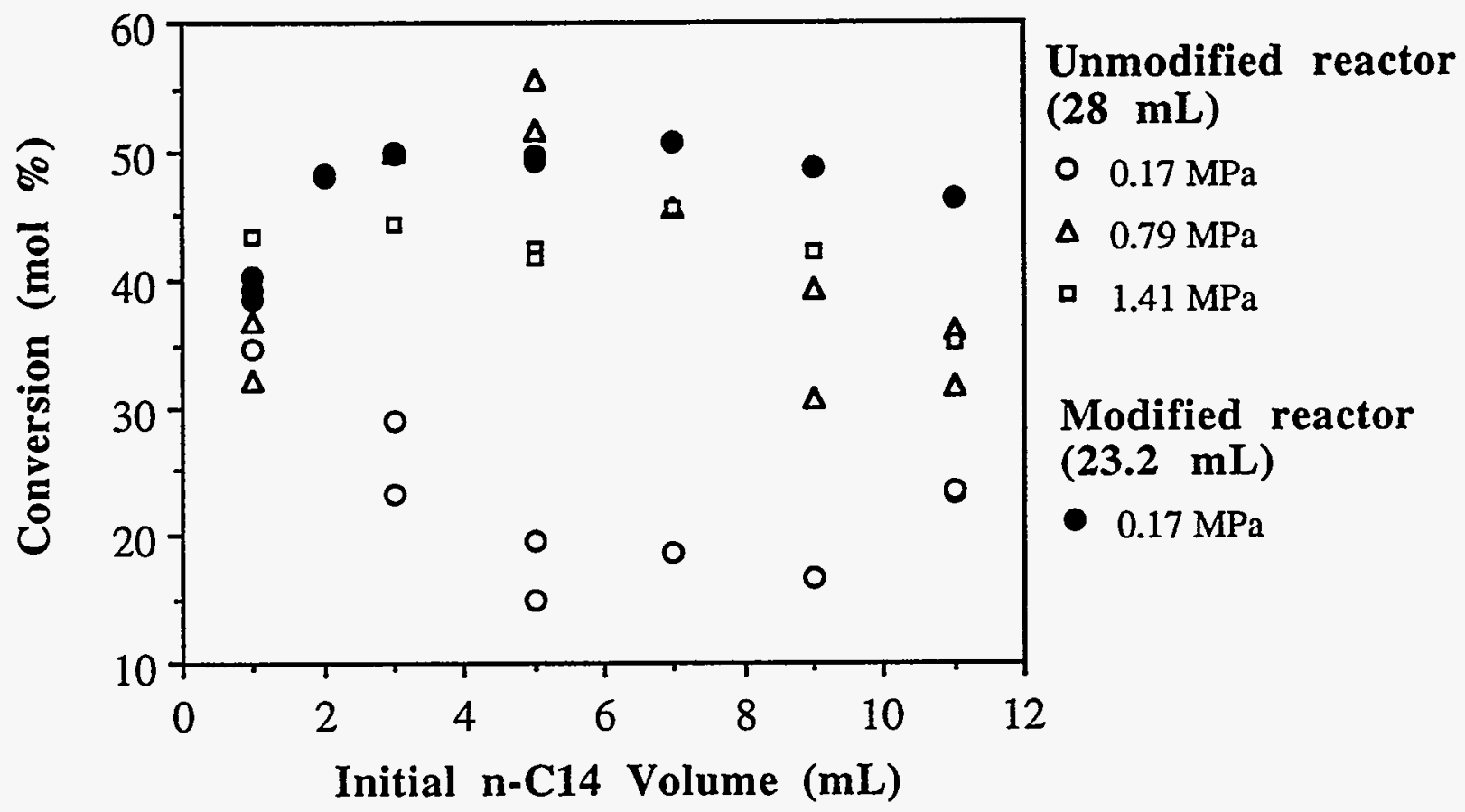

Figure 31. Effects of Initial Sample Volume of $n$ - $\mathrm{C}_{14}$ (at Room Temperature) on its Pyrolytic Conversion at $450^{\circ} \mathrm{C}$ for 30 Minutes under Different Initial Pressure of $\mathrm{N}_{2}$ in Two Tubing Bombs with Different Capacities (23.2-mL and $28-\mathrm{mL}$ ). 

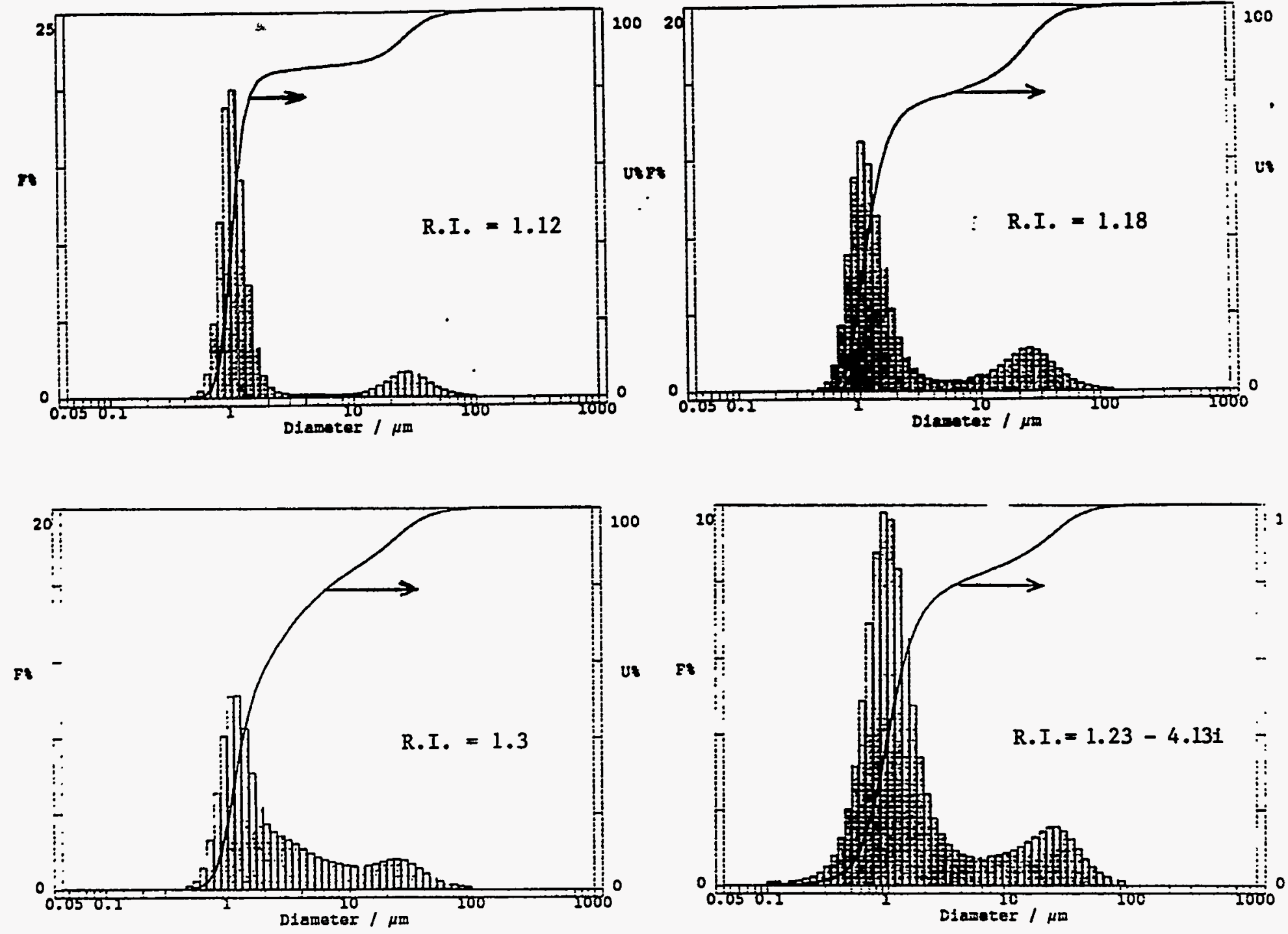

Figure 32. Size Distributions of Carbon Black Particles for Refractive Index values (R.I.) of $1.18,1.23-4.13 i, 1.12$, and 1.30 .

On the vertical axis on the left side is the percent of total particle volume in each size bin (F\%) and the scale on the right side of graph is cumulative size distribution (U\%). 

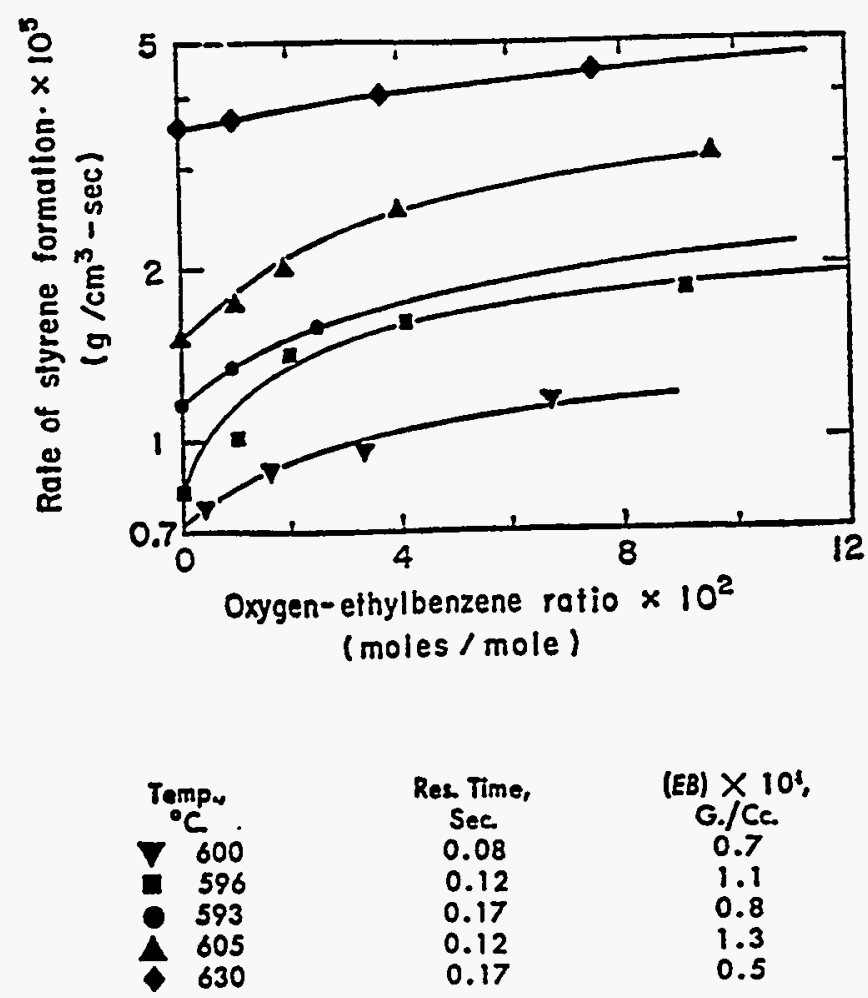

(EB) $\times 104$

G./Ce.

0.7

1.1

0.8

0.5

Figure 33. Efeect of oxygen-ethylbenzene ratio on rate of styrene formation [30]
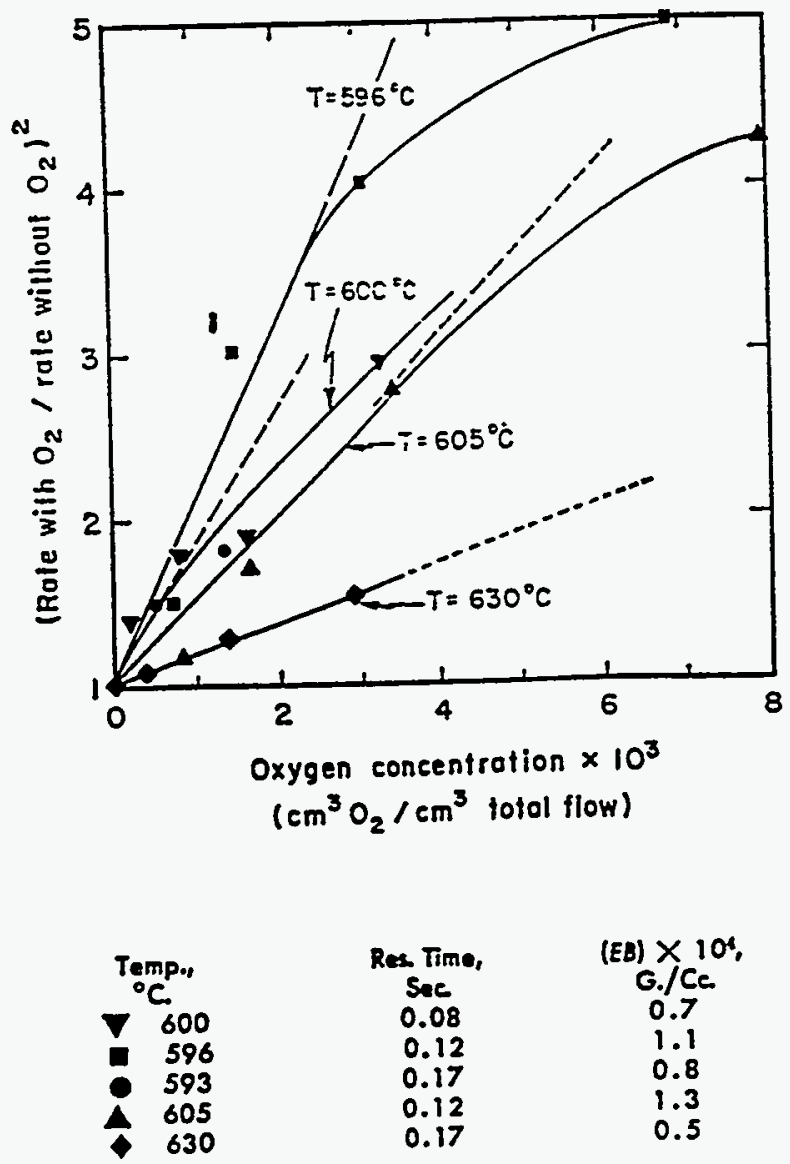

Res Time,
Sec
0.08
0.12
0.17
0.12
0.17

(EB) $\times 10 \%$

G./ Ce.

0.7

1.1

0.8

0.5

Figure 34. Increase of rate due to oxygen according to equation $40[30]$ 

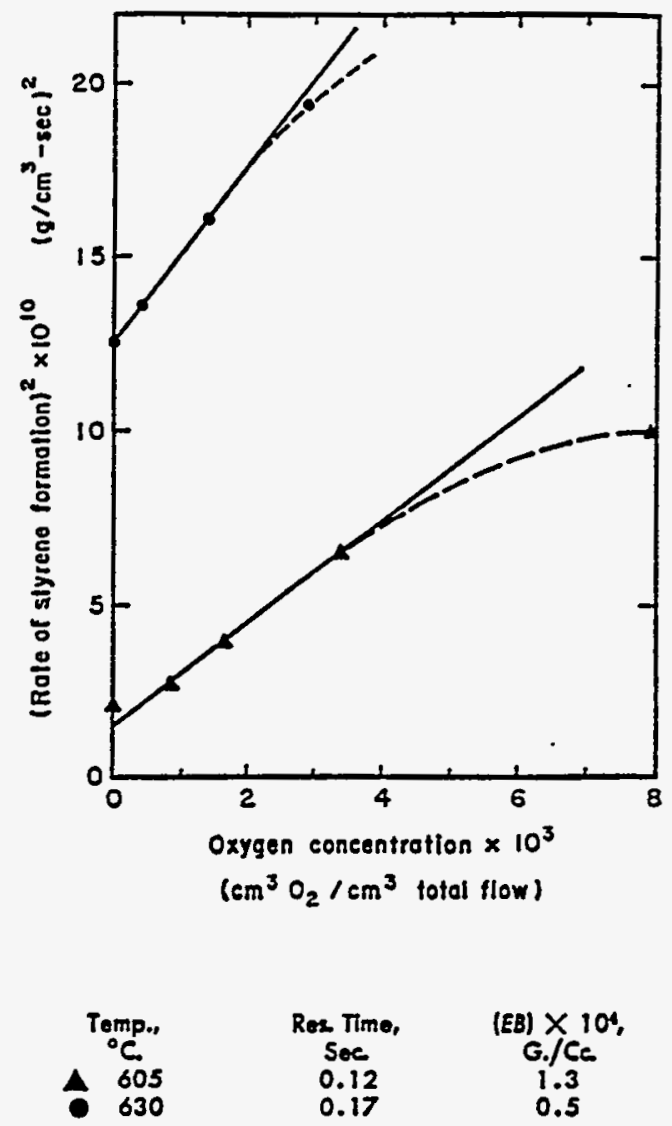

Figure 35. Increase of rate due to oxygen [30]

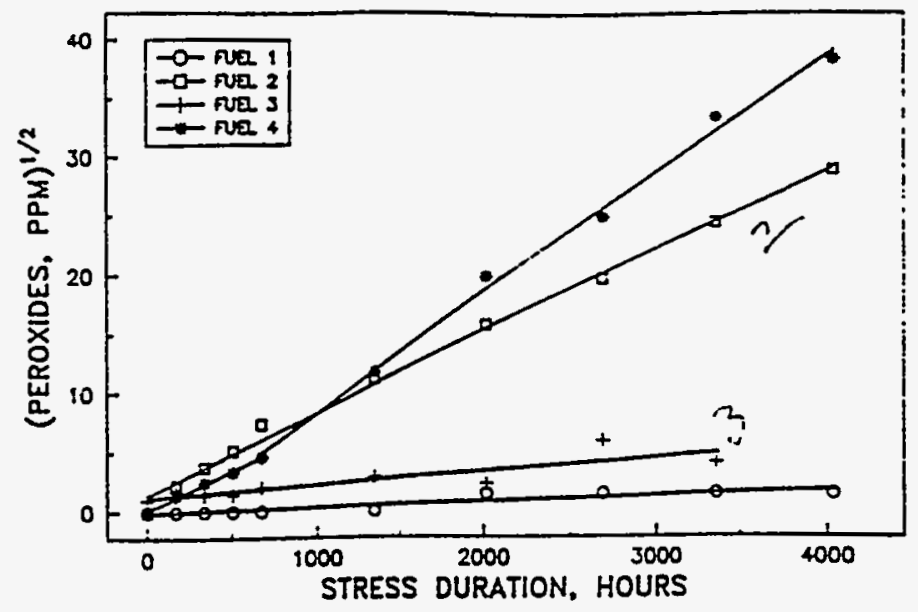

Figure 36. Oxidation of fuels $1-4$ with air at $43^{\circ} \mathrm{C}$ [37] 


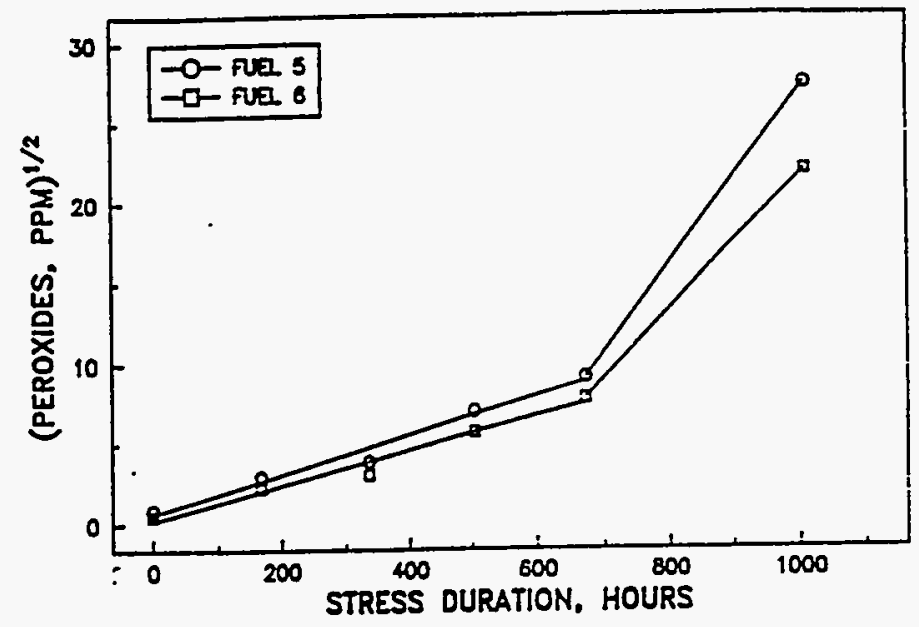

Figure 37. Oxidation of fuels 5 and 6 with air at $65^{\circ} \mathrm{C}$ [37]

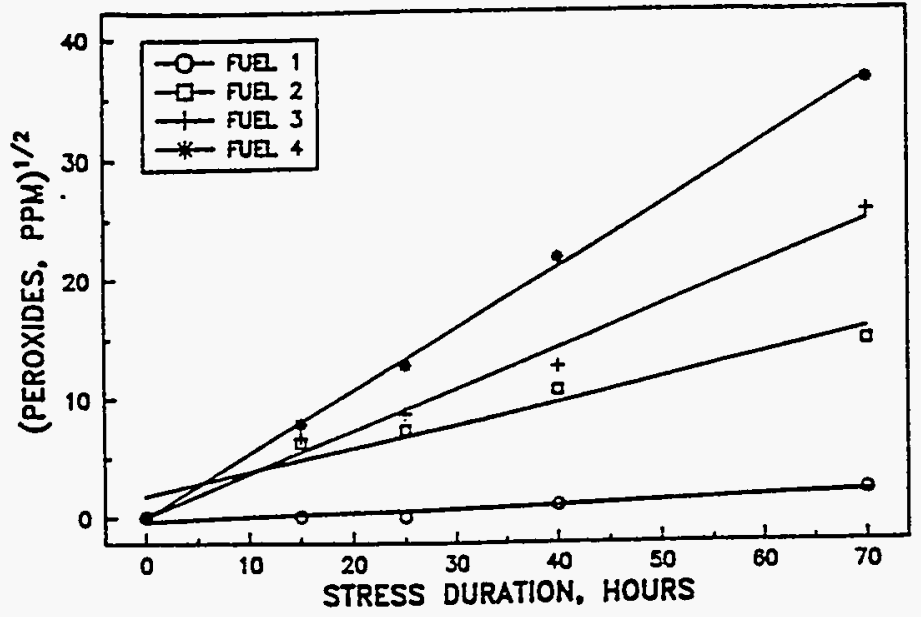

Figure 38 . Oxidation of fuels $1-4$ with 790 and $1140 \mathrm{kPa}$ of oxygen at $80^{\circ} \mathrm{C}$ [37]

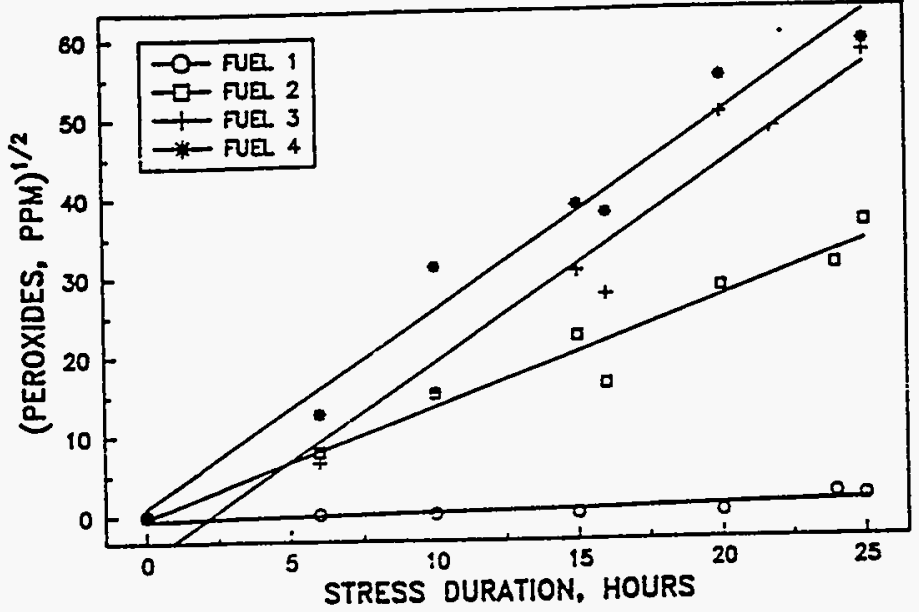

Figure 39. Oxidation of fuels $1-4$ with 240 and $790 \mathrm{kPa}$ of oxygen at $100^{\circ} \mathrm{C}$ [37] 


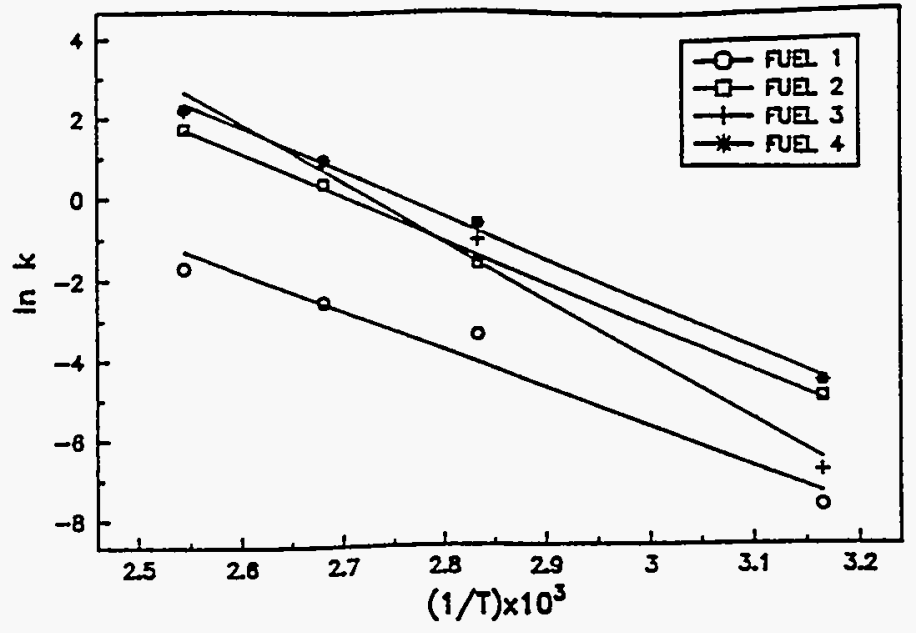

Figure 40. Arrhenius plot of the oxidation of fuels 1-4 [37]

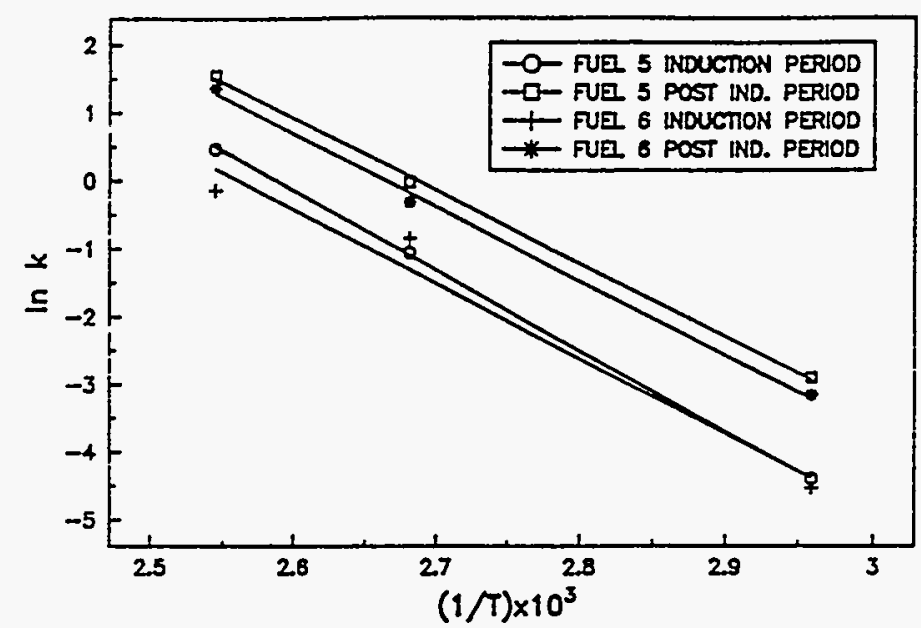

Figure 41. Arrhenius plot of the oxidation of fuels 5 and 6 [37] 


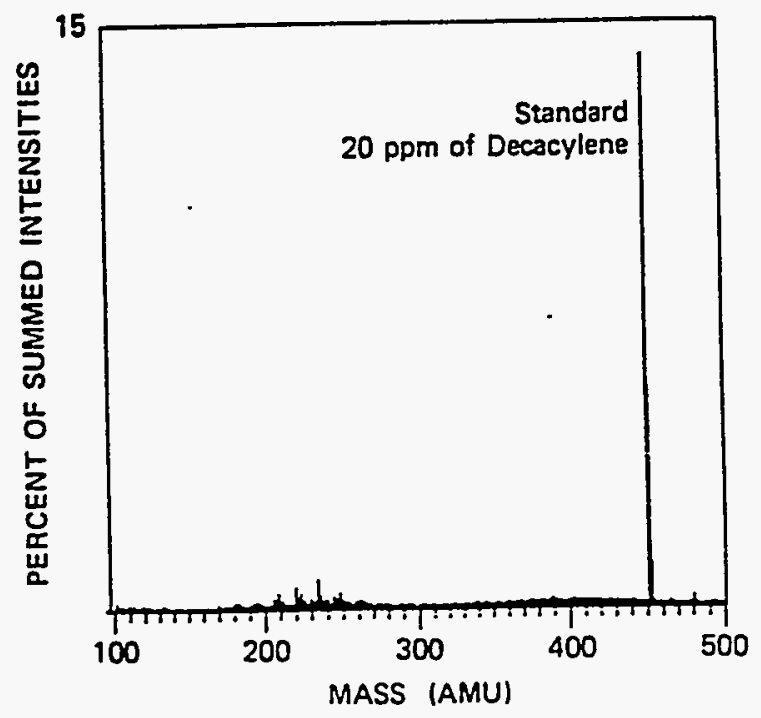

Figure 42. FIMS of deposit precursors isolated from vacuum distilled, unoxidized fuel C [43]

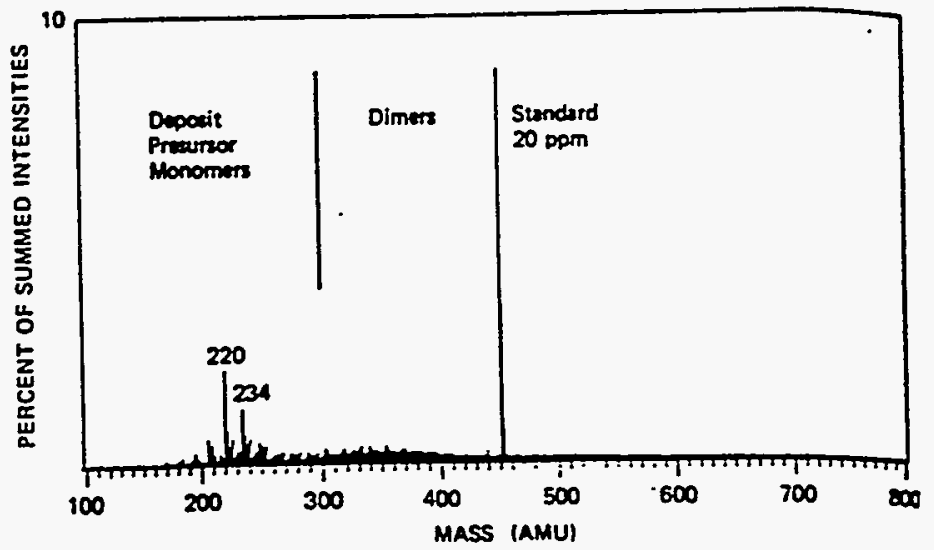

Figure 43. FIMS of the deposit precursors formed in fuel $\mathrm{C}$ after oxidation for $4.25 \mathrm{~h}$ at $130^{\circ} \mathrm{C}[43]$ 


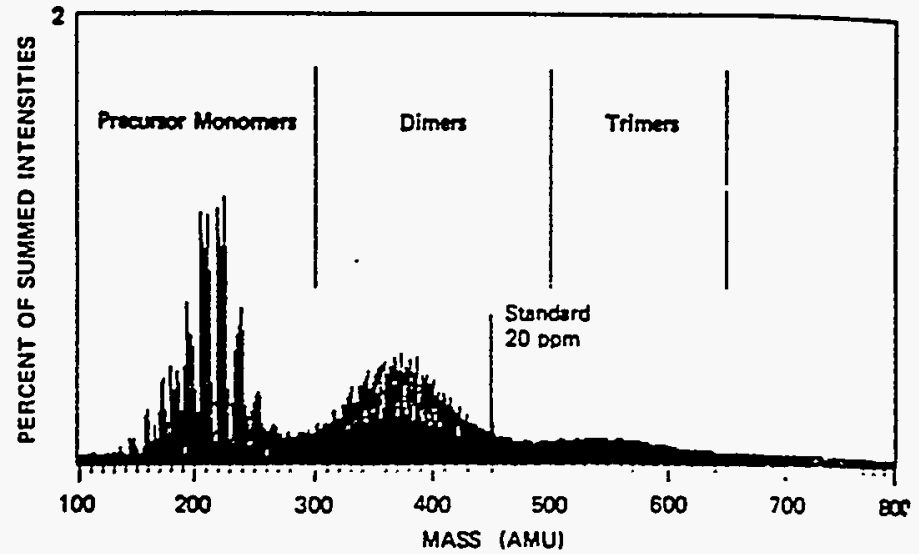

Figure 44. FIMS of the deposit precursors formed in fuel $\mathrm{C}$ after oxidation for $7.17 \mathrm{~h}$ at $130^{\circ} \mathrm{C}[43]$

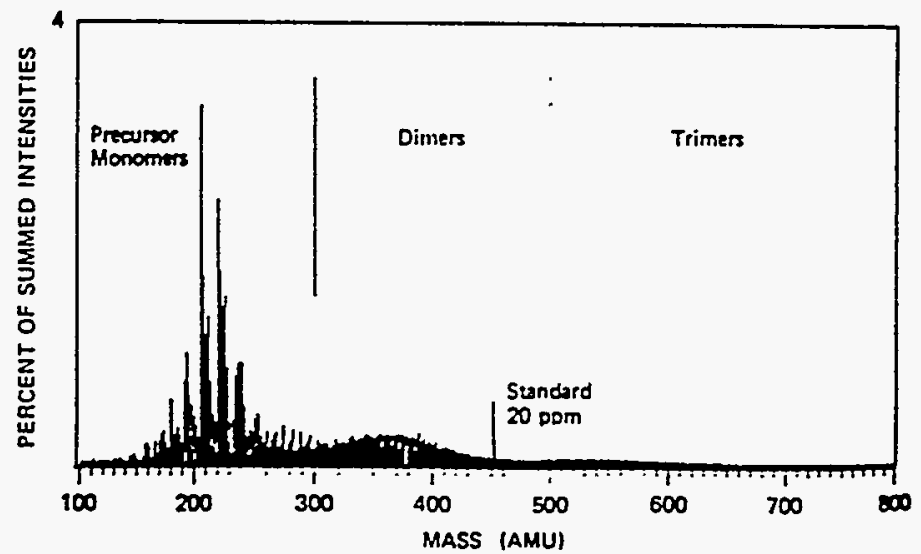

Figure 45. FIMS of the deposit precursors formed in fuel $\mathrm{C}$ after oxidation for $11.7 \mathrm{~h}$ at $130^{\circ} \mathrm{C}$ [43] 


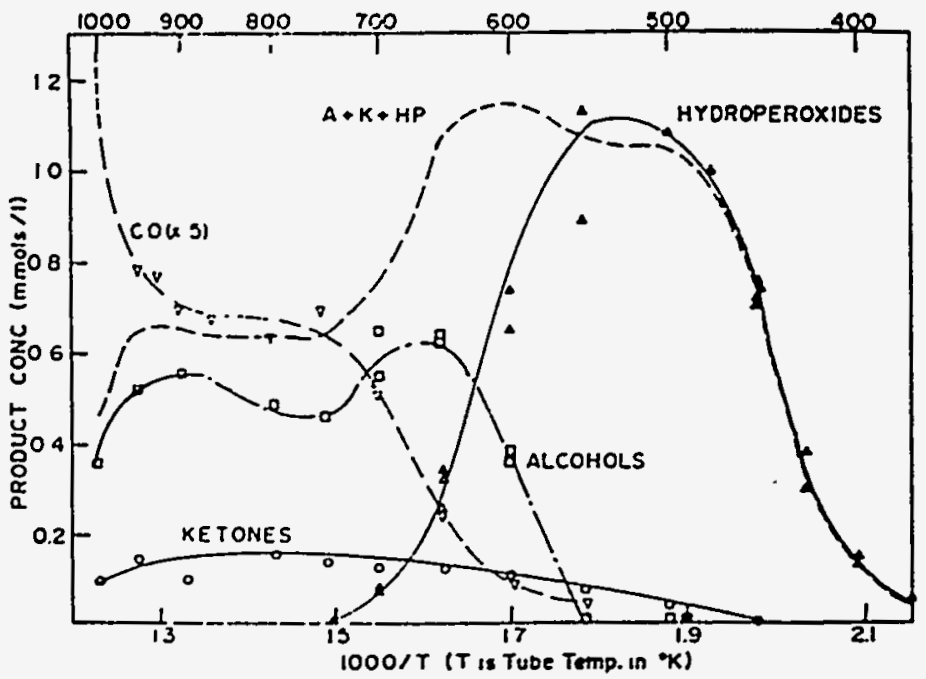

Figure 48. Oxygenated compounds from n-dodecane flowing over a 316 ss tube: $\mathrm{A}+\mathrm{K}+\mathrm{P}=$ alcohol + ketone + hydroperoxide [8]

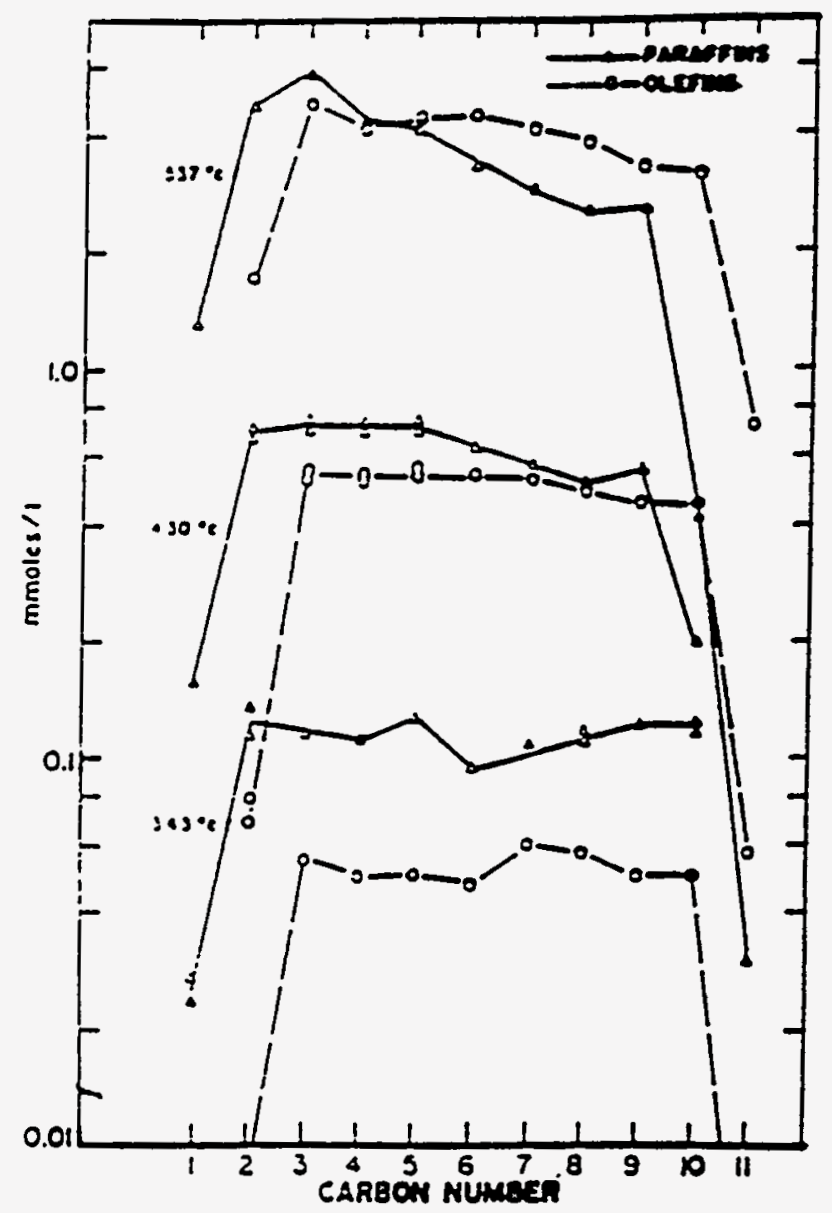

Figure 49. Distribution of n-alkanes and 1-olefins at three temperatures [8] 


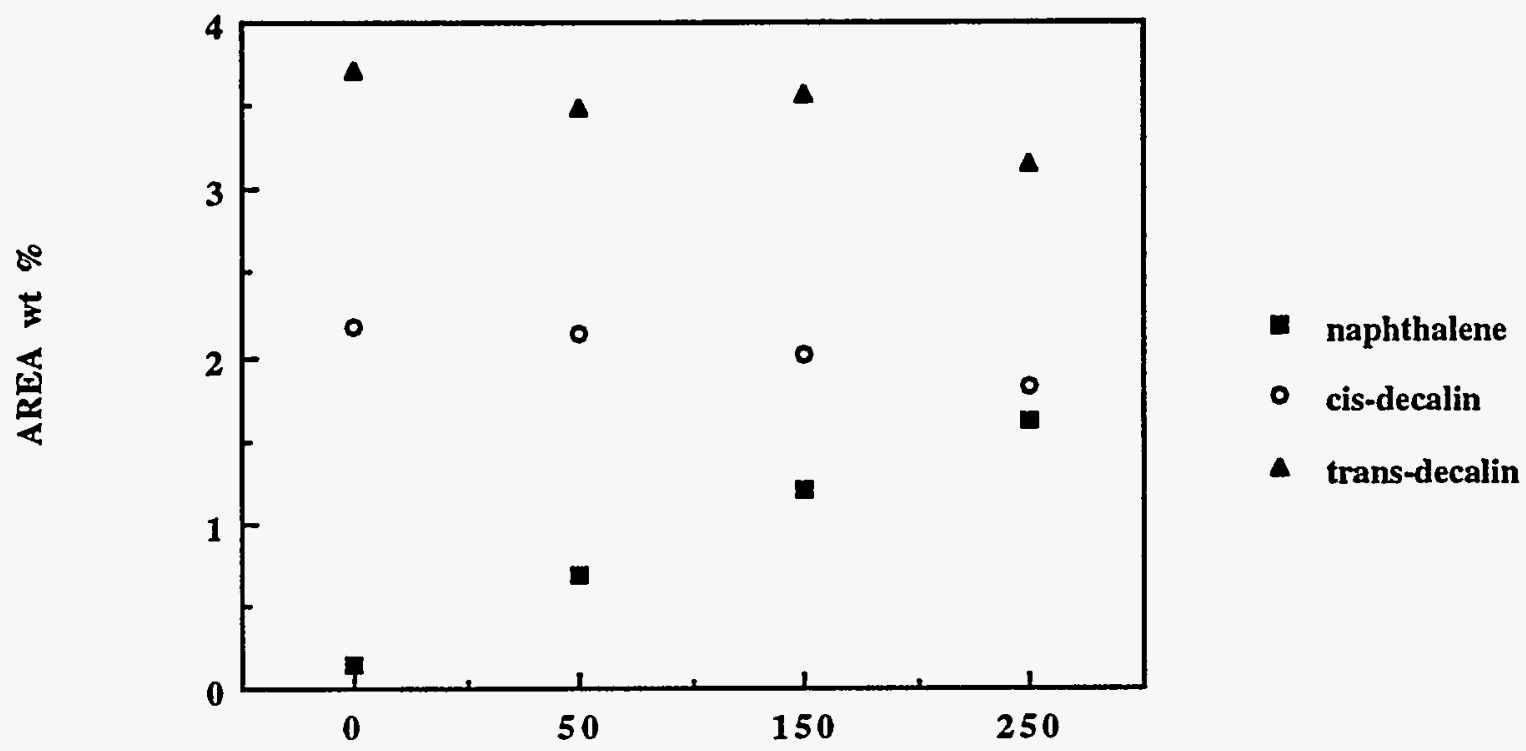

PX-21 mg

Figure 50. Effect of PX-21 Concentration on the Naphthalene and Decalin Concentrations in the Liquids Obtained from Thermal Stressing of $n$-Dodecane with Decalin 


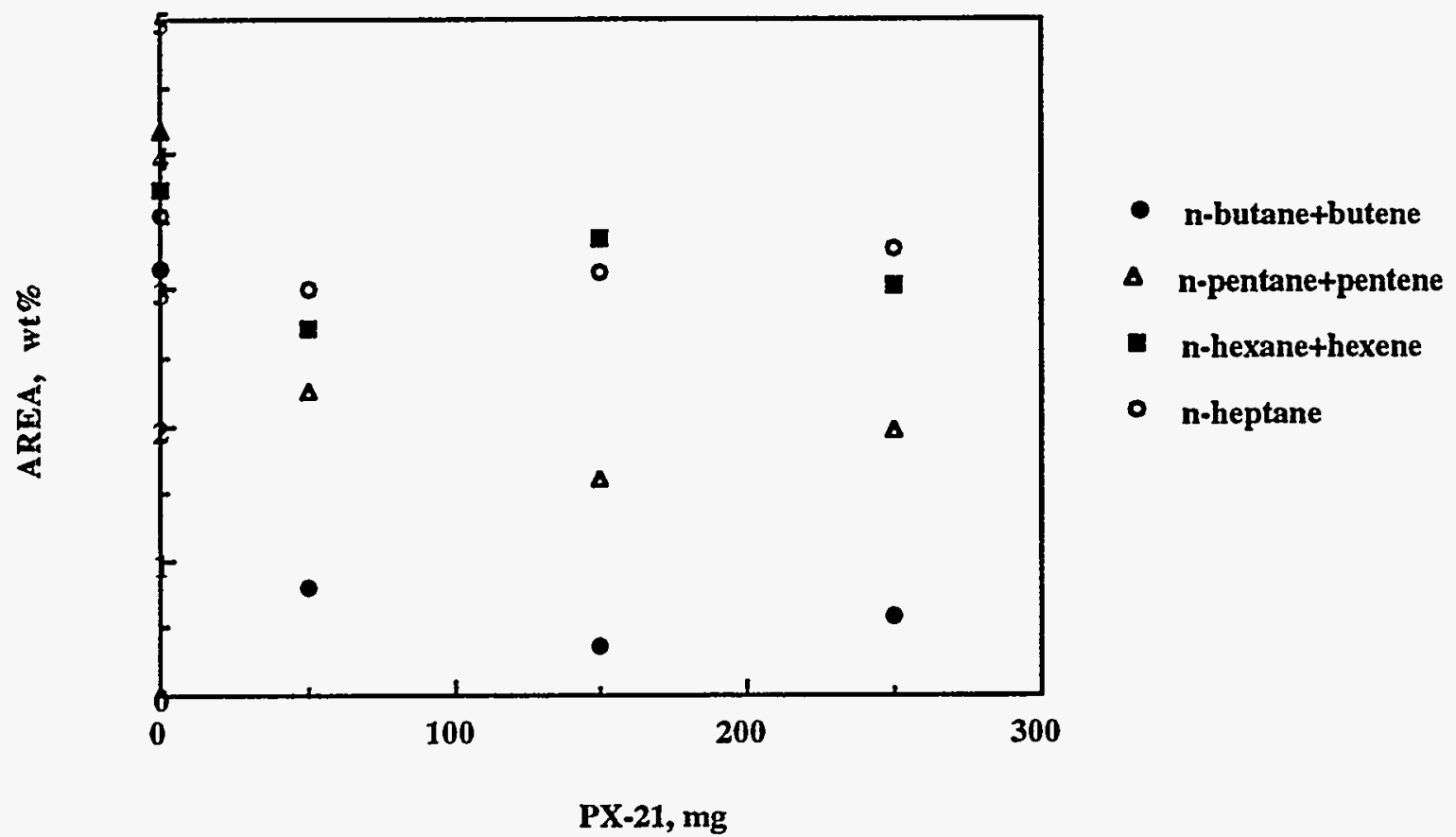

Figure 51. The relative Concentrations of Shorter n-Alkanes as a Function of the Amount of PX-21 Added 


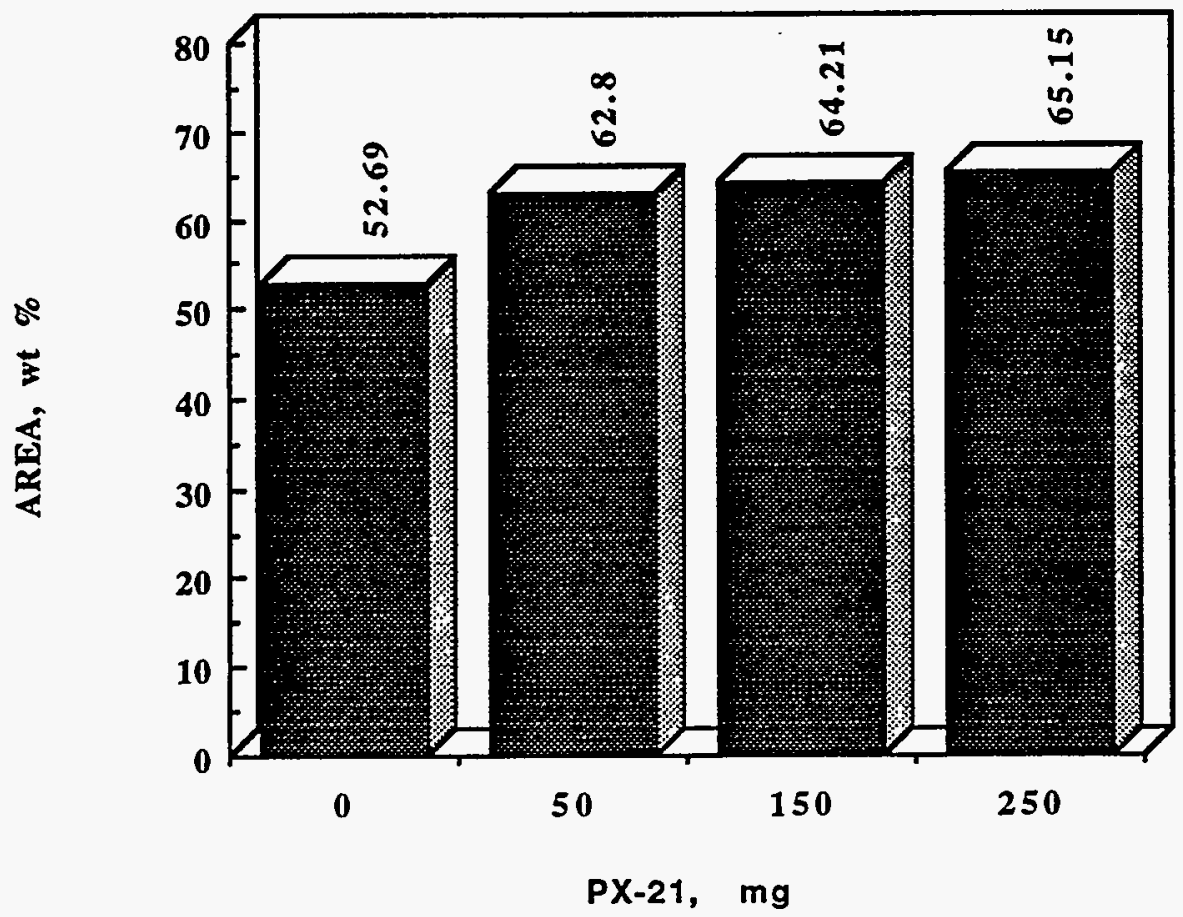

Figure 52. The Relative Concentration of n-Dodecane in the Liquids Obtained from Stressing with and without Added PX-21. 
- IZ-Xd Jum OSZ

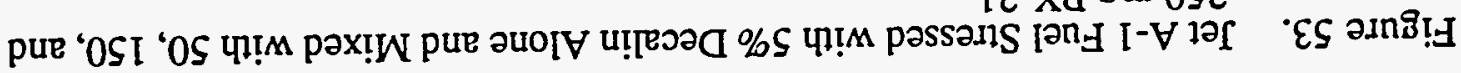

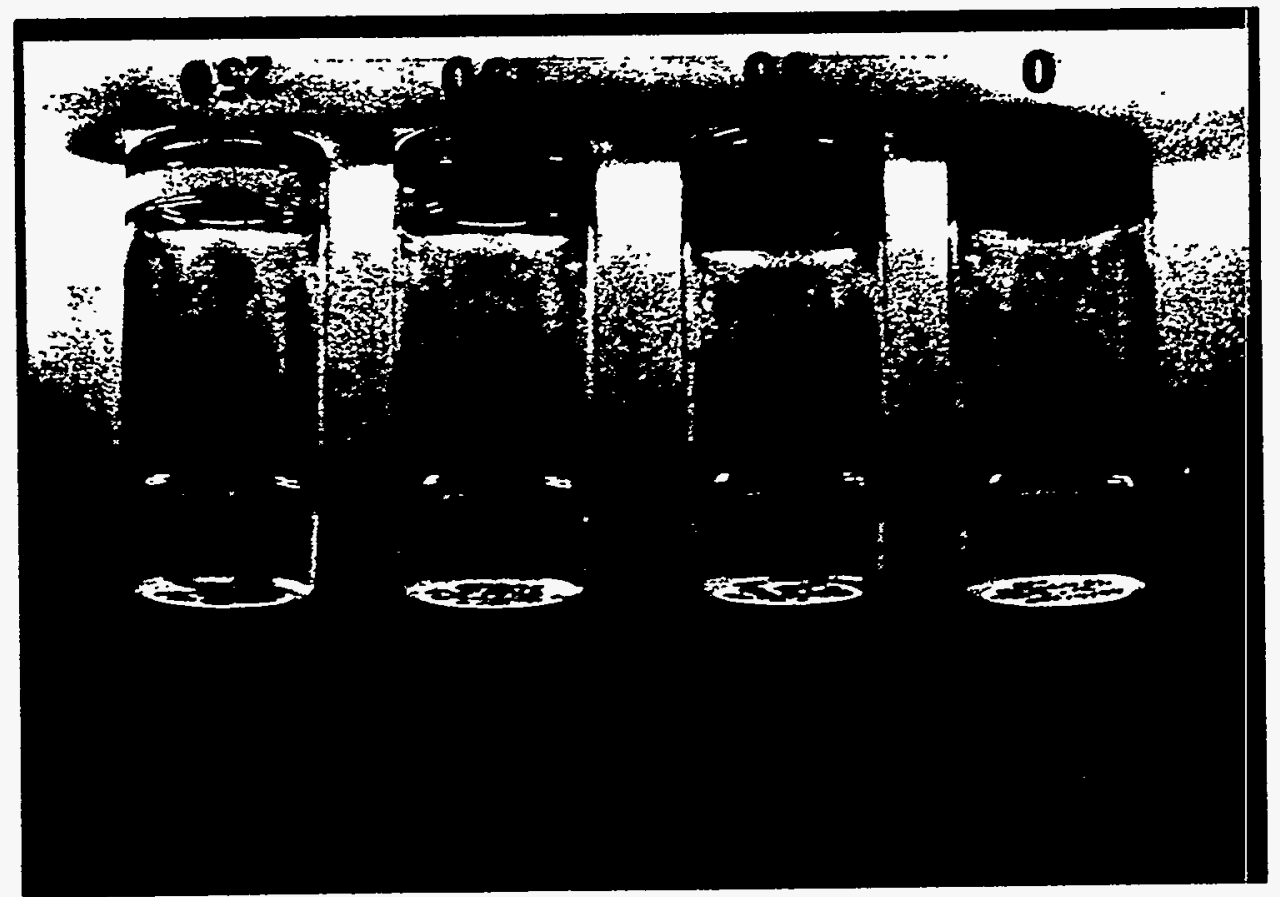




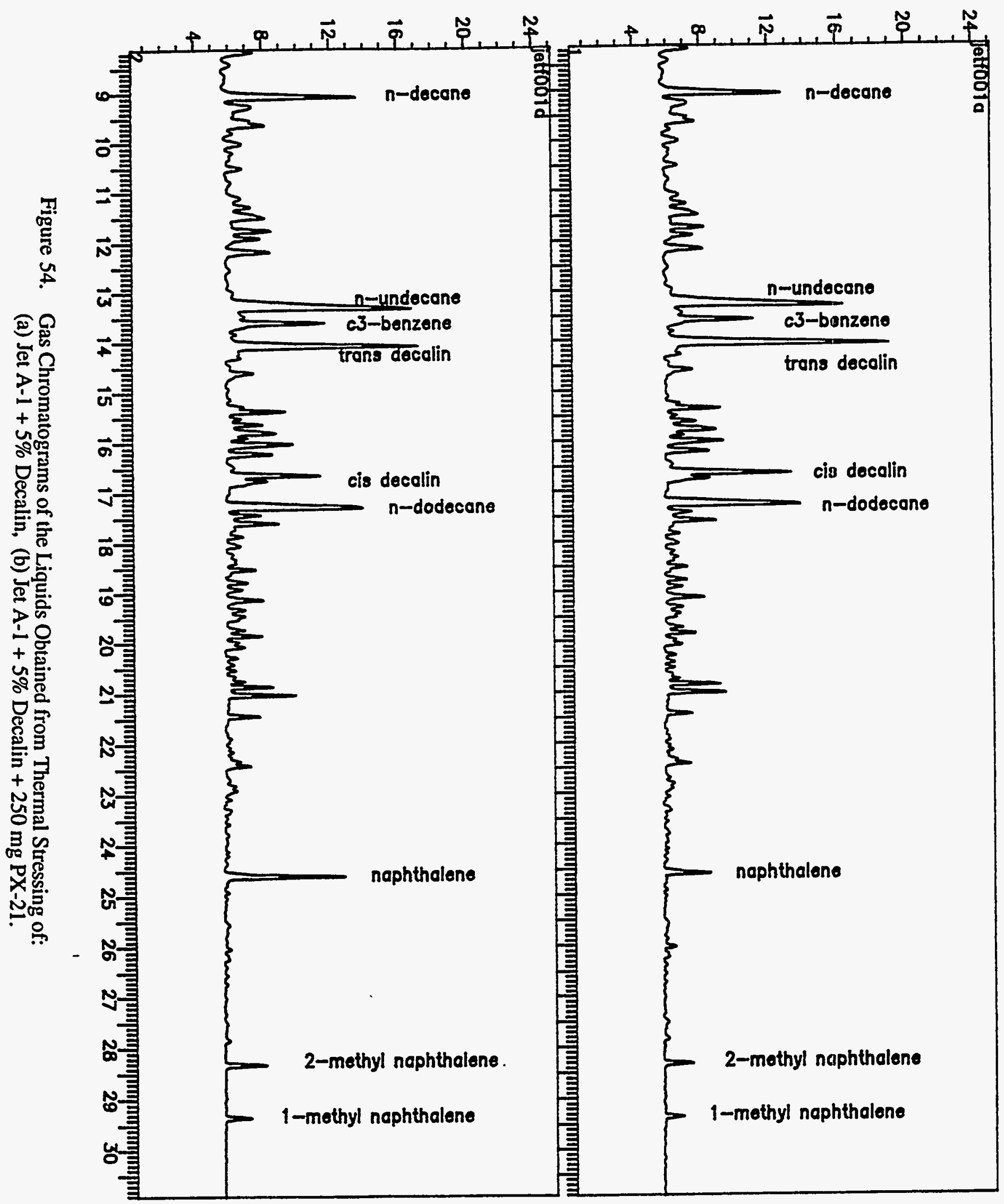




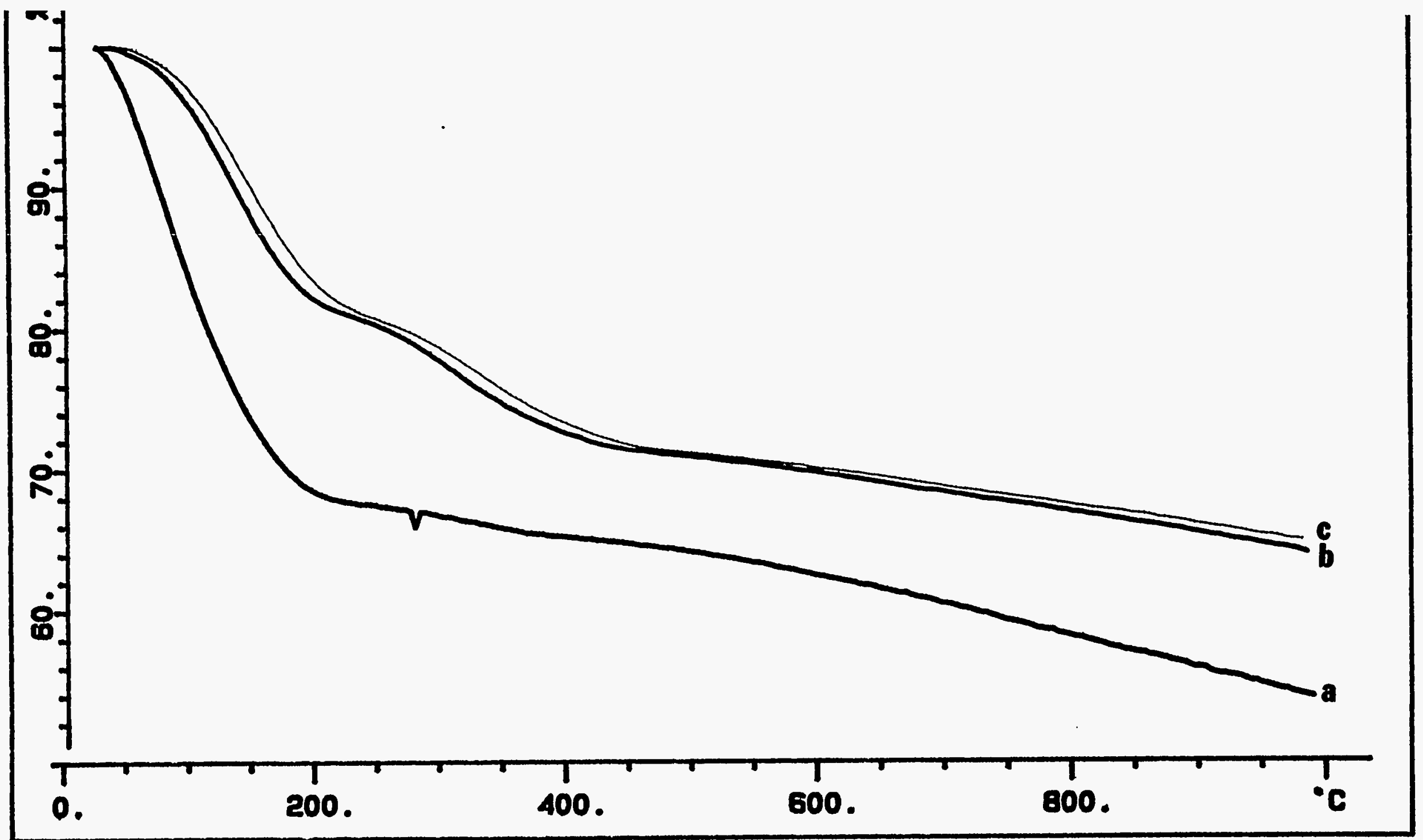

Figure 55. Thermogravimetric Analysis of $250 \mathrm{mg}$ PX-21 Stressed with n-Dodecane + 50\% Decalin: (a) at Heating Rate $10^{\circ} \mathrm{C} / \mathrm{min}$, (b) at Heating Rate $20^{\circ} \mathrm{C} / \mathrm{min}$, (c) at Heating Rate $30^{\circ} \mathrm{C} / \mathrm{min}$. 

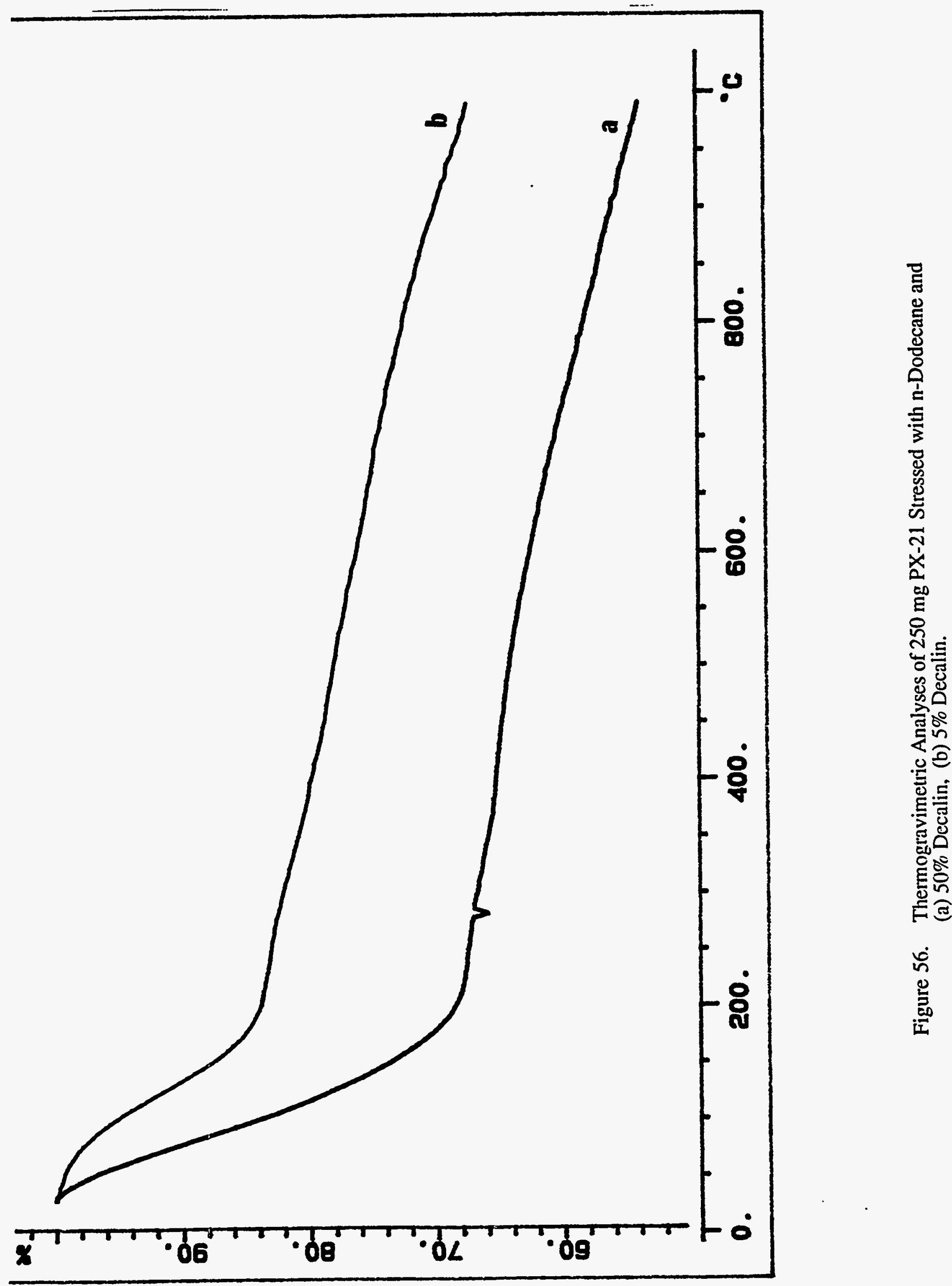


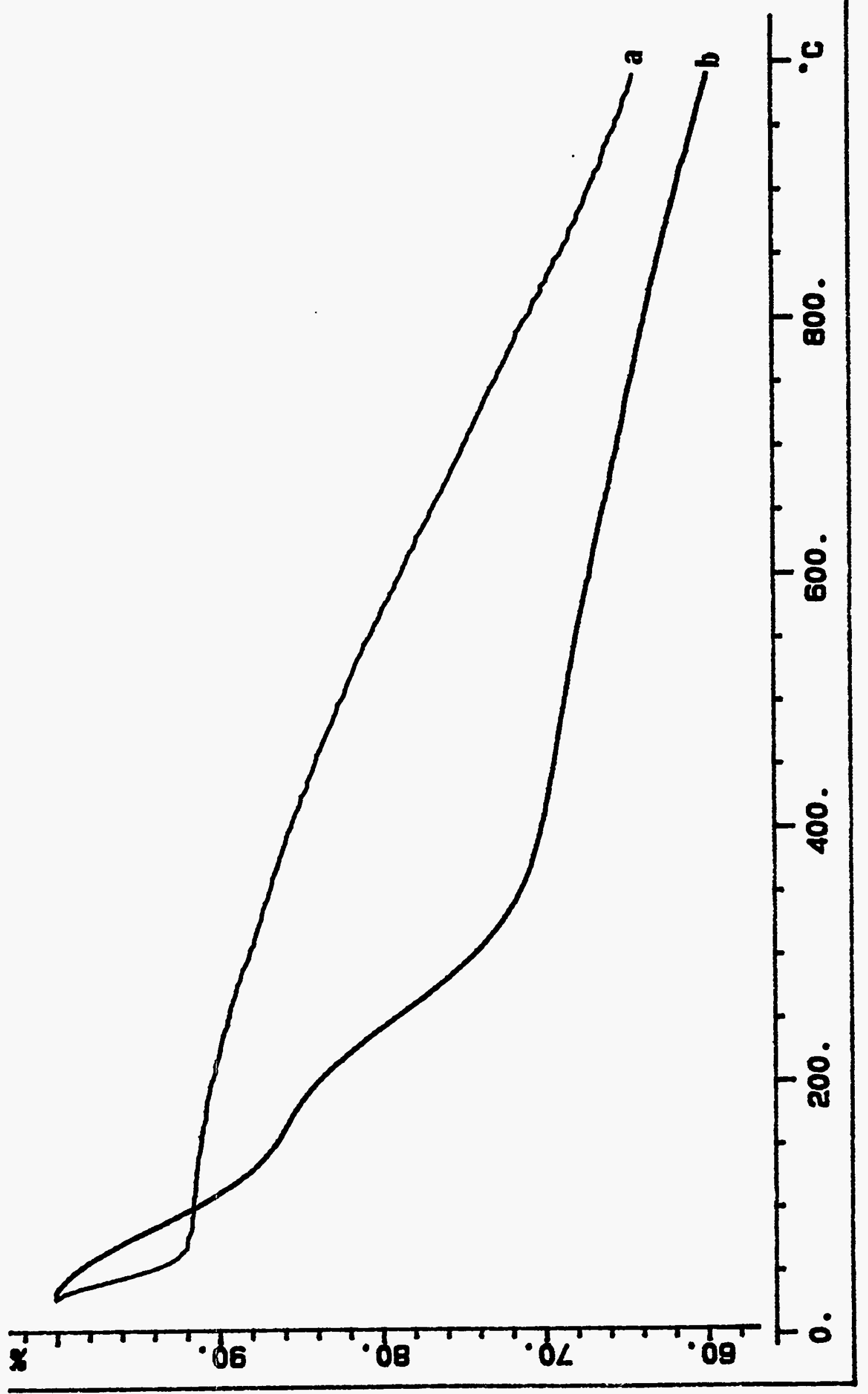

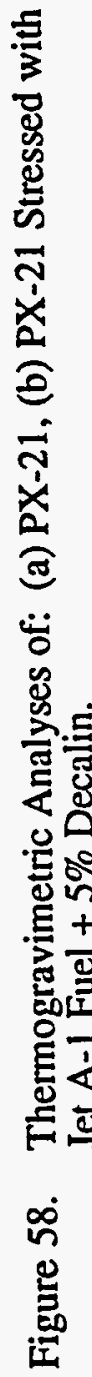




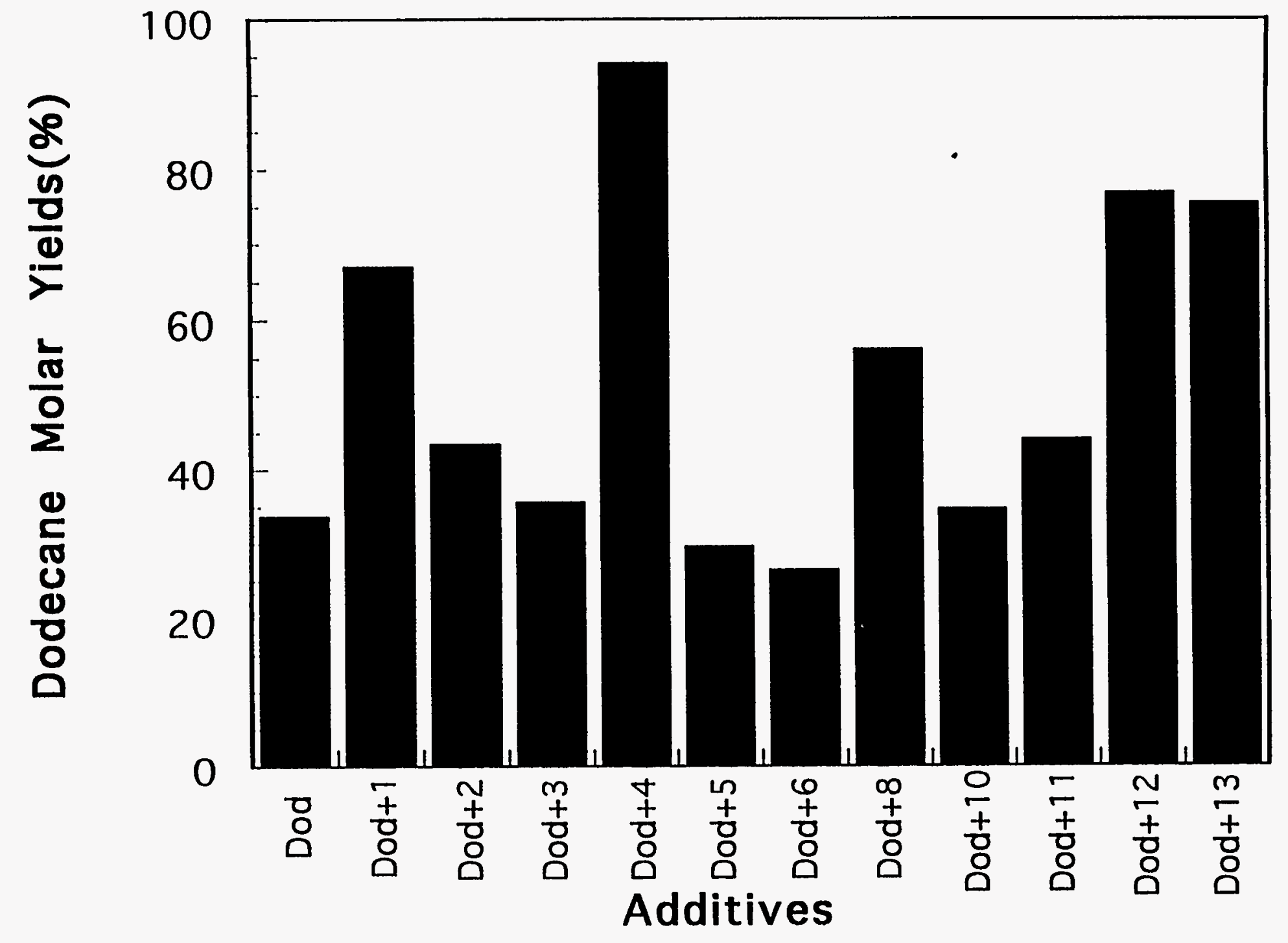

Figure 59. Effects of hydrogen donor additives 1 thru 13 on the molar yields of dodecane at $425^{\circ} \mathrm{C}$ for 6 hours under initial $\mathrm{N}_{2}$ pressure of $0.69 \mathrm{MPa}$. 


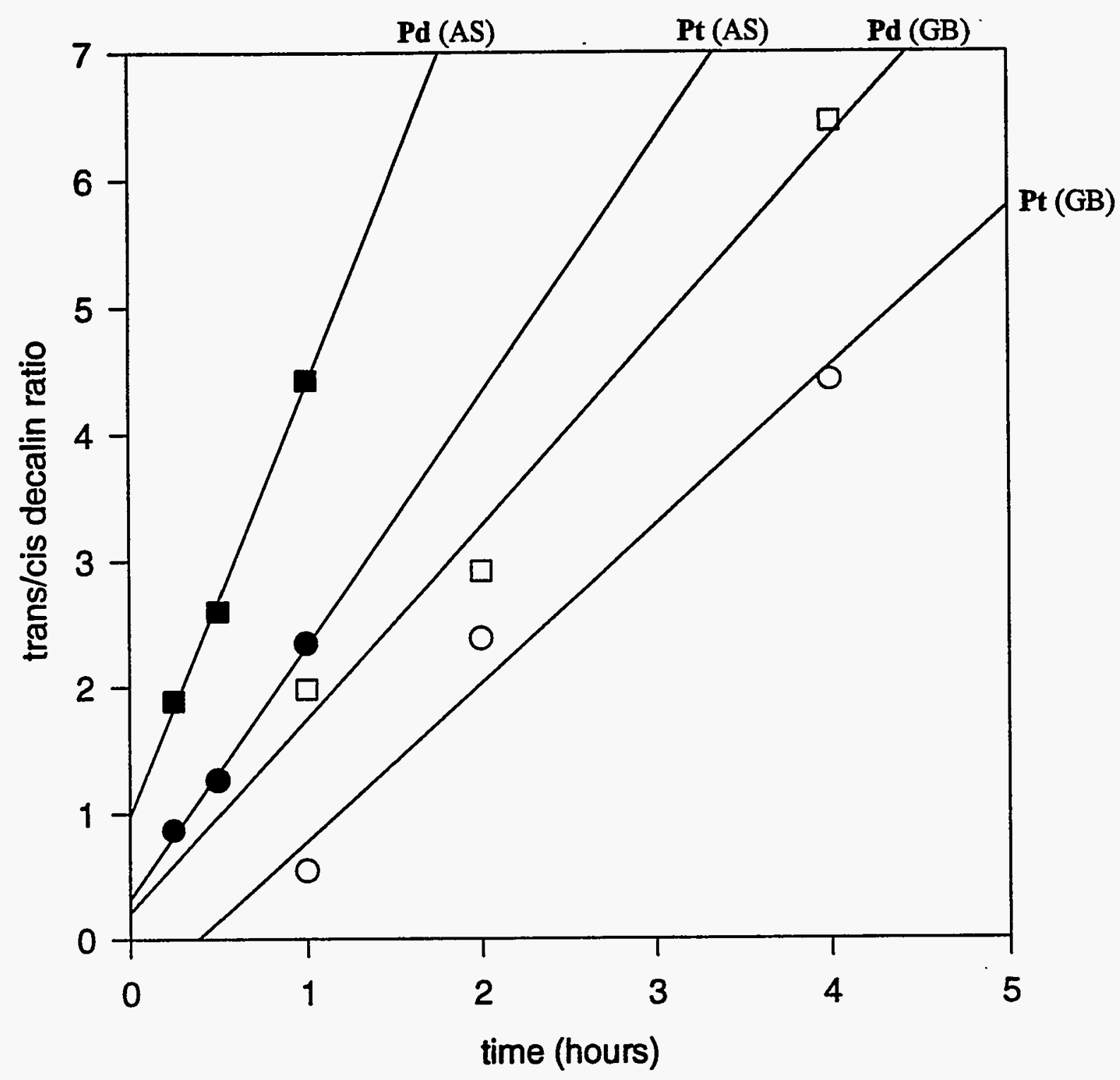

Figure 60. Decalin trans/cis Ratios for HM38-Based Catalysts; Filled Symbols, A. Schmitz Data; Open Symbols, G. Bowers Data. 


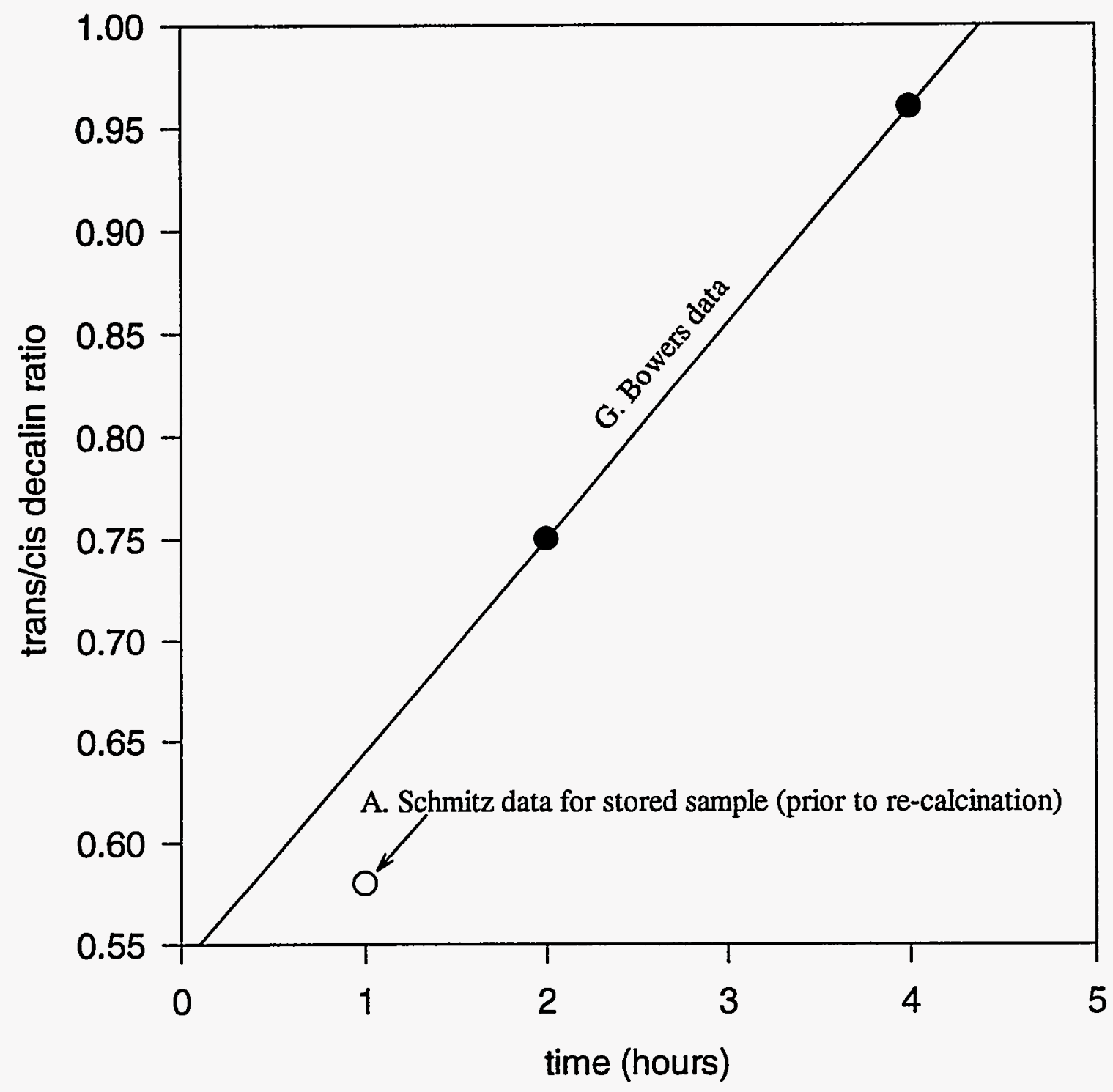

Figure 61. Decalin trans/cis Ratios for Pt/HM17 Catalysts 


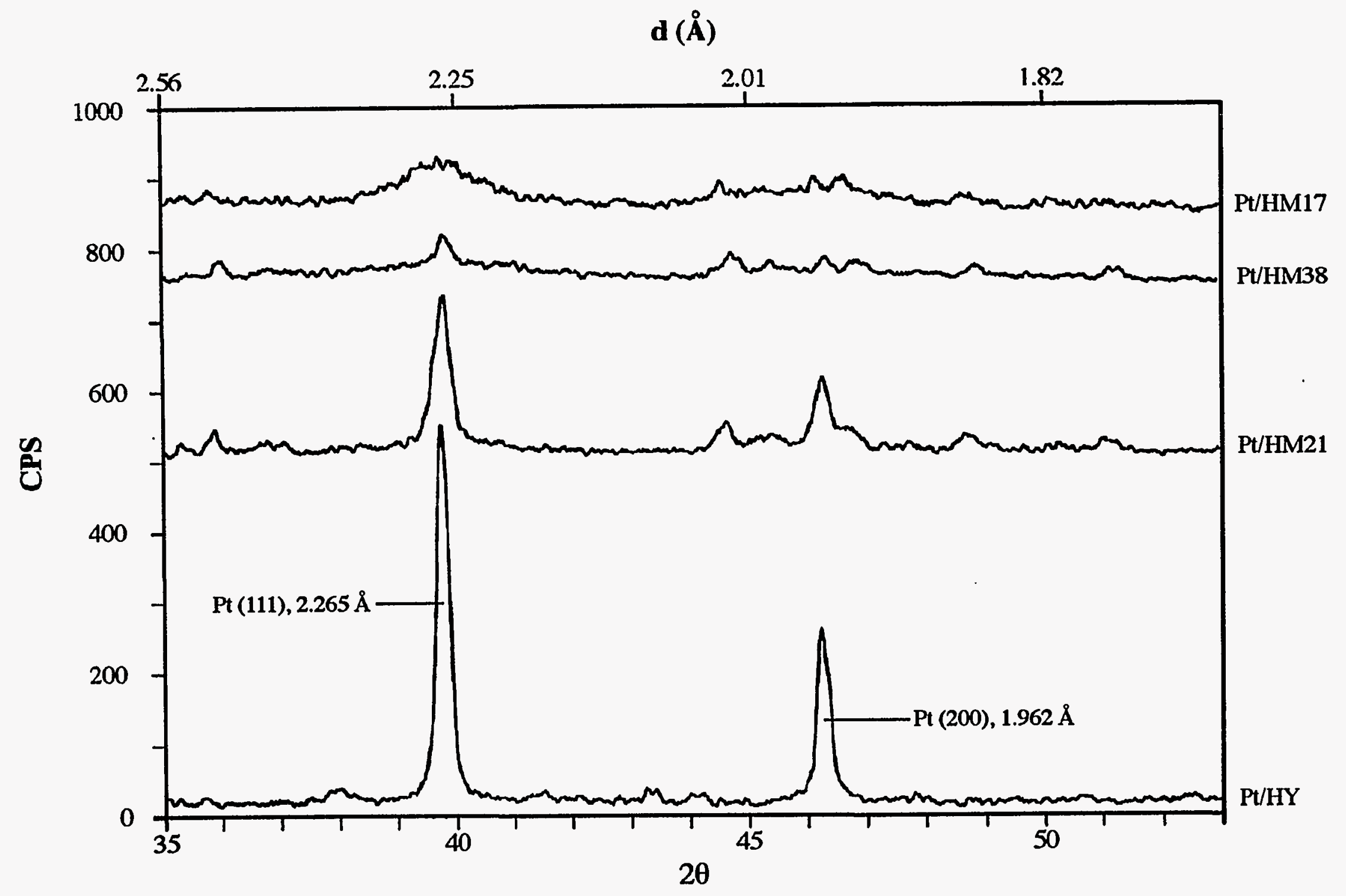

Figure 62. X-ray Powder Diffraction Patterns for Platinum/Zeolite Catalysts 


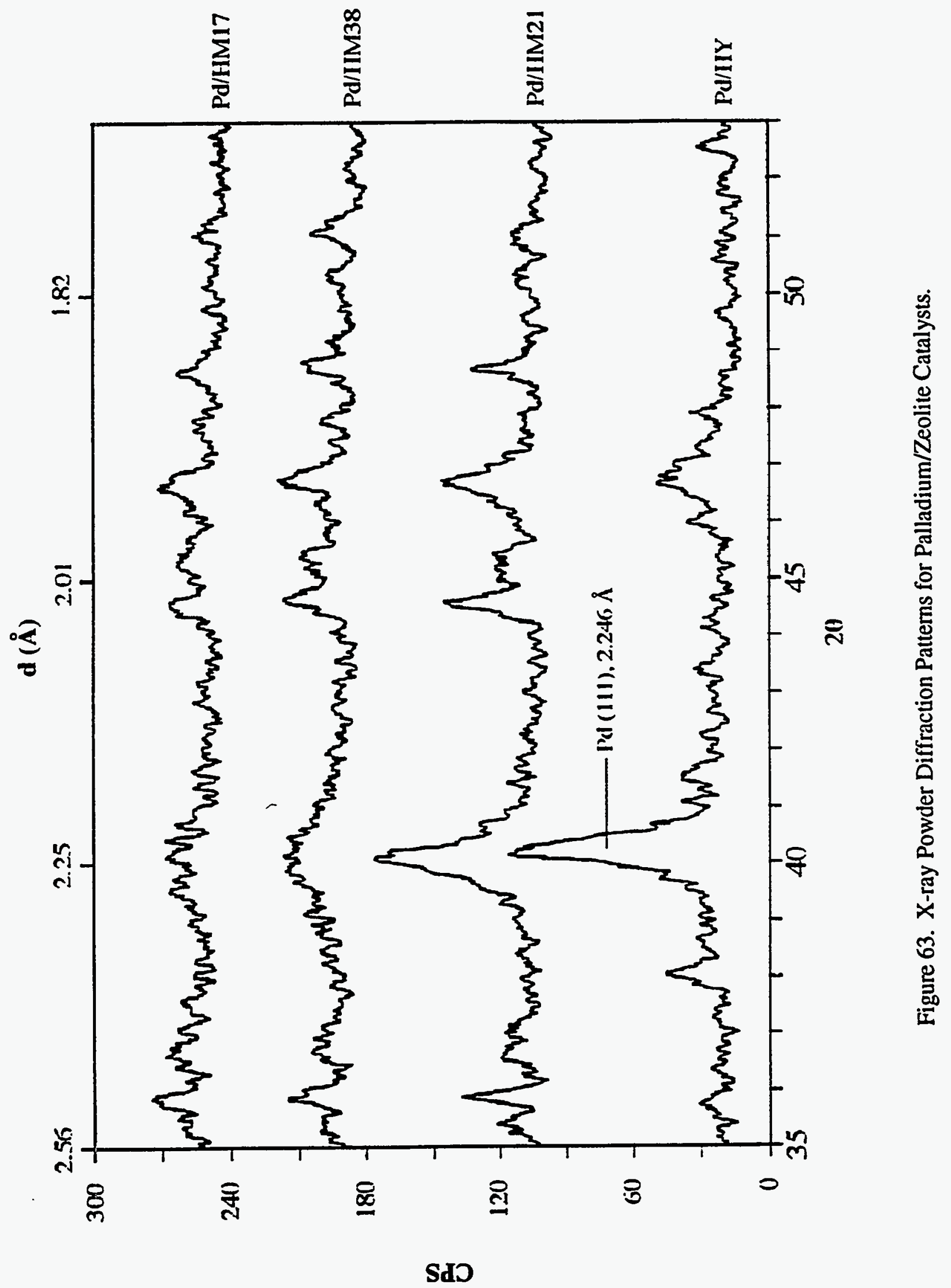




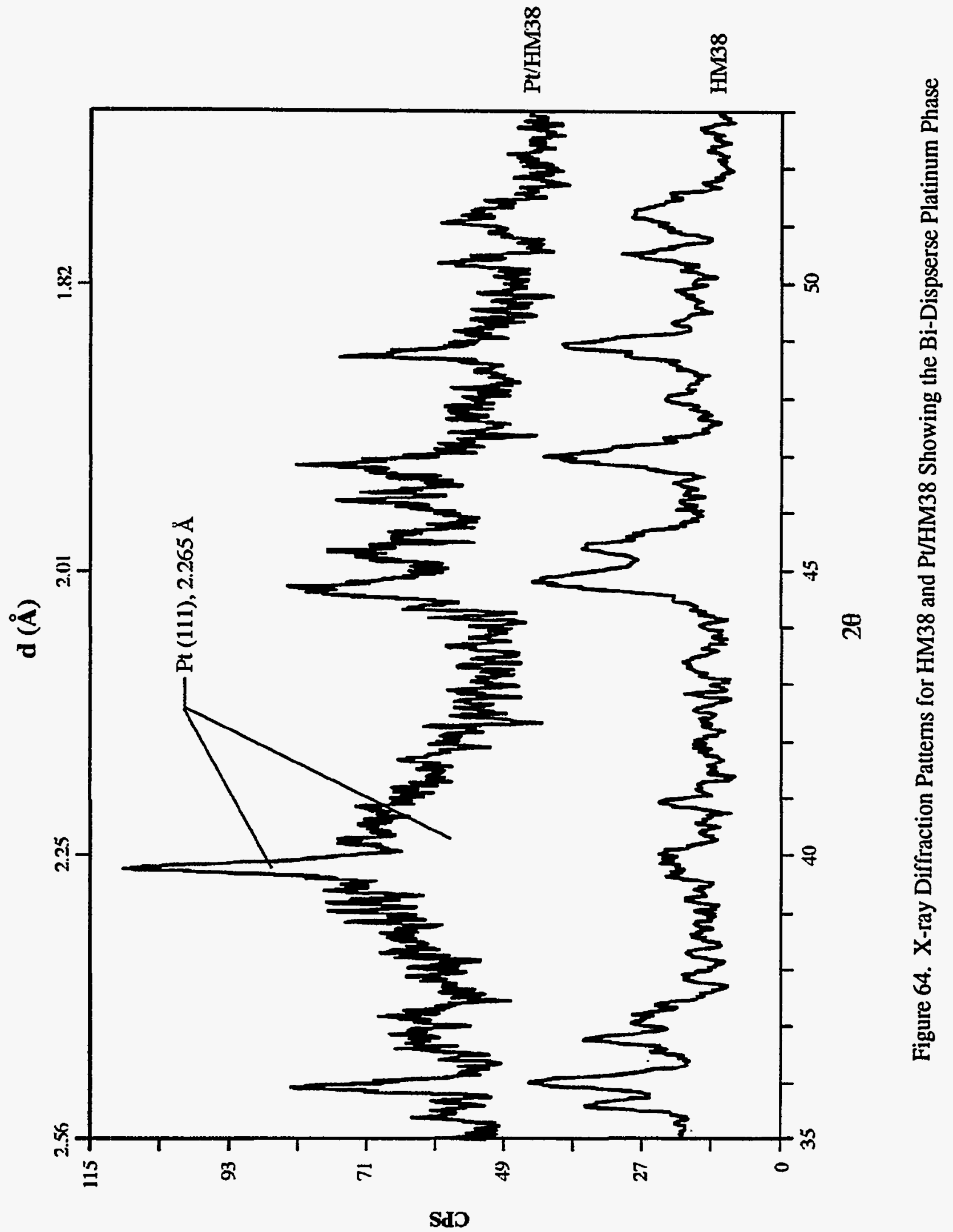

